\title{
Annual Report 1993 Chemical Structure and Dynamics
}

Prepared by

Steven D. Colson Associate Director and the staff of the Chemical Structure and Dynamics Program

July 1994

Prepared for the U.S. Department of Energy under contract DE-AC06-76RLO 1830

Pacific Northwest Laboratory Operated for the U.S. Department of Energy by Battelle Memorial Institute 
, 


\section{DISCLAIMER}

This report was prepared as an account of work sponsored by an agency of the United States Government. Neither the United States Government nor any agency thereof, nor any of their employees, make any warranty, express or implied, or assumes any legal liability or responsibility for the accuracy, completeness, or usefulness of any information, apparatus, product, or process disclosed, or represents that its use would not infringe privately owned rights. Reference herein to any specific commercial product, process, or service by trade name, trademark, manufacturer, or otherwise does not necessarily constitute or imply its endorsement, recommendation, or favoring by the United States Government or any agency thereof. The views and opinions of authors expressed herein do not necessarily state or reflect those of the United States Government or any agency thereof. 


\section{DISCLAIMER}

Portions of this document may be illegible in electronic image products. Images are produced from the best available original document. 


\section{Contents}

Introduction $1-1$

\section{Reaction Mechanisms at Solid Interfaces}

Molecularly-Resolved Surface Chemistry ${ }^{a}$

M. C. Gallagher, L. A. Bumm, S. A. Joyce, and J. P. Cowin

Electronic Absorption Spectra of Large Benzene-Ar $\mathrm{r}_{\mathrm{n}}$ Clusters $^{a}$

R. D. Knochenmuss, D. Ray, and W. P. Hess

Molecular Dynamics at the Water/Solid Interface ${ }^{a, b}$

B. L. Maschhoff, X. Zhou, M. Kwini, M. J. Iedema, and J. P. Cowin

Kinetics of Methyl Radical Formation on Metal Oxide Catalysts ${ }^{a}$

R. S. Smith, B. D. Kay, and S. D. Colson

Dynamics and Kinetics of Ice and Oxide Surface Chemistry $a, b$

B. D. Kay, R. S. Smith, C. Huang, and E. K. L. Wong

Dynamical Effects in Laser-Induced Particle Emission from Surfaces ${ }^{a}$

A. J. Peurrung, G. R. Teeter, J. P. Cowin, S. E. Barlow, and T. M. Orlando.

Electron- and Photon-Stimulated Surface/Interface Chemistry ${ }^{a}$

T. M. Orlando, R. G. Tonkyn, and G. A. Kimmel

Photodissociation of Acetyl Chloride: $\mathrm{Cl}$ and $\mathrm{CH}_{3}$ Quantum Yields and Energy Distributions ${ }^{a}$

S. M. Deshmukh and W. P. Hess

Spectroscopy and Dynamics of Single Molecules at Surfaces with a Near-Field Microscope ${ }^{a, c}$

X. S. Xie, R. C. Dunn, E. V. Allen, G. R. Holtom, G. A. Anderson, and S. A. Joyce

Electronic Structure and Dynamics of Silicon Oxide Clusters ${ }^{a}$

L. S. Wang, S. D. Colson, J. Fan, and J. B. Nicholas

Photoelectron Spectroscopy and Electronic Structure of Metal Clusters

and Chemisorbed Metal Cluster Complexes ${ }^{a}$

L. S Wang and J. Fan.

\section{Solutions and Solution Interfaces}

Intramolecular Charge Transfer (ICT) in Cyanoaniline Compounds ${ }^{a}$

D. M. Friedrich, A. G. Joly, H. B. Lueck, M. A. Thompson, J. P. LaFemina, and A. R. Hebecker

Dynamics of Large Water Clusters Probed by Excited-State Proton Transfer ${ }^{a}$

R. D. Knockenmuss, D. E. Smith, G. R. Holtom, and D. Ray

High-Resolution Spectroscopy of Molecular Species and Clusters ${ }^{a}$

S. W. Sharpe

Structure and Dynamics of Liquid Water Molecules by Femtosecond Infrared Spectroscopy ${ }^{a}$

G. R. Holtom, R. C. Crowell, and X. S. Xie

\section{Structure and Dynamics of Biological Systems}

Scanning Probe Microscopy Users Facility $b$

M. J. Iedema 4-1

Biological Applications of Near-Field Fluorescence Spectroscopy ${ }^{a, c}$

X. S. Xie, R. C. Dunn, G. R. Holtom, and E. V. Allen. 


\section{Analytical Methods Development}

Laser Ablation of Sodium Nitrate ${ }^{a, d}$

M. I. McCarthy, R. A. Bradley, and W. P. Hess

High-Resolution Infrared Analytical Methods ${ }^{b, e}$

S. W. Sharpe, J. F. Kelly, and R. S. McDowell.

Laser Ablation Mass Spectrometry Scanning of Waste Tank Core Samples $f$

S. E. Barlow, S. D. Colson, J. P. Cowin, M. E. Geusic, and B. M. Wise

Flowing-Afterglow Mass Spectrometry of High-Energy Coronas ${ }^{b}$

T. M. Orlando, R. G. Tonkyn, and S. E. Barlow.

\section{Atmospheric Chemistry}

Photodissociation of the Ozonide Ion in the Gas Phase: Implications for Ozone Thermochemistry ${ }^{a}$

K. W. Brown and D. Ray.

$\mathrm{Cl}\left({ }^{2} \mathrm{Pj}\right)$ Fine Structure Quantum Yields from UV Dissociation of $\mathrm{PCl}_{3}, \mathrm{CCl}_{4}, \mathrm{CHCl}_{3}$, and $\mathrm{Cl}_{2}{ }^{a}$

S. M. Deshmukh and W. P. Hess

\section{Publications and Presentations}

Publications $7-1$

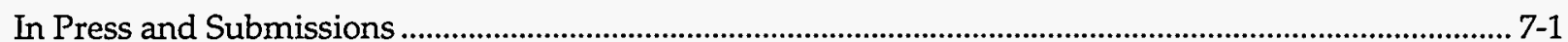

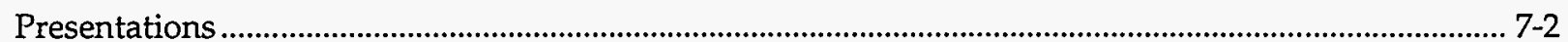

\section{Collaborations}

Outside Collaborations.

Funding Support:

${ }^{a}$ Office of Basic Energy Sciences, Chemical Sciences.

${ }^{b}$ Laboratory Directed Research and Development (LDRD).

$c$ Cooperative Research and Development Agreement (CRADA).

$d$ Strategic Environmental Research and Development Proposal (SERDP).

$e$ Office of Arms Control.

$f$ EM-50 Characterization, Monitoring, and Sensor Technology Integrated Program. 


\section{Introduction}

The Chemical Structure and Dynamics program responds to the need for a fundamental, molecular-level understanding of chemistry at the wide variety of environmentally-important interfaces. The research program is built around the established relationship between structure, thermodynamics, and kinetics. This research effort was initiated in 1989 and will continue to evolve over the next few years into a program of rigorous studies of fundamental molecular processes in model systems (e.g., well-characterized surfaces, singlecomponent solutions, clusters, and biological molecules), and studies of complex systems found in the environment (e.g., multispecies, multiphase solutions; solid/liquid, liquid/liquid, and gas/ surface interfaces; colloidal dispersions; ultrafine aerosols; and functioning biological systems).

Experimental studies of molecular and supramolecular structures and thermodynamics are key to understanding the nature of matter, and lead to direct comparison with computational results. Kinetic and mechanistic measurements, combined with real-time dynamics measurements of atomic and molecular motions during chemical reactions, provide for a molecular-level description of chemical reactions. The anticipated results of this work are the achievement of a quantitative understanding of chemical processes at complex interfaces, the development of new techniques for the detection and measurement of species at such interfaces, and the interpretation and extrapolation of the observations in terms of models of interfacial chemistry.

The Chemical Structure \& Dynamics research program includes five areas described in detail in this report.

\section{Chemical Structure and Dynamics Staff}

Associate Director, MSRC

Steven D. Colson

Program Manager

Robin S. (Rod) McDowell

Operations Manager

Gary R. Holtom

Staff

Stephan E. Barlow

James P. Cowin

Donald M. Friedrich

Wayne P. Hess

Stephen A. Joyce

Bruce D. Kay

Thomas M. Orlando

Douglas Ray

Steven W. Sharpe

Lai-Sheng Wang

Xiaoliang (Sunney) Xie

Scientists/Technical Specialists

Martin J. Iedema

Alan G. Joly

Greg A. Ritter

R. Scott Smith

Russell G. Tonkyn
Office Administration

Denise A. Motsenbocker

Brenda K. Neeley

Post-Doctoral Fellows

Albert $\mathrm{H}$. Bahnmaier

Richard A. Bradley Jr.

Kirk W. Brown

Robert A. Crowell II

Subhash M. Deshmukh

Robert C. Dunn

Jiawen Fan

Mark C. Gallagher

T. Albert Hu

Chen Huang

Gregory A. Kimmel

Richard D. Knochenmuss

Larisa Krishtopa

Horst B. Lueck

Brian L. Maschhoff

Vincent A. Venturo

Kwok L. (Eric) Wong

Songlin $\mathrm{Xu}$

$X$ inliang Zhou

Graduate Students

John Bieseker

Axel R. Hebecker

Eric J. Lanzendorf 


\section{Reaction Mechanisms at Solid Interfaces}

To impact problems as important as (1) soil and aquifer contaminant transport rates and persistence, (2) the impact of atmospheric aerosols and dust in pollution and global change, and (3) waste processing (separations, catalytic destruction, etc.), we must understand the mechanisms of interfacial reactions, and how surface structures dictate those mechanisms.

Catalyzed destruction of contaminants in gaseous or aqueous flow reactors is an area that CS\&D will impact using novel techniques: packed-bed flow reactors are notoriously difficult to understand, due to repeated interactions of the reagents and products with millions of reactive grains. A major simplification developed here uses a single grain of catalyst, with the reagents and products expanding directly after contact into a mass spectrometer.

Complex surface kinetics such as catalytic destruction of chlorocarbons are being further probed by molecular-beam surface techniques. The delivery of reagents through multiple, modulated beams, including radical intermediate species, and subsequent line-of-sight analysis of the products, allows multistep surface reactions to be dissected into their individual steps. This will clarify the role of adsorption, site competition, diffusion, and thermal energy.

An MSRC-wide effort to create thin-film versions of many minerals will make feasible many new experiments. CS\&D is participating, exploring the role of defects (steps, vacancies, substitutions, dislocations, etc.) on thin-film $\mathrm{MgO}$ in its catalytic activation of water, and its reactivity with chlorocarbons. Controlled defects are being introduced and correlated with reactivity.

CS\&D has scanning probe microscope capabilities: an ultrahigh-vacuum scanning tunneling microscope (UHV STM), an ambient (aqueous or air) scanning tunneling and force microscope, and, under construction, a 20-Kelvin UHV STM and a scanning near-field optical microscope (NFOM). These provide direct real-space images of ongoing chemical reactions at surfaces. The UHV STMs are used to determine where reactants bind, the nature of the water-adsorbate complex, and defect sites on thin-film oxides. The ambient system has had many cross-center applications (it is a user facility), including observing calcite dissolution, optical material morphology, and DNA fragment chemistry. Biological applications are discussed below. The near field optical microscope which is under development (see below) will also provide a completely new tool for the study of structures and dynamics at interfaces by combining spectroscopic, time, and spatial resolution.

Water-solid interfaces are being explored by four separate strategies: (1) Water/surface interactions at low coverages are studied by the UHV systems described above. (2) Surfaces immersed in water are probed by the ambient STM/AFM/NFOM. (3) Several in-situ spectroscopic probes are described in the "Solutions and Solution Interfaces" section. (4) Another approach is to lower the surface temperature to below $170 \mathrm{~K}$, allowing multilayer ices to be grown in UHV, doped with molecular and ionic reactants. Because of strong hydrogen bonding, liquid water structure on a local scale is very similar to that of ice. Below $100 \mathrm{~K}$, the films are immobile, so we can place species within the water film at precise distances from the surface or each other. This permits the study of chargetransfer-mediated destruction of chlorocarbons, recreating the electrochemical double layer; and exploration of a wide range of ion-water-surface interactions. Atmospheric applications are also discussed below.

Ions and electrons are important to most aqueousmineral chemistry, and to high-temperature/ energy reactions. A variable-energy electron beam is currently being used to look at electron-induced reactions of water films on surfaces. These are crucial to understanding radiation-induced reactions, including hydrogen generation. Electronstimulated production of molecular hydrogen has been observed from low-energy electron-beam irradiation of amorphous ice. Detailed studies on the radiolytic decay of homogeneous samples or heterogeneous mixtures of hydrocarbons on $\mathrm{NaNO}_{3}$ substrates will be carried out. Such processes may be relevant to understanding the aging mechanisms of mixed wastes. Ion beams to deliver low-energy, mass-selected, atomic and molecular ions (both + and - ) are being built, to explore ion-water complexes and ion reactivity at surfaces.

CS\&D has several projects involving cluster chem- 
istry, the study of the transition region between individual molecules and extended condensed and interfacial phases, which will mimic adsorbate/surface interactions. Some of the cluster production will be targeted at the surface chemistry occurring on those clusters. This has relevance to supported catalysts, and to material formation via nanoparticles. Novel ion-beam sources are being developed to provide high-flux beam currents of cold, mass-selected clusters of metals, metal alloys, metal oxides, minerals, and insulator materials, using laser-, ion-, and electron-beam sputtering/ablation techniques. These ion-beam capabilities will allow detailed study of model molecular systems and interfaces; the accurate measurement of ion-molecule reaction rates; and the study of plasma processes.

CS\&D expertise with laser techniques will enhance many of the above activities, making available laser production of novel reactants, extremely sensitive detection of products, in-situ studies, and exploration of photocatalyzed reactions, such as natural and induced destruction of organics under sunlight.

\section{Molecularly-Resolved Surface Chemistry M. C. Gallagher, ${ }^{*}$ L. A. Bumm, * S. A. Joyce, and J.P. Cowin \\ Supported by Office of Basic Energy Sciences. \\ * Postdoctoral Research Associate.}

Many aspects of environmental problems, such as soil contamination and transport through groundwater, involve the adsorption of molecules on a surface. The scanning tunneling microscope (STM) is capable of imaging solid surfaces and molecular adsorbates with atomic-scale resolution. As a real space probe, the STM can directly determine the role of surface structure, especially at defects such as steps, vacancies, etc., in the adsorption and heterogeneous chemistry of molecules on surfaces.

Many of the solid surfaces of relevance to environmental chemistry are insulating in their bulk forms and therefore cannot be imaged with the STM. Ultrathin films, however, may be sufficiently conductive to enable tunneling. Studies of thin film magnesium oxide, $\mathrm{MgO}$, grown on a molybdenum substrate were begun to test this hypothesis. Topographic images of a 2-3 layer film of $\mathrm{MgO}$ were obtained, indicating the feasibility of the thin-film approach. Atomically-resolved images of the film were not obtained, most likely due the inherent roughness of the underlying molybdenum substrate. Efforts to obtain flatter substrates are under way.

At room temperature many adsorbates of interest, such as $\mathrm{H}_{2} \mathrm{O}$, simple hydrocarbons, etc., either do not chemisorb or diffuse too rapidly to be imaged with a STM. Using a cryogenic STM operating at $20 \mathrm{~K}$, one can essentially freeze out diffusional motion of all but the most weakly-bound adsorbates, and thereby directly observe the adsorption geometry. The initial design of the ultrahigh-vacuum, low-temperature STM is complete. Construction of the STM head and procurement of the cold stage and ultrahigh vacuum chambers have begun. Assembly is anticipated to begin in the spring of 1994.

\section{Electronic Absorption Spectra of Large Benzene'Arn Clusters R. D. Knochenmuss, * D. Ray, and W. P. Hess}

Supported by Office of Basic Energy Sciences.

* Senior Research Fellow.

One motivation for cluster research is the expectation that sufficiently large clusters will have properties approaching those of the bulk, and that the study of cluster spectra over a large size range will therefore illuminate the connection between molecular and macroscopic observables. In one well-studied cluster category used as a model for solvent-solute interactions, that of rare gases on aromatic substrates, this expectation has only partially been met. A readily measured quantity is the change in the electronic absorption spectrum due to complexation with varying numbers of adatoms. The spectral shift vs. cluster size is typically non-monotonic at small sizes due to site-specific interactions between the chromophore and various low-energy cluster configurations, but trends smoothly at larger sizes (a few tens of adatoms) toward asymptotic values that, in some cases, are very similar to what is observed in bulk low-temperature matrices. This is interpreted as indicating that the rare gas forms solvation shells enclosing the substrate, and that one or two such shells have the same effect as an infinite matrix.

One of the most extensively studied and apparently non-converging systems is that of benzene. $A r_{n}$ clusters. Up to about $n=40$, Hahn and Whetten ${ }^{1}$ found that the $S_{1}-S_{0} 6_{0}{ }^{1}$ vibronic peak seemed to reach an asymptotic shift vs. free ben- 
zene of -30 to $-40 \mathrm{~cm}^{-1}$, significantly less than the $-112 \mathrm{~cm}^{-1}$ reported for benzene in an argon matrix ${ }^{2}$ or $-65 \mathrm{~cm}^{-1}$ in high-pressure argon at liquid-like densities. ${ }^{3}$

$\mathrm{C}_{6} \mathrm{D}_{6} \cdot \mathrm{Ar}_{n}$ clusters were generated in a conventional molecular beam apparatus, via seeded supersonic expansion from a heated, pulsed valve. Deuterobenzene was selected over $\mathrm{C}_{6} \mathrm{H}_{6}$ primarily due to the larger mass differences between the desired clusters and the frequently observed and neighboring (benzene) $2 \cdot \mathrm{Ar}_{(\mathrm{n}-2)}$ clusters. Fragmentation after one-color, two-photon ionization of deuterobenzene-argon clusters by loss of one or more argon atoms also occurs to a smaller extent than in the non-deuterated complexes, due to a higher ionization threshold.

The carrier gas consisted of 1:1 or 1:3 mixtures of argon with helium, at total absolute pressures near 4 bar. The gas stream was passed over filter paper saturated with $\mathrm{C}_{6} \mathrm{D}_{6}$ at $-30^{\circ} \mathrm{C}$, resulting in concentrations of about $0.04 \%$. The gas mixture was expanded through a 0.4-mm diameter pulsed nozzle at controlled temperatures of $30^{\circ}$ to $90^{\circ} \mathrm{C}$. After passing through a $1.5-\mathrm{mm}$-dia. skimmer $4 \mathrm{~cm}$ downstream, the collimated beam was crossed by a pulsed laser that was tuned across the $60^{1}$ vibronic band of the $\mathrm{C}_{6} \mathrm{D}_{6} \mathrm{~S}_{1}-\mathrm{S}_{0}\left({ }^{1} \mathrm{~B}_{2 \mathrm{u}}{ }^{1} \mathrm{~A}_{1 \mathrm{~g}}\right)$ electronic transition. The pulse duration was about 5 nsec FWHM, with $\sim 0.15 \mathrm{~mJ}$ of energy, and a 3-4 $\mathrm{mm}$ diameter. Following resonant two-photon ionization (R2PI), the clusters were mass analyzed in a reflectron time-of-flight mass spectrometer.

Figure 2.1 shows a typical R2PI mass spectrum of large benzene-argon clusters, excited at $257.95 \mathrm{~nm}$. Under the conditions used, signal levels became insufficient for spectroscopy above about $n=70$. This is nevertheless about 30 atoms larger than the largest such clusters previously reported.

The one-color R2PI spectra of clusters up to $n=20$ obtained were essentially as reported earlier by Hahn and Whetten. ${ }^{1}$ Between $n=17$ and $n=20$, the spectra consist mostly of twin narrow $\left(5 \mathrm{~cm}^{-1}\right.$ FWHM) peaks at -32 and $-43 \mathrm{~cm}^{-1}$. The spectra reported by Hahn and Whetten exhibit no additional change in peak positions or overall pattern up to $n=25$, nor was any change reported in later work up to $n=40.1$ In contrast, under our chosen expansion conditions, significant intensity further to the red appears above $n=20$, as seen in Fig. 2.2. With increasing size, this develops into a broad band at about $-55 \mathrm{~cm}^{-1}$, while the $-43 \mathrm{~cm}^{-1}$ peak

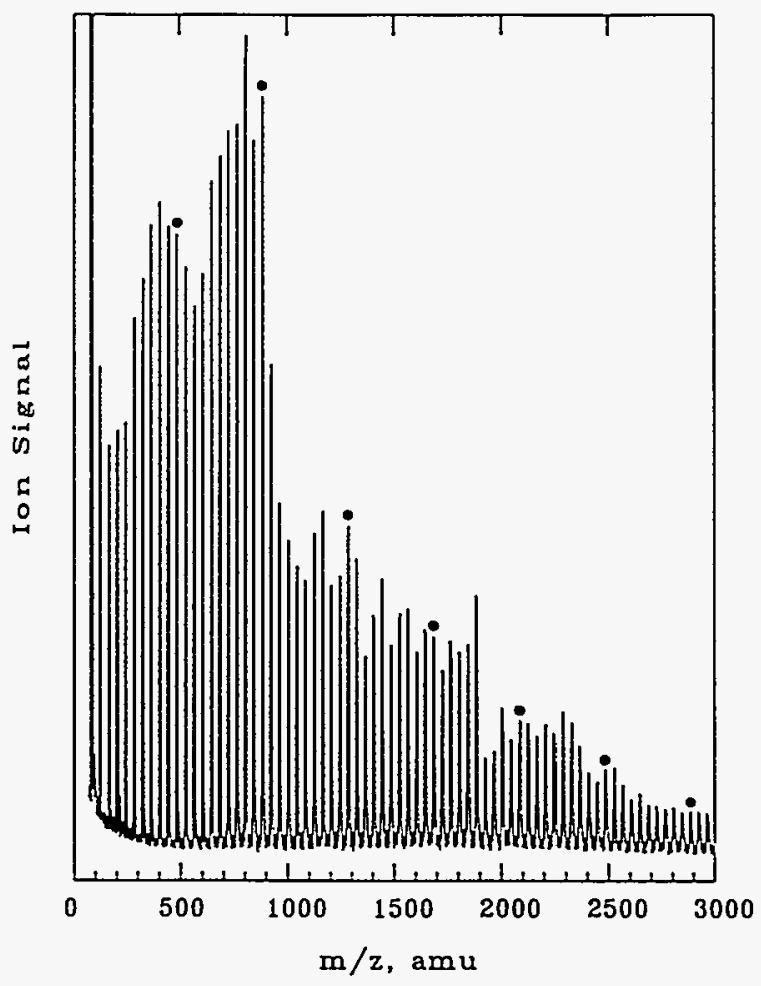

Figure 2.1. Mass spectrum of $\left(\mathrm{C}_{6} \mathrm{D}_{6} \cdot \mathrm{Ar}_{n}\right)^{+}$clusters, with resonant two-photon ionization at $257.95 \mathrm{~nm}$, or $-31.4 \mathrm{~cm}^{-1}$ with respect to free $\mathrm{C}_{6} \mathrm{D}_{6}$. The first peak is $\mathrm{C}_{6} \mathrm{D}_{6}{ }^{+}$and is truncated. Dots mark size multiples of ten.

decays. By $\mathrm{n}=30$ there are again only two peaks, at -55 and $-32 \mathrm{~cm}^{-1}$, which are about twice as broad ( 10 to $15 \mathrm{~cm}^{-1} \mathrm{FWHM}$ ) as those observed at lower mass.

As shown in Fig. 2.3, there is a second qualitative change in spectra above $n=35$. At $n=40$, the -55 $\mathrm{cm}^{-1}$ peak is notably less intense than at $\mathrm{n}=35$, and for $45<n<60$, nearly all intensity is in the least-shifted band, which also has moved to the blue (to $-26 \mathrm{~cm}^{-1}$ ) and narrows. A third notable change in spectral features occurs between $n=60$ and 65 , where there appears to be a sudden broadening and reappearance of intensity in the -40 to $-60 \mathrm{~cm}^{-1}$ range. However, these cluster masses are at the upper limit of our current ability to resolve $\mathrm{C}_{6} \mathrm{D}_{6} \cdot \mathrm{Ar}_{\mathrm{n}}$ and $\left(\mathrm{C}_{6} \mathrm{D}_{6}\right)_{2} \cdot \mathrm{Ar}(\mathrm{n}-2)$ spectra, and spectral contamination cannot be completely ruled out.

From Fig. 2.2 it is clear that most of the structural types observed appear in the $n=20-35$ range. The well-known narrow -43 and $-32 \mathrm{~cm}^{-1}$ peaks in $\mathrm{n}=$ 16-25 spectra have recently been shown by Venturo, Maxton, and Felker ${ }^{4}$ to be due to separate sub-populations on the basis of stimulated Raman spectra. Those measurements were only 
made up to $\mathrm{n}=20$, but given the similarities in peak positions and widths, the assignments are probably the same up to $n=25$.

The structures of the four cluster types we see in the $n=20$ to 40 range remain to be definitively determined, but coarse assignments can be made on the basis of band positions, by application of conventional additivity rules. These rules were developed from spectroscopy of small clusters, and from calculations. 5 They state that "onesided" clusters in which benzene is on the exterior of an argon aggregate, and thus has an exposed, unsolvated side, should exhibit substantially smaller spectral shifts than "two-sided" clusters in which the benzene is sandwiched between or enclosed by argon aggregates.

As the most red-shifted band, we consider the -55 $\mathrm{cm}^{-1}$ peak the most likely to arise from a fully enclosed structure type. If the least-shifted bands at $-32 \mathrm{~cm}^{-1}$ are assigned to essentially one-sided structural types, the narrow $-42 \mathrm{~cm}^{-1}$ peaks may reasonably be due to a class of structures in which the benzene chromophore is partially enclosed by

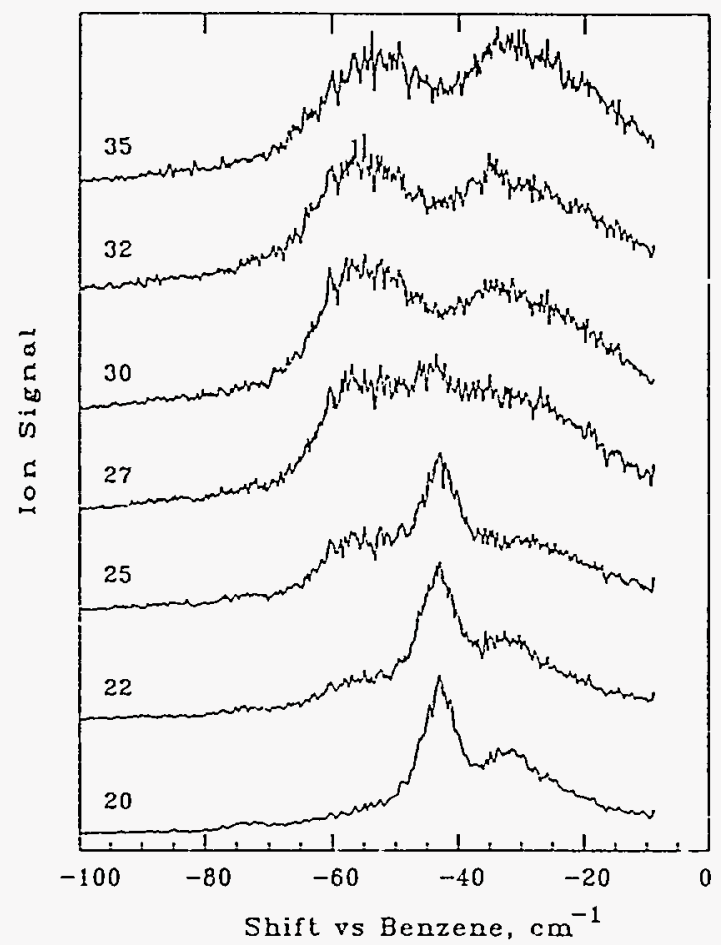

Figure 2.2. One-color R2PI spectra of $\mathrm{C}_{6} \mathrm{D}_{6} \cdot \mathrm{Ar}_{\mathrm{n}}$ clusters with $20 \leq n \leq 35$. The spectra are plotted with respect to the absorption frequency of free $\mathrm{C}_{6} \mathrm{D}_{6}$, and shifted vertically for ease of comparison. the argon. Such "clamshell" or "bridged" structures have been invoked on the basis of simulation results to explain naphthalene-argon spectra in similar size ranges. They are intuitively reasonable structures by which clusters can optimize the relative contributions of argon-argon and argon-substrate interactions to the total binding energy.

Between $n=40$ and 60 , only a single narrow feature was definitely observed in the spectra, in dramatic contrast to the smaller clusters. The small width, 7 to $10 \mathrm{~cm}^{-1}$, probably indicates that these clusters are relatively rigid. This peak appears at very low shift, $-26 \mathrm{~cm}^{-1}$, which would conventionally suggest that it is due to more or less onesided structural types, although no calculations have yet suggested that any such structures are favorable in any size range above $n=16$. Alternatively, and by analogy to the analysis of Schmidt et al. ${ }^{6}$ of small cluster spectra, it seems possible that such low shifts may be indicative of structures in which argon atoms do not tend to coordinate directly with the center of the benzene pi-electron system.

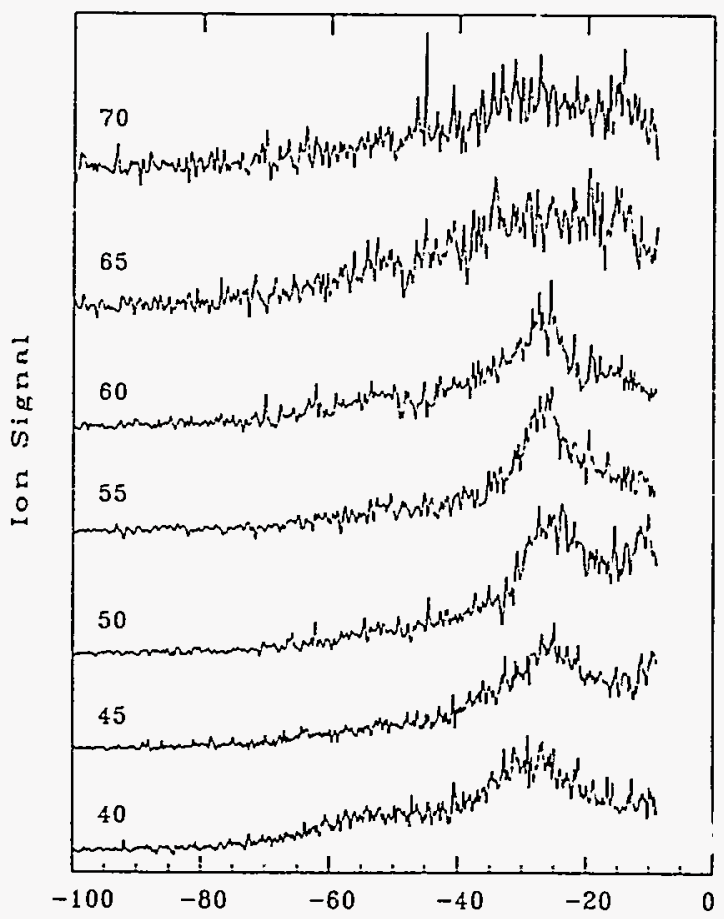

Figure 2.3. One-color R2PI spectra of $\mathrm{C}_{6} \mathrm{D}_{6} \cdot \mathrm{Ar}_{\mathrm{n}}$ clusters with $40 \leq n \leq 70$. The spectra are plotted with respect to the absorption frequency of free $\mathrm{C}_{6} \mathrm{D}_{6}$, and shifted vertically for ease of comparison. 
Above $\mathrm{n}=60$, the very broad bands with maxima around $-25 \mathrm{~cm}^{-1}$ and extending to as much as -60 $\mathrm{cm}^{-1}$ are suggestive of either inhomogeneous broadening due to many stable isomers, or rapid fluxional interchange between such isomers. Why such effects should suddenly dominate in this size range is unclear, as is why $n=60$ clusters should appear in only one low-shift structural type. As noted above, spectral contamination problems cannot be ruled out here, but it seems certain that the spectra are significantly broader than for $\mathrm{n}<$ 65. In any case, there is definitely no large change to strongly red-shifted spectra, which could indicate approach to bulk-like spectra.

Details of both the local and extended environment are, in fact, crucial in determining the spectral shifts in the recent model of Stratt and Adams. ${ }^{7}$ Their model includes two effects, a blueshifting short-range "electron confinement," opposed by a red-shifting, longer-range, collective polarization effect. The magnitudes of these two effects are large (hundreds of wavenumbers) and they nearly cancel. Since they vary differently with density, order, physical extent, and temperature/internal energy (fluctuations), small relative changes in either one could lead to significant variations in the net shift. They find, for example, very different shifts in liquid vs. solid bulk argon, which agrees with experimental results.

Up to about $n=40$, Adams and Stratt found good correlation between their calculations and shifts reported by Whetten. ${ }^{1}$ These shifts, however, are for structural types we identify as partially enclosed, while the calculations were made assuming fully enclosed structures, which we believe absorb at significantly greater shifts. It is not clear that the theory can predict these larger shifts, even if very warm fluxional clusters are simulated, in which case computed band widths also become much too large. In the $40<\mathrm{n}<65$ range, strong disagreement between this theory and experiment currently exists. A salient feature of the theory seems to be that, in this size range, the long-range polarization effects become dominant, leading to a strong red-shifting trend, which we do not observe. On the other hand, recent results suggest that this trend may be much less pronounced or even nonexistent in one-sided clusters. ${ }^{7}$ If so, better agreement with experiment could appear as such calculations are completed.

\section{References:}

1. M. Y. Hahn and R. L. Whetten, Phys. Rev. Lett.
61, 1190 (1988); X. Li, M. Y. Hahn, M. S. El-Shall, and R. L. Whetten, J. Phys. Chem. 95, 8524 (1991).

2. T. J. Barton, I. N. Douglas, and R. Grinter, Mol. Phys. 30, 1677 (1975); R. B. Merrithew, G. V. Marusak, and C. E. Blount, J. Mol. Spect. 25, 269 (1968).

3. R. Nowak and E. R. Bernstein, J. Chem. Phys. 87, 2457 (1987).

4. V. A. Venturo, P. M. Maxton, and P. M. Felker, Chem. Phys. Lett. 198, 628 (1992).

5. S. Leutwyler and J. Bösiger, Chem. Rev. 90, 489 (1990).

6. M. Schmidt, J. LeCalvé and M. Mons, J. Chem. Phys. 98, 6102 (1993).

7. R. M. Stratt and J. E. Adams, J. Chem. Phys. 99, 775 (1993); J. E. Adams and R. M. Stratt, Z. Phys. D 26, S323 (1993).

\section{Molecular Dynamics at the \\ Water/Solid Interface}

\section{B. L. Maschhoff, * X. Zhou,* M. Kwini, †}

M. J. Iedema, and J. P. Cowin

Supported by Office of Basic Energy Sciences and Laboratory Directed Research and Development (LDRD).

* Postdoctoral Research Associate.

$\dagger$ Graduate Student, University of California at Santa Barbara.

Reactions at the water/solid interface are crucial to understanding both soil and atmospheric environmental reactions. Our efforts are aimed at two areas: photochemical/charge transfer processes, and interactions of ions at these interfaces. In both studies, the water-solid interface is modeled using water multilayers adsorbed below $150 \mathrm{~K}$ (down to $50 \mathrm{~K}$ ). We can co-deposit other species into the water film, to recreate solid-aqueous interfaces. We intend to explore solvation and hydration processes, the electrochemical double layer, and ionwater-surface interactions.

Water adsorption of single and multiple monolayers will be crucial to studying hydration and diffusion kinetics. We have completed a study looking at the morphology of water adsorption on $\mathrm{Cu}(110)$. Other researchers have demonstrated that water adsorbs in a single monolayer in an iceI like structure ( $\mathrm{T}>100 \mathrm{~K}$ ), and becomes disordered at higher coverages. Using thermal desorption of xenon, $\mathrm{CH}_{3} \mathrm{Cl}$, and krypton from a single monolayer of water, before and after annealing, we determined that the unannealed water had bare patches of the substrate exposed. Annealed to $120 \mathrm{~K}$, the water film is nearly unbroken. 
$\mathrm{CH}_{3} \mathrm{Cl}$ and $\mathrm{Kr}$ adsorption confirmed this. Multiple layers of water, even after annealing, show uneven heights in the second and third layers on this particular substrate, which must be kept in mind for spacer experiments.

Pure $\mathrm{CH}_{3} \mathrm{Cl}$ adsorbs on $\mathrm{Cu}(110)$ from zero to one monolayer with a strong self-repulsion due to dipole-dipole repulsions. For multilayers, $\mathrm{CH}_{3} \mathrm{Cl}$ adsorbs without dipole-dipole repulsion, suggesting an alternating dipole geometry. The relation between molecular dipole moments and polarizabilities to adsorbate self-repulsion has been recognized for years. However, most of the theories are incomplete as they generally include only the dipole energy and neglect the polarization energy and changes in the self-image energy with the metal. We have developed a model that includes all of the relevant energy terms, which more reasonably explains our data. For coverages of water up to completion of the first layer, hydrogen bonding induces 2-D clustering (islands). $\mathrm{CH}_{3} \mathrm{Cl}$ coadsorbed with 2-D water clusters first adsorbs on the uncovered metal patches, and then on top of water. With the surface covered with one monolayer water, $\mathrm{CH}_{3} \mathrm{Cl}$ still preferentially adsorbs to the water. At thicker water coverages, however, the $\mathrm{CH}_{3} \mathrm{Cl}$ tends to form clusters.

This year we began studies of the adsorption/desorption kinetics and photochemistry of water and halocarbons on thin oxide films. Thin crystalline films of $\mathrm{MgO}$ have been grown on a $\mathrm{Mo}(100)$ surface. Water adsorption on these surfaces has been characterized with thermal desorption. Isotope studies indicate proton exchange in the water layers, but little or no exchange of oxygen between the $\mathrm{H}_{2} \mathrm{O}$ and substrate oxygens.

Adsorption of zero to many monolayers of $\mathrm{CCl}_{4}$, an abundant soil contaminant at Hanford, on thin films $\mathrm{MgO}$ was studied. The thermal desorption shows three peaks that appear in an unusual order with increasing coverage. A high-temperature peak, associated with chemisorbed molecules, appears first. A low-temperature peak arises from adsorption on top of the chemisorbed layer. Surprisingly, further adsorption results in a peak at intermediate temperatures. The desorption kinetics from this state are quite close to that expected for sublimation from bulk $\mathrm{CCl}_{4}$. While the geometry of the first layer has not been identified, several arrangements give fairly close packing, none of which have any relation to bulk $\mathrm{CCl}_{4}$ structures. The second layer is commensurate with the first. Adsorption of a third layer destabilizes the second layer and leads to the formation of 3-D structures of incommensurate bulk $\mathrm{CCl}_{4}$. The metastability of the second layer has been confirmed by thermal annealing studies. We have observed similar behavior for $\mathrm{CH}_{3} \mathrm{Cl}$ adsorbed on water films.

Oxide surfaces can have very reactive sites, especially at defects. Narrow-gap oxide insulators additionally can convert visible or UV light to chemically-reactive holes and electrons. We examined the photochemistry of $\mathrm{CCl}_{4}$ on dry and water-covered thin film MgO. At $193 \mathrm{~nm}$, no photochemistry was seen for pure adsorbed water. $\mathrm{CCl}_{4}$ can directly absorb this light via dissociative states. $\mathrm{Cl}$ and either $\mathrm{CCl}_{3}$ or $\mathrm{CCl}_{4}$ desorb with hyperthermal velocities with each low-power laser pulse. A number of photoproducts are detected during subsequent thermal desorption, as illustrated in Fig. 2.4 The compounds $\mathrm{Cl}_{2} \mathrm{C}=\mathrm{CCl}_{2}$ and $\mathrm{Cl}_{2} \mathrm{CO}$ (phosgene!) are the major desorbed products for the dry surface. The oxygen in phosgene comes from an abstraction from the $\mathrm{MgO}$ surface. For $\mathrm{CCl}_{4}$ and $\mathrm{H}_{2} \mathrm{O}$ coadsorption, $\mathrm{HCl}$ is the dominant photoproduct along with significant amounts of phosgene and $\mathrm{Cl}_{2} \mathrm{C}=\mathrm{CCl}_{2}$. Isotope studies indicate that the oxygen in phosgene comes preferentially from the $\mathrm{H}_{2} \mathrm{O}$ in the coadsorbed system.

Much of the chemistry of importance in aqueousmineral and electrochemistry involves ions. Our studies of ions at surfaces involve a collaboration between PNL and the University of Colorado.

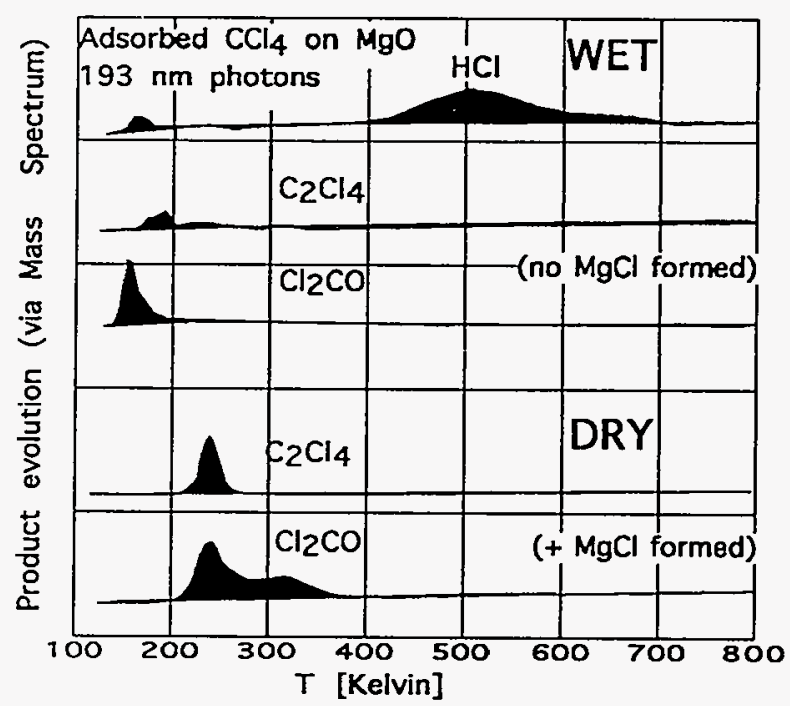

Figure 2.4. Photodestruction of $\mathrm{CCl}_{4}$ on a $\mathrm{MgU}$ surface. 
Professor Barney Ellison and his student John Biesecker are building an ion source to be delivered to PNL for joint use. We will use cryogenic temperatures $(\leq 20 \mathrm{~K})$ and molecular-beam dosing to create models of aqueous interfaces with known spacing (in $z$ ) between various molecules, ions, and the surface. Unlike others, we will employ a mass-selected, negative molecular ion beam, producing around $50 \mathrm{nA}$ of anions at several eV impact energy. This allows study of anionic surface processes for a wide range of molecular anions $\left(\mathrm{NO}_{3}^{-}, \mathrm{ClO}^{-}, \mathrm{CN}^{-}, \mathrm{OH}^{-}\right)$. We can prepare systems at equilibrium, or ones that are highly metastable. A switching polarity changes the source into a positive molecular ion source. With either polarity one can deposit ions that can be neutralized, making it an effective radical source. These capabilities will also allow studies of important atmospheric chemistry of aerosols, for species like $\mathrm{ClO}, \mathrm{ClO}^{-}$, and $\mathrm{NO}_{x} \pm$.

The negative-ion source is now undergoing testing at the University of Colorado, and we have completed several experiments at PNL aimed at exploring our ability to create well-defined layered models and to trap radicals. The ion source consists of a 1-mm nozzle at 3 torr with a crossed e-beam, followed by $1-\mathrm{cm}$ diameter skimmers and collimators, a $5^{\circ}$ bend to eliminate neutrals, differential pumping, a Wein mass filter, and a short $1-\mathrm{cm}$ deaccelerator stage. Shake-down testing as a positive ion source is nearly complete. Preliminary anion production from an $\mathrm{N}_{2} \mathrm{O}$ feed gas produced over $50 \mathrm{nA}$ of current. The new surface system has sample cooling cold enough to grow multilayer argon over the target surfaces to aid in "soft-landing" the ions.

Trapping radicals in non-equilibrium arrangements is a good way to study kinetics that are believed to proceed via these radicals. The ion source will be a good source of these radicals (after neutralization at the surface). To explore trapping radicals, we used photolysis of adsorbed methyl halides to produce surface methyl radicals within thin multilayers. We found that $193-\mathrm{nm}$ photolysis of multilayer $\mathrm{CH}_{3} \mathrm{Cl}$ on a $\mathrm{Cu}(110)$ substrate produced ethane during subsequent sample heating (from 70 to $100 \mathrm{~K}$ ). Ethane, the product of $\mathrm{CH}_{3}$ recombination, appeared abruptly at 3 monolayers or above. This ethane is distinct from that previously seen for surface-bound $\mathrm{CH}_{3}$ radicals on bare copper, which desorbs at $400 \mathrm{~K}$. Photolysis in either the top or bottom layer is ineffective for matrix trapping $\mathrm{CH}_{3}$, as radicals produced in the top layer cannot lose enough of their nascent kinetic energy to remain trapped. Those coming from the bottom immediately bind to the surface. Thus three layers are required for effective trapping of $\mathrm{CH}_{3}$ radicals at $60 \mathrm{~K}$.

\section{Kinetics of Methyl Radical Formation on Metal Oxide Catalysts \\ R. S. Smith, B. D. Kay and S. D. Colson}

Supported by Office of Basic Energy Sciences.

Gas-surface interactions are important for determining reaction mechanisms involved in heterogeneous catalysis. ${ }^{1,2}$ Understanding these mechanisms may lead to advances in catalyst design for applications in the chemical industry and for the decomposition of hazardous chemical waste. In the past year, we have studied the catalytic oxidative coupling of methane, which leads to the formation of gas-phase methyl radicals and $C_{2}$ hydrocarbons.

Our approach involves the use of a microreactor that quenches the reaction via a supersonic expansion into vacuum. The expansion effectively quenches gas-phase reactions because of attendant rapid cooling and greatly reduced collision rates. As a result, even very reactive species exist long enough to be ionized (a variety of techniques can be used) and, thus, detected using laser ionization mass spectrometry (LIMS). The primary advantage of this reactor is the capability for the direct detection of reactive intermediates and radicals. In addition, the apparatus is equipped with a quadrupole mass spectrometer for the detection of all other reactants and products (including $\mathrm{H}_{2} \mathrm{O}$, $\mathrm{CO}$, and $\mathrm{CO}_{2}$ ).

Previously we reported the relative yield of methyl radicals on a $1 \% \mathrm{Sr} / \mathrm{La}_{2} \mathrm{O}_{3}$ catalyst bed versus reactor temperature. ${ }^{1}$ In this study the yield of methyl radicals went through a maximum with increasing reactor temperature, peaking near $800^{\circ} \mathrm{C}$. In subsequent experiments the production of methyl radicals and ethene displayed different temperature dependences. In an effort to more completely understand these observations we have focused our research efforts on the kinetics of methyl radical formation.

To study the methyl radical formation reaction the catalyst bed was modified to minimize both pressure gradients and residence times to avoid secondary reactions. Our results demonstrate that 
methyl radical production increases with temperature over the range 500 to $1000^{\circ} \mathrm{C}$. An Arrhenius analysis of the data yields an apparent activation energy of about $20 \mathrm{kcal} /$ mole. Furthermore, at all temperatures the methyl radical yield is nearly zero order in $\mathrm{O}_{2}$ and first order in methane. These data are consistent with the reaction mechanism proposed by Gutman et al.: ${ }^{3}$

$$
\begin{aligned}
& \mathrm{O}_{2}(\mathrm{~g})+2 \mathrm{~S}-\leftrightarrow 2 \mathrm{OS}- \\
& \mathrm{CH}_{4}+\mathrm{OS}-\leftrightarrow \mathrm{CH}_{3}(\mathrm{~g})+\text { HOS- }
\end{aligned}
$$

where S- represents an active site on the surface. The active sites are regenerated by recombinative desorption of surface hydroxyls to form water. In related experiments, we have conclusively demonstrated that the previously-observed maximum in methyl radical production ${ }^{1}$ arises from depletion of OS- sites along the reactor bed. This depletion is due to insufficient gas-phase $\mathrm{O}_{2}$ to maintain the heterogeneous equilibrium depicted in Eq. (1) above. We are presently examining the kinetics of the reactions responsible for the formation of $\mathrm{C}_{2}$ products such as $\mathrm{C}_{2} \mathrm{H}_{6}$ and $\mathrm{C}_{2} \mathrm{H}_{4}$.

References:

1. E. E. Gulcicek, L. D. Pfefferle, and S. D. Colson, J. Phys. Chem. 94, 7069 (1990).

2. T. H. Ballinger, R. S. Smith, S. D. Colson, and J. $T$. Yates, Langmuir (in press).

3. Y. Feng, J. Niiranen, and D. Gutman, J. Phys. Chem. 95, 6558 (1991).

\section{Dynamics and Kinetics of Ice and Oxide Surface Chemistry \\ B. D. Kay, R. S. Smith, C. Huang* and $E . K$. L. Wong*}

Supported by Office of Basic Energy Sciences and Laboratory Directed Research and Development (LDRD).

* Postdoctoral Research Associate.

Molecular beam scattering from surfaces is a powerful experimental tool for studying the dynamics and kinetics of the interaction of molecules with surfaces. The coupling of surface science, molecular beam, and laser technologies makes possible the measurement of total energy disposal and redistribution in gas-surface scattering. Previously these experimental methods have been employed to acquire detailed surface kinetics and state-to-state scattering measurements of molecules interacting with metallic substrates. Such experiments have resulted in a fairly detailed understanding of surface chemistry on metals. Unfortunately we currently do not have a similar understanding of the elementary dynamical and kinetic processes occurring on ice and oxide surfaces. Such interactions are clearly important from an environmental viewpoint, since they form the molecular-level basis for the complex physiochemical processes that take place on the surface of atmospheric aerosols, at the aqueous-mineral geochemical interface, and at the vapor-liquid interface. Our goal is to apply and extend molecular beam surface scattering techniques to these systems in an effort to elucidate the relevant interactions.

\section{A. Structure and Reactivity of Ice Surfaces and Interfaces (BES support)}

In this work the chemisorption and solvation kinetics and dynamics of polar molecules on multilayer ice surfaces are studied using molecular beam-surface scattering, thermal desorption (TPD and isothermal), and laser spectroscopy These experiments will help unravel the mechanism by which a strongly polar neutral molecule dissolves into an aqueous solvent and ultimately forms solvated ions. Sticking coefficients of prototypical "electrolytes" such as $\mathrm{HCl}$ and $\mathrm{NH}_{3}$ on ice surfaces will be determined as a function of incident energy, angle, and surface temperature. The branching ratio between molecular vs. dissociative ("solvation") chemisorption will be probed via isotope exchange between the hydrogens of the "electrolyte" and the "solvent" substrate. In related experiments hydrophobic and hydrophilic interactions between water and various other materials will be probed using beam-generated thin films. Interlayer diffusion and phase separation will be probed using thermal desorption and surface analytic techniques.

Our initial efforts have focused on the synthesis of thin films of $\mathrm{H}_{2} \mathrm{O}$ and $\mathrm{D}_{2} \mathrm{O}$ ice grown on $\mathrm{Au}(111)$ and $\mathrm{Ru}(0001)$ substrates. These substrates were chosen because water wets $R u$ but does not wet Au. Combining molecular-beam dosing with isothermal and temperature-programmed desorption techniques, we are able to grow and characterize ultra-thin films $(<1000 \AA)$ of solid $\mathrm{H}_{2} \mathrm{O}$ and $\mathrm{D}_{2} \mathrm{O}$. Using a molecular beam reflection technique we have determined that the sticking coefficient is unity and independent of incident angle for surface temperatures below $130 \mathrm{~K}$. Above $130 \mathrm{~K}$ the apparent sticking coefficient decreases due to the onset of desorption, but the trapping probability 
remains near unity. This is the first direct measurement of the sticking coefficient of gaseous water on ice surfaces. Previous indirect techniques have yielded conflicting values between 0.01 and 1 for the sticking coefficient.

At temperatures below $140 \mathrm{~K}$ the initial water deposited forms a vitreous solid phase that is metastable with respect to crystalline ice. The existence of this metastable phase has been known for a long time, but the rate and mechanism by which it crystallizes is not understood. By an extensive series of careful desorption measurements (both temperature programmed and isothermal) we were able to study the attendant crystallization kinetics quantitatively. The desorption kinetics are extremely sensitive to this phase transformation since the additional free energy stabilization associated with the crystalline state must now be overcome to achieve sublimation into the vapor phase. To our knowledge, this is the first time such a transition has been observed in desorption. We observe large isotope effects in both the glass temperature and crystallization rate, with $\mathrm{H}_{2} \mathrm{O}$ having a faster rate. Interestingly, the TPD spectra for films grown on $\mathrm{Au}$ and $\mathrm{Ru}$ appear surprisingly similar. However, isothermal measurements clearly indicate that the desorption kinetics are substrate sensitive. In contrast to conventional wisdom, the desorption kinetics exhibit marked departures from zero-order behavior. Quantitative analysis of the isothermal desorption waveform yields an order of $\sim^{2} / 3$ for $\mathrm{Au}$ and $\sim 0.2$ for $\mathrm{Ru}$. We have also examined H/D isotopic exchange as a function of film thickness, temperature, and crystalline state. Surprisingly, we find complete isotopic scrambling over distances up to $250 \AA$ at temperatures as low as $150 \mathrm{~K}$. Our findings clearly indicate that mass transport occurs at a measurable rate within these solid films. We are currently using this experimental data to formulate a mechanistic kinetic model for the crystallization process.

Based upon the progress to date, we are now able to begin a detailed study of the interaction of various molecules with well-characterized ice substrates. Initial efforts will focus on the adsorption, desorption, and reaction kinetics of $\mathrm{CH}_{3} \mathrm{OH}, \mathrm{NH}_{3}$, and $\mathrm{HCl}$ with ultra-thin ice films. Concurrent with these studies of model hydrophilic interactions, we will begin to explore hydrophobic interactions by examining the interaction of chlorinated hydrocarbons with the ice substrates. After we demonstrate the utility of our approach to under- standing solvation phenomena, we will extend the experiments to include quantum-resolved measurements of the nascent rovibrational distributions of the products that are scattered from the ice substrates. In related experiments we will explore the applicability of using this thin-film chemistry to create chemically-tailored substrates that mimic the aqueous-mineral geochemical interface.

\section{B. Chemisorption on Oxide Surfaces (LDRD support; joint with S. A. Joyce)}

The objective of this program is to examine chemical phenomena occurring at model oxide surfaces. Oxide interfaces are important in the subsurface environment. Specifically, molecular-level interactions at mineral surfaces are responsible for the transport and reactivity of subsurface contaminants at Hanford. Unfortunately our molecularlevel understanding of oxide surface chemistry is severely lacking. Initial experiments will focus on the dissociative chemisorption dynamics of halogenated hydrocarbons (e.g., $\mathrm{CCl}_{4}, \mathrm{CHCl}_{3}, \mathrm{CH}_{2} \mathrm{Cl}_{2}$, $\left.\mathrm{CH}_{3} \mathrm{Cl}\right), \mathrm{H}_{2} \mathrm{O}$, and $\mathrm{HCl}$ on model oxide surfaces (e.g., $\mathrm{MgO}, \mathrm{SiO}_{2}, \mathrm{Al}_{2} \mathrm{O}_{3}$ ). These studies will employ variable-energy supersonic molecular beams to determine energy-, angle-, and coveragedependent trapping and/or dissociation probabilities. A variety of techniques such as molecular beam epitaxy and/or chemical vapor deposition will be explored to grow epitaxial thin oxide films on single-crystal metallic substrates. The successful synthesis of such crystalline thin oxide films will enable the entire arsenal of electron-based surface analytical techniques to be applied to the characterization of these non-conducting materials. In related experiments, catalytic reactions will be studied at high pressure with laser ionization to assess the role of gaseous radical intermediates play in the oxidation of halogenated hydrocarbons.

During FY94, we will explore the dissociative chemisorption of $\mathrm{H}_{2} \mathrm{O}$ on both $\mathrm{MgO}$ and amorphous $\mathrm{SiO}_{2}$. Our initial efforts have focused on the adsorption and desorption kinetics of $\mathrm{H}_{2} \mathrm{O}$ interacting with $\mathrm{MgO}$ thin films. For reasons outlined below, our $\mathrm{MgO}$ films were grown on $\mathrm{Ru}(0001)$, a hexagonal substrate. Interestingly, we find that our TPD spectra are essentially identical to those obtained by Goodman et. al. for $\mathrm{MgO}$ grown epitaxially on $\mathrm{Mo}(100)$, a square lattice. We find that approximately 1 water molecule is bound per surface metal ion, with a binding energy that decreases from $\sim 20 \mathrm{kcal} / \mathrm{mole}$ to $15 \mathrm{kcal} / \mathrm{mole}$ as 
the water coverage increases from zero to saturation (1 monolayer). Since the sticking coefficient is determined to be unity, there is no kinetic barrier to adsorption. From the data to date, we are unable to determine definitively whether the adsorption is molecular or dissociative. Current efforts are focused on examining these kinetics on bulk single crystal $\mathrm{MgO}(001)$ substrates.

In addition to our efforts on $\mathrm{MgO}$, we have also explored techniques to synthesize thin films of $\mathrm{Mg}(\mathrm{OH})_{2}$, which has a hexagonal surface structure closely matched with that of $\mathrm{Ru}(0001)$. Using molecular beams of $\mathrm{H}_{2} \mathrm{O}$, we hydrolyzed $\mathrm{Mg}(0001)$ epitaxially grown on the Ru substrate. This highly exothermic reaction produces copious amounts of molecular hydrogen at temperatures as low as $85 \mathrm{~K}$. Thermal decomposition of the resulting model $\mathrm{Mg}(\mathrm{OH})_{2}$ film produces water and $\mathrm{MgO}$. The water is produced with an apparent activation energy of $\sim 30 \mathrm{kcal} /$ mole. Using this value and the tabulated thermochemical data on the $\mathrm{Mg}(\mathrm{OH})_{2}, \mathrm{MgO}, \mathrm{H}_{2} \mathrm{O}$ system, we estimated a barrier of $10-15 \mathrm{kcal} / \mathrm{mole}$ for the dissociation of $\mathrm{H}_{2} \mathrm{O}$ on $\mathrm{MgO}$. This finding strongly suggests that water adsorbed on $\mathrm{MgO}$ thin films is molecular in nature. Interestingly, water adsorption on the $\mathrm{MgO}$ film produced by the decomposition of $\mathrm{Mg}(\mathrm{OH})_{2}$ is identical to that described above. Our initial experiments have also shown that $\mathrm{Mg}(\mathrm{OH})_{2}$ reacts spontaneously with $\mathrm{Mg}$ metal to form $\mathrm{MgO}$ and $\mathrm{H}_{2}$. This result indicates that simultaneous exposure to $\mathrm{H}_{2} \mathrm{O}$ and $\mathrm{Mg}$ beams will not result in formation of multilayer hydroxide films. We are currently exploring sequential exposure cycles to circumvent this problem.

\section{Dynamical Effects in Laser-Induced Particle Emission from Surfaces}

\section{A. J. Peurrung, * G. R. Teeter, † J. P. Cowin,} S. E. Barlow, and T. M. Orlando

Supported by Office of Basic Energy Sciences.

* Postdoctoral Research Associate, Computing and Information Sciences.

$\dagger$ Science and Engineering Research Semester Student.

Pulsed-laser irradiated surfaces sometimes emit electrons or ions at energies several volts higher than what one would expect, even at modest $(<0.1$ $\mathrm{J} / \mathrm{cm}^{2}$ ) fluences. When the photon energy is above the work function, a $0.1-\mathrm{J} / \mathrm{cm}^{2}$ laser fluence can easily yield thousand of amperes of electron emission. The electron's self repulsion (space charge) creates a negative potential high enough to return most of the emitted electrons after a micron-scale excursion. The establishment and evolution of this space-charge layer involves plasma-like dynamics that can accelerate a few electrons (or ions, if present) to several volts. Computer simulations and earlier experimental work ${ }^{1}$ have shown how the highest-energy photoemitted electrons can be accelerated to 5.4 times their initial energy. We have continued this study to demonstrate the completely different way that ions are accelerated. ${ }^{2}$ The electron space-charge potential at the peak of a typical laser pulse is a volt or more deep, and located at a distance from the surface that varies as the inverse of the squared laser flux. Thus, as the laser pulse decays in time, this potential waveform increasingly accelerates away from the surface to macroscopic distances. This moving potential can sweep up and accelerate ions. We simulated a continuous distribution of electron energies from 0 to $1 \mathrm{eV}$, and a variety of laser time profiles, interacting with $\mathrm{H}^{+}$ ions. The results showed that thermal ions can be readily accelerated by $1 \mathrm{eV}$, and sometimes up to 3 $\mathrm{eV}$ (see Fig. 2.5). These energies are similar to those seen for ions coming from laser-irradiated surfaces using modest fluences.

We have also explored the effects of ion mass, electron current density (screening), and ion velocity on the acceleration process. Generally, space-charge acceleration of ions is found to be robust, causing substantial acceleration over a wide range of experimental parameters. ${ }^{3}$

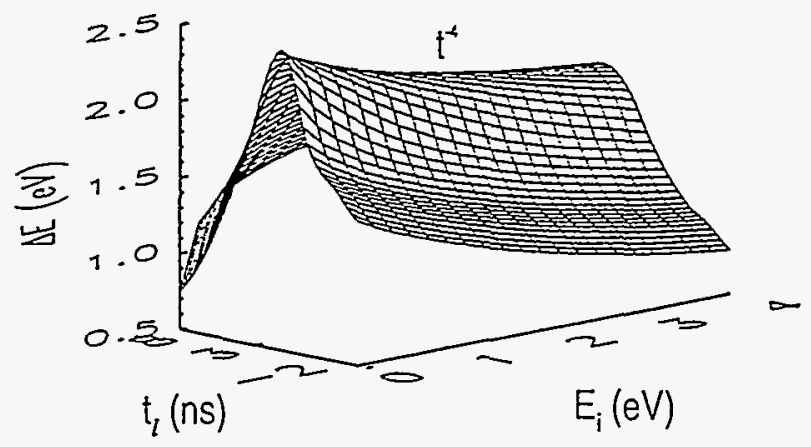

Figure 2.5. $\mathrm{H}^{+}$energy gain vs. launch time and initial kinetic energy for a laser profile that varies roughly as $t^{-4}$. The contour profiles show the wide range of conditions for which substantial acceleration can occur. 
References:

1. T. Gilton, J. P. Cowin, G. Kubiak, and A. V. Hamza, J. Appl. Phys. 68, 4802 (1990).

2. T. M. Orlando, J. P. Cowin, G. Teeter, and S. E. Barlow, AIP Conf. Proceedings 288, Laser Ablation: Mechanisms and Applications-II, pp. 341-346 (1993).

3. A. J. Peurrung, J. P. Cowin, G. Teeter, S. E. Barlow, and T. M. Orlando, J. App. Phys., in press.

\section{Electron- and Photon-Stimulated Surface/Interface Chemistry T. M. Orlando, R. G. Tonkyn, and G. A. Kimmel*}

Supported by Office of Basic Energy Sciences.

* Postdoctoral Research Associate.

The fundamental mechanisms involved in radiation damage of molecules in the condensed phase are often probed by studying the interactions of high-energy radiation (i.e. X-rays, gamma rays, and energetic electrons) with condensed molecular ices. Despite the importance of high-energy processes, it should be noted that energetic particles lose energy primarily via the production of lowenergy secondary electrons. For example, the average energy lost by a fast $(\sim 600 \mathrm{keV})$ Compton electron in a single ionization event in the condensed phase is approximately $30 \mathrm{eV}$. Thus, before degrading, such an electron can produce $\sim 10^{3}-10^{4}$ low-energy $(1-100 \mathrm{eV})$ secondary electrons. The study of low-energy electron interactions in the condensed phase is therefore relevant to understanding the chemical transformations that occur in irradiated systems, and may also be particularly helpful in understanding the novel chemical processes occurring in harsh radiation containment environments.

We have completed the construction of an ultrahigh vacuum system that will be dedicated to the study of energetic interfacial processes. Thus far we have measured, via quadrupole mass spectrometry, the stimulated production of $\mathrm{D}_{2}\left(\mathrm{H}_{2}\right)$ during low-energy $(5-50 \mathrm{eV})$ electron beam irradiation of amorphous $\mathrm{D}_{2} \mathrm{O}\left(\mathrm{H}_{2} \mathrm{O}\right)$ ice (Fig. 2.6). We are particularly interested in water ice because the amorphous structure resembles the liquid state. The results have been submitted for publication ${ }^{1}$ and are briefly described below.

Below the electronic excitation threshold $(\sim 7.3 \mathrm{eV})$ for condensed $\mathrm{D}_{2} \mathrm{O}\left(\mathrm{H}_{2} \mathrm{O}\right), \mathrm{D}_{2}\left(\mathrm{H}_{2}\right)$ production can be attributed to reactions that are initiated by dis-

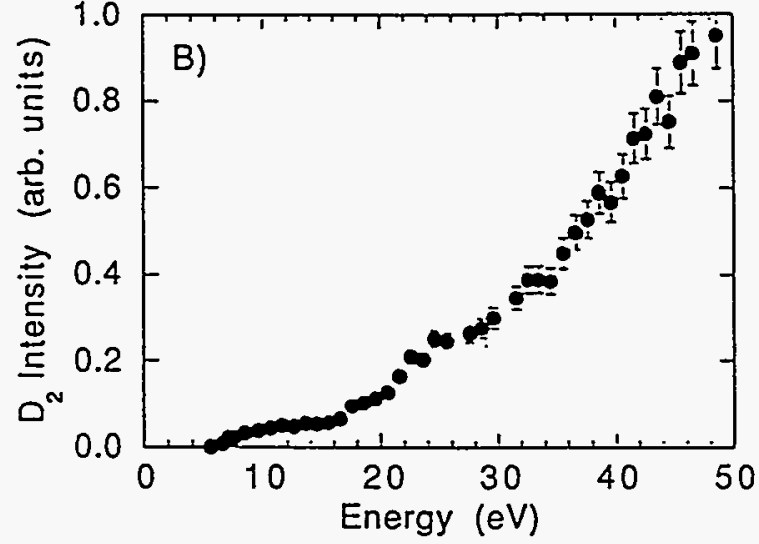

Figure 2.6. $D_{2}$ yield from low-energy $(5-50 \mathrm{eV})$ electron-irradiated amorphous $\mathrm{D}_{2} \mathrm{O}$ ice at $50 \mathrm{~K}$.

sociative electron attachment (DA). This finding strongly supports the hypothesis that the unscavenged $\mathrm{H}_{2}$ yield in water radiolysis is due to the fast proton transfer process $\mathrm{H}^{-}+\mathrm{H}_{2} \mathrm{O} \rightarrow \mathrm{H}_{2}+$ $\mathrm{OH}^{-}$. (This is an important conclusion, since it is an unresolved issue in radiation chemistry). The $\mathrm{D}_{2}\left(\mathrm{H}_{2}\right)$ yield above the DA resonance but below the valence-to-conduction band edge $(\sim 11 \mathrm{eV})$ is associated with excitations that can be described as Frenkel excitons. Above $\sim 11 \mathrm{eV}$, dissociative recombination of molecular ions, $\mathrm{D}_{2} \mathrm{O}^{+}\left(\mathrm{H}_{2} \mathrm{O}^{+}\right)$ and $\mathrm{D}_{3} \mathrm{O}^{+}\left(\mathrm{H}_{3} \mathrm{O}^{+}\right)$, with quasifree or trapped electrons, creates excited states that can decay to produce $\mathrm{D}_{2}\left(\mathrm{H}_{2}\right)$ directly via molecular elimination, or indirectly via reactive scattering of energetic $D(H)$ atom fragments. Dipolar excitations and curve crossings to ion-pair states become important at energies $\geq \sim 17 \mathrm{eV}$, whereas multi-hole, multi-electron final states become important above $\sim 21 \mathrm{eV}$. These results suggest that several types of electronic excitations and the study of the neutral products are important in understanding nonthermal reactions in molecular ices. These types of reactive scattering events occur on a subpicosecond time-scale and are also expected to be prevalent in the liquid state.

\section{Reference:}

1. G. A. Kimmel, T. M. Orlando, C. Vezina, and L. Sanche, "Low-energy (5-50 eV) electron-stimulated production of molecular hydrogen from amorphous ice," J. Chem Phys., in press. 


\section{Photodissociation of Acetyl Chloride: $\mathrm{Cl}$ and $\mathrm{CH}_{3}$ Quantum Yields and Energy Distributions \\ S. M. Deshmukh* and W. P. Hess}

Supported by Office of Basic Energy Sciences.

* Postdoctoral Research Associate.

Discharge of chlorocompounds to the environment is a potential threat to terrestrial ecosystems, groundwater supplies, ${ }^{1}$ and stratospheric ozone. ${ }^{2}$ Understanding energetic processes leading to the breakdown of chlorine-containing compounds is important to (1) the storage and processing of radioactive mixed chemical wastes; (2) the destruction of chloro-organic wastes (i.e., by plasma processing); (3) monitoring waste remediation efforts; and (4) modeling atmospheric ozone depletion. Acetyl chloride is one such chlorinated hydrocarbon, and its photochemistry is relevant to such efforts. The photochemical mechanism involves $\alpha$ bond cleavage upon ${ }^{1}\left(n, \pi^{*}\right)$ excitation. Acetyl chloride is an example of an asymmetrically-substituted carbonyl compound, and therefore the weaker $\alpha$-bond, the $C-C$ bond, is expected to break preferentially over the $\mathrm{C}-\mathrm{Cl}$ bond upon ${ }^{1}\left(n, \pi^{*}\right)$ excitation. Unexpectedly, the $\mathrm{C}-\mathrm{Cl}$ bond breaks preferentially over the $\mathrm{C}-\mathrm{C}$ bond upon ${ }^{1}\left(n, \pi^{*}\right)$ excitation, suggesting a different mechanism for $\alpha$-bond fission in acid halides from that in aldehydes and ketones.

Molecular systems that lead to three-body dissociation following single-photon absorption constitute an interesting subfield of photochemistry. Primary photodissociation in such systems generates free radicals that can further react, relax, or decompose, all of which form competing paths in the total reaction mechanism. Investigation of unimolecular reaction mechanisms, particularly those involving cleavage of two chemical bonds either in a single kinetic step (concerted process) or by two distinct kinetic steps (stepwise process), is important in understanding subsequent radical reactions. While photofragmentation involving the scission of one bond leading to the production of radical pairs is well studied, there is much less experimental work reported on systems that lead to multiple bond cleavage.

In this work, we seek answers to some simple questions pertaining to the photodissociation of acetyl chloride following ${ }^{1}\left(n, \pi^{*}\right)$ excitation at 236 $\mathrm{nm}$. What happens to the acetyl radical that is generated in the primary dissociation step? Does a subsequent unimolecular reaction channel exist to produce $\mathrm{CH}_{3}$ and $\mathrm{CO}$ from $\mathrm{CH}_{3} \mathrm{CO}$ ? If so, what fraction of the acetyl radicals formed have sufficient internal excitation to fragment further?

We excite acetyl chloride near the maxima of the ${ }^{1}\left[n, \pi^{*}(\mathrm{C}=\mathrm{O})\right]$ transition, and probe the methyl product state distributions using $(2+1)$ multiphoton ionization (MPI). We determine the quantum yield for $\mathrm{CH}_{3}$ production from acetyl chloride relative to the $\mathrm{CH}_{3}$ yield from methyl iodide, under identical experimental conditions. Since methyl iodide has significant absorption around $286 \mathrm{~nm}$, we probe methyl fragments from the 236$\mathrm{nm}$ photodissociation of both $\mathrm{CH}_{3} \mathrm{I}$ and $\mathrm{CH}_{3} \mathrm{COCl}$, by two-photon excitation to the $3 \mathrm{p}^{2} \mathrm{~A}_{2}$ " Rydberg state near $334 \mathrm{~nm}$. We find that the quantum yield for the formation of methyl radical from acetyl chloride is roughly $28 \%$, and this result is consistent with energetic constraint arguments. We also probe the atomic chlorine photofragments in the ground ${ }^{2} \mathrm{P}_{3 / 2}$ and spin-orbit excited ${ }^{2} \mathrm{P}_{1 / 2}$ states using $(2+1)$ MPI. Translational energy of $\mathrm{Cl}$ atoms is obtained from the widths of the Doppler profiles. The results are used to discuss the mechanism of acetyl chloride dissociation, leading to the formation of methyl fragments via the acetyl radical intermediate. The experimental apparatus used for this work is explained in detail elsewhere. ${ }^{3}$

Figure 2.7 displays the REMPI Doppler profiles of $\mathrm{Cl}\left({ }^{2} \mathrm{D}_{3 / 2} \leftarrow{ }^{2} \mathrm{P}_{3 / 2}\right)$ and $\mathrm{Cl}^{*}\left({ }^{2} \mathrm{D}_{3 / 2} \leftarrow{ }^{2} \mathrm{P}_{1 / 2}\right)$ transitions following the photodissociation of acetyl chloride. The experimental points (solid circles) are fitted to Gaussian functions to obtain the integrated areas under the profiles. The ratio of these areas, corrected for the respective twophoton oscillator strengths of the two transitions, yields the relative concentrations of $\mathrm{Cl}$ and $\mathrm{Cl}^{*}$. The ratio for the two-photon transition strengths for $\mathrm{Cl}$ and $\mathrm{Cl}^{*}$ has been determined to be $\mathrm{f}\left({ }^{2} \mathrm{D}_{3 / 2}\right.$ $\left.\leftarrow{ }^{2} \mathrm{P}_{3 / 2}\right) / \mathrm{f}\left({ }^{2} \mathrm{D}_{3 / 2} \leftarrow{ }^{2} \mathrm{P}_{1 / 2}\right)=2.5$. We measure the relative $\mathrm{Cl}^{*}$ yield following $236-\mathrm{nm}$ photodissociation of $\mathrm{CH}_{3} \mathrm{COCl}$ to be $\varphi^{*}=0.4 \pm 0.02$. The mean $\mathrm{Cl}$ translational energy is reflected in the Dopplerbroadened line profiles, and can be extracted from the transition lineshape. We determine the mean kinetic energy of $\mathrm{Cl}$ atoms generated in the acetyl chloride photolysis to be $0.28 \pm 0.02 \mathrm{eV}$, from the Doppler profiles in Fig. 2.7.

Figure 2.8 displays a $(2+1)$ MPI spectrum of the methyl photofragments from the 236-nm dissociation of acetyl chloride through the $4 \mathrm{p}^{2} \mathrm{~A}_{2} " \leftarrow X$ ${ }^{2} \mathrm{~A} 2$ " $0-0$ Rydberg transition. The $\mathrm{O}, \mathrm{P}, \mathrm{R}$, and $\mathrm{S}$ 

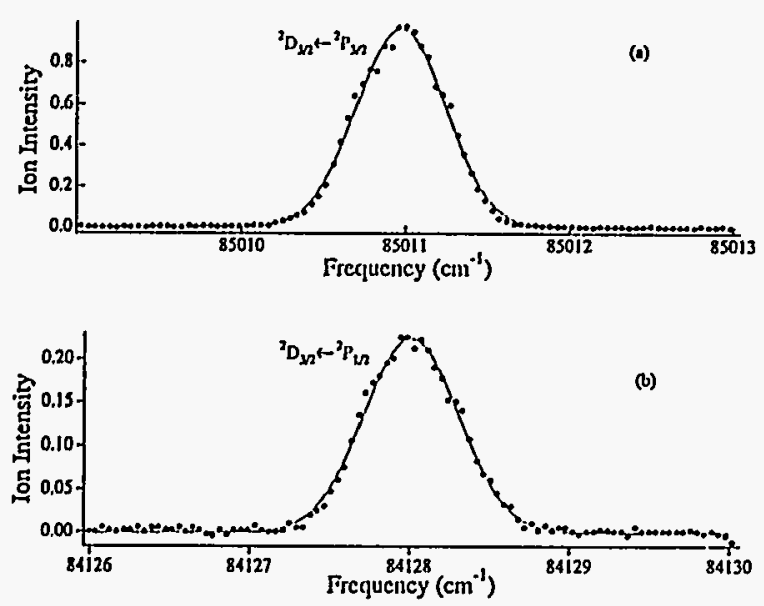

Figure 2.7. MPI $(2+1)$ Doppler profiles of (a) $\mathrm{Cl}$ $\left({ }^{2} \mathrm{D}_{3 / 2} \leftarrow{ }^{2} \mathrm{P}_{3 / 2}\right)$ and (b) $\mathrm{Cl}^{*}\left({ }^{2} \mathrm{D}_{3 / 2} \leftarrow{ }^{2} \mathrm{P}_{1 / 2}\right)$ transitions, following 236-nm photolysis of acetyl chloride. The abscissas display resonance twophoton frequencies. The experimental points (solid circles) are fitted to Gaussian functions (solid lines) to obtain integrated areas under the profiles.

branches have been identified, along with the dominant, intense $Q$ branch. The rotational population extends only up to $\mathrm{N}^{\prime \prime}=5$. Figure 2.9 shows the $(2+1)$ MPI spectrum of the $3 \mathrm{p}_{\mathrm{z}} \leftarrow \mathrm{X}$ transition of the methyl photofragments from the 236-nm dissociation of acetyl chloride. The spectrum is dominated by a strong origin band, but also shows the small first band of the $v_{2}$ umbrella vibration mode. No higher overtones of the $v_{2}$ mode are observed. The $v_{1}$ symmetric stretch band is believed to exist roughly $90 \mathrm{~cm}^{-1}$ to the red of the band origin, ${ }^{4}$ but due to the dominance of the $0^{0} 0$ band, it is difficult to isolate the $v_{1}$ band. The inset shows the detailed origin band spectrum with the $\mathrm{O}, \mathrm{P}, \mathrm{R}$, and $\mathrm{S}$ transitions assigned. Again, the rotational distribution extends only up to $\mathrm{N}^{\prime \prime}=5$. Excluding the small population (less than $1 \%$ of the $0-0$ band) of the lowest $v_{2}$ umbrella vibration level, the internal energy of $\mathrm{CH}_{3}$ is less than 0.02 $\mathrm{eV}$.

A key question in any photodissociation process is the quantum yield for product formation. In order to obtain the quantum yield for $\mathrm{CH}_{3}$ formation from $\mathrm{CH}_{3} \mathrm{COCl}$, we measure the $\mathrm{CH}_{3}$ yield relative to that from $\mathrm{CH}_{3} \mathrm{I}$, photolyzed at $236 \mathrm{~nm}$. We have measured absorption spectra of $\mathrm{CH}_{3} \mathrm{COCl}$ and $\mathrm{CH}_{3} \mathrm{I}$ at $236 \mathrm{~nm}$ and find that the absorption coefficient of $\mathrm{CH}_{3} \mathrm{COCl}$ is 3.1 times larger than that of $\mathrm{CH}_{3} \mathrm{I}$. We correct the ratio of $\mathrm{CH}_{3}$ integrated line strengths, over the $Q$ branch of the $3 p_{z}$ $\leftarrow \mathrm{X}$ transition, from $\mathrm{CH}_{3} \mathrm{COCl}$ and $\mathrm{CH}_{3} \mathrm{I}$ dissocia-

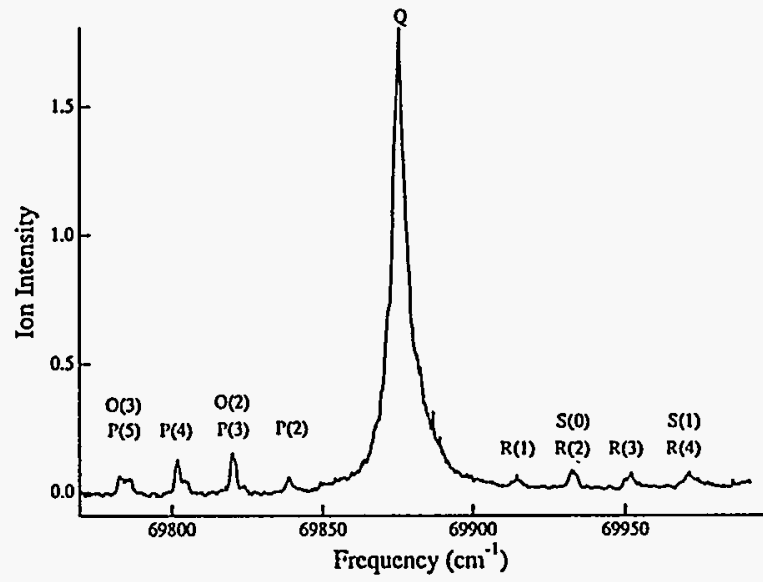

Figure 2.8. MPI $(2+1)$ spectrum of the $4 \mathrm{p}_{z} \leftarrow X(0-$ 0 ) transition of the methyl photofragment from the 236-nm dissociation of acetyl chloride. The abscissa displays resonance two-photon frequencies.

tion by their relative absorption coefficients at 236 $\mathrm{nm}$. Assuming that the quantum yield for $\mathrm{CH}_{3}$ formation from $236 \mathrm{~nm}$ excitation of $\mathrm{CH}_{3} \mathrm{I}$ is unity, we can calculate the relative yield for $\mathrm{CH}_{3}$ formation from dissociation of $\mathrm{CH}_{3} \mathrm{COCl}$, provided we make some assumptions about the $\mathrm{CH}_{3}$ vibrational state distributions. The MPI technique detects vibrationally-excited $\mathrm{CH}_{3}$ radicals less efficiently due to predissociation in the $\mathrm{CH}_{3}$ resonant excited state. ${ }^{4}$ By probing the $\mathrm{Q}$ branch of the $3 \mathrm{p}_{\mathrm{z}}$ $\leftarrow X$ transition we observe $\mathrm{CH}_{3}$ predominantly in the ground vibrational state and fail to detect any $\mathrm{CH}_{3}$ formed in overtones of $v_{2}$, the methyl bend vibration, in the dissociation of $\mathrm{CH}_{3} \mathrm{I}$. We therefore must consider the relative vibrational state distributions of methyl radicals produced in the photolysis of $\mathrm{CH}_{3} \mathrm{I}$ and $\mathrm{CH}_{3} \mathrm{COCl}$. We shall not consider the symmetric $\left(v_{1}\right)$ and antisymmetric $\left(v_{3}\right)$ stretch vibrations, since $v_{1}$ is believed to be incorporated within the Doppler broadened $0_{0}^{0}$ band and it is unlikely that either mode receives much excitation.

The relative vibrational state distribution of $\mathrm{CH}_{3}$ radicals produced in the $248-\mathrm{nm}$ photolysis of $\mathrm{CH}_{3} \mathrm{I}$ has been determined to be 0.66:0.26:0.08:0.008 for $\mathrm{v}=0: 1: 2: 3$ by infrared diode laser kinetic spectroscopy. ${ }^{5}$ We assume the same relative ground vibrational state yield $(0.66)$ in the 236-nm dissociation of $\mathrm{CH}_{3} \mathrm{I}$. As previously mentioned, nearly all the $\mathrm{CH}_{3}$ produced in the photolysis of $\mathrm{CH}_{3} \mathrm{COCl}$ is in the vibrational ground state. Using the above assumptions, we calculate the relative $\mathrm{CH}_{3}$ quantum yield in the 236-nm dissociation of $\mathrm{CH}_{3} \mathrm{COCl}$ to be 0.28 . 


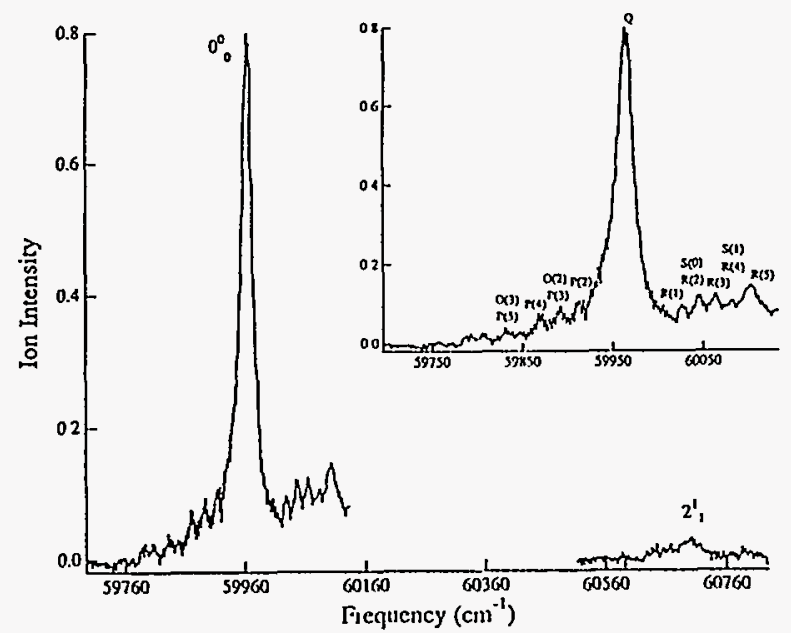

Figure 2.9. MPI $(2+1)$ spectrum of the $3 p_{z} \leftarrow X$ transition of the methyl photofragment from the 236- $\mathrm{nm}$ dissociation of acetyl chloride. The spectrum is dominated by the large origin band near $59970 \mathrm{~cm}^{-1}$, but also shows the small first band of the $v_{2}$ umbrella vibration mode. The inset displays the origin band on an expanded frequency scale to show the rotational distribution. The abscissa displays resonance two-photon frequencies.

The main focus of this work is on the second step of the stepwise dissociation of acetyl chloride, involving the acetyl radical intermediate to produce $\mathrm{CO}$ and $\mathrm{CH}_{3}$ fragments. Butler and coworkers ${ }^{6}$ reported that $\mathrm{Cl}$ atoms are generated in the primary dissociation of $\mathrm{CH}_{3} \mathrm{COCl}$, following ${ }_{1}\left[\mathrm{n}, \pi^{*}(\mathrm{C}=\mathrm{O})\right]$ excitation, and determined an anisotropy parameter of $\beta=1$ for the dissociation process. This implies that the transition moment is aligned nearly parallel to the $\mathrm{C}-\mathrm{Cl}$ bond and that the dissociation is prompt. However, no methyl radical signal was observed above the background. 6 Methyl radical product might be expected following $\mathrm{C}-\mathrm{Cl}$ bond cleavage because coincident with the breaking of the $\mathrm{C}-\mathrm{Cl}$ bond, the $\mathrm{C}-\mathrm{C}$ bond in acetyl radical weakens dramatically.

A rough accounting of the mean available energy shows that for some acetyl radicals the secondary dissociation is accessible, but for others it is energetically constrained. Houston and co-workers ${ }^{7}$ point out that only $48 \mathrm{~kJ} / \mathrm{mol}$ or $0.49 \mathrm{eV}$ is required to produce $\mathrm{CH}_{3}$ and $\mathrm{CO}$ from $\mathrm{CH}_{3} \mathrm{CO}$, and adopting this value, we calculate that the recoiling $\mathrm{CH}_{3} \mathrm{CO}$ fragments that correlate to $\mathrm{Cl}$ formation dissociate leaving a mean $0.65 \mathrm{eV}$ to be partitioned between the translational and internal degrees of freedom of $\mathrm{CH}_{3}$ and $\mathrm{CO}$. We estimate the internal energy of $\mathrm{CH}_{3}$ to be $0.02 \mathrm{eV}$. This leaves $0.22 \mathrm{eV}$ that is available to be partitioned between the $\mathrm{CO}$ rotational and vibrational degrees of freedom. Although we have not measured the $\mathrm{CO}$ internal state distributions, it is unlikely that $\mathrm{CO}$ is vibrationally and rotationally highly excited. The quantum yield measurement indicates that $28 \%$ of the acetyl fragments produced in the primary acetyl chloride dissociation step, generate methyl radicals. It is likely that the acetyl fragments that correlate to slower $\mathrm{Cl} / \mathrm{Cl}^{*}$ atoms produce $\mathrm{CH}_{3}$. Perhaps those $\mathrm{CH}_{3} \mathrm{CO}$ intermediates that correspond to faster $\mathrm{Cl}$ atoms do not have enough energy to generate $\mathrm{CH}_{3}$. Those $\mathrm{CH}_{3} \mathrm{CO}$ radicals that correlate to $\mathrm{Cl}^{*}$ formation have 0.11 $\mathrm{eV}$ less energy than those that correlate to $\mathrm{Cl}$. But, consistent with the energy argument presented above, there is less than $0.11 \mathrm{eV}$ remaining after accounting for all the fragment energetics. Accordingly, the $\mathrm{CH}_{3} \mathrm{CO}$ intermediates that correlate to $\mathrm{Cl}^{*}$ formation are less likely to generate $\mathrm{CH}_{3}$.

\section{References:}

1. U. S. Congress, Office of Technology Assessment, Complex Cleanup: The Environmental Legacy of Nuclear Weapons Production OTA-O-484 (U. S. Government Printing Office, Washington, DC, 1991), p. 150.

2. S. Solomon, Rev. Geophys. 26, 131 (1988); V. Vaida, S. Solomon, E. C. Richard, E. Ruhl, and A. Jefferson, Nature 342, 405 (1989).

3. S. Deshmukh and W. P. Hess, J. Photochem. Photobiol. A, in press.

4. T. G. DiGiuseppe, J. W. Hudgens, and M. C. Lin, J. Chem. Phys. 76, 3338 (1982); J. W. Hudgens, T. G. DiGiuseppe, and M. C. Lin, J. Chem. Phys. 79, 571 (1983).

5. T. Suzuki, H. Kanamori, and E. Hirota, J. Chem. Phys. 94, 6607 (1991).

6. M. D. Person, P. W. Kash, and L. J. Butler, J. Phys. Chem. 96, 2021 (1992); J. Chem. Phys. 97, 355 (1992).

7. K. A. Trentelman, S. H. Kable, D. B. Moss, and P. L. Houston, J. Chem. Phys. 91, 7498 (1989). 


\author{
Spectroscopy and Dynamics of \\ Single Molecules at Interfaces \\ with a Near-Field Microscope \\ X. S. Xie, R. C. Dunn, * E. V. Allen, $\dagger$ \\ G. R. Holtom, G. A. Anderson, $\$$ \\ and S. A. Joyce \\ Supported by Office of Basic Energy Sciences and a \\ Cooperative Research and Development Agree- \\ ment (CRADA). \\ * Postdoctoral Research Associate. \\ $†$ Applied Physics Center. \\ $\S$ Computing and Information Sciences.
}

In recent years, near-field optical microscopy has emerged as a new area of scanning probe microscopy. ${ }^{1}$ Near-field optical microscopy involves scanning a spot of light, of dimension much smaller than a wavelength of light, across the surface of a sample. Recently a technique has been developed for pulling optical fibers that can provide a fiber tip with a $15-\mathrm{nm}$ diameter. When the distance between the ultrafine fiber tip and the sample is sufficiently small (ten nanometers), the spatial resolution is limited only by the cross section of the tip, and can be much higher than the far-field diffraction limit in ordinary optical microscopy.

While this technique has numerous potential applications, such as surface imaging and optical storage, we are exploiting the capability of conducting molecular spectroscopy at the nanometer scale, on a single-molecule basis. This would make possible implementing the wealth of techniques of optical spectroscopy with an unprecedented spatial resolution, providing information about molecular species and their chemical reactions not accessible with SEM, STM and AFM. The time resolution afforded by optical measurements would allow observations of dynamical processes.

In 1993, a state-of-the-art near-field fluorescence microscope became fully operational. Figure 2.10 shows the schematic. We have taken special care to build an optics train in order to achieve singlemolecule fluorescence detection sensitivity. A feedback mechanism based on shear force has been implemented in order to regulate the sample tip distance and to obtain simultaneous force images. A CRADA has been established with Digital Instruments, a leading manufacturer of scanning probe microscopes, which is commercializing the microscope. Using this microscope, we have recently achieved the capability of imaging single chromophores (sulforhodamine 640 dye

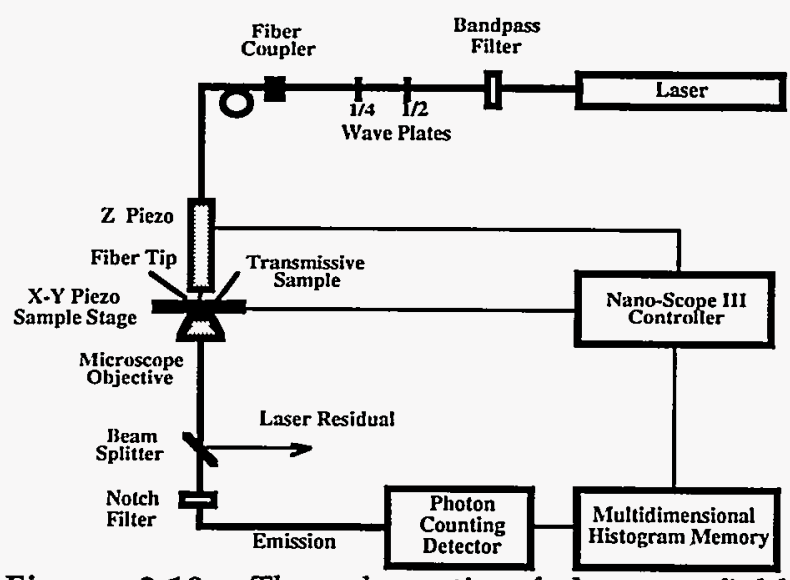

Figure 2.10. The schematic of the near-field fluorescence microscope.

molecules) ${ }^{2}$ and single proteins. ${ }^{3}$ Similar experiments have also been demonstrated independently by two other groups. ${ }^{4,5}$ The signal strengths of our total fluorescence images were sufficient to spread the fluorescence counts in frequency to obtain fluorescence spectra, or in time to measure fluorescence lifetimes. This will make it possible to conduct molecular spectroscopy on a singlemolecule basis.

From a chemical physics point of view, conducting spectroscopy on single molecules would allow removal of spectral heterogeneity and the study of one molecule at a time in its specific local environment. Time-resolved spectroscopy on single molecules would make it possible to study chemical reactions (such as electron transfer), which can offer a great deal of detailed information compared to the experiments done on a large ensemble of molecules.

Recently we have incorporated time-correlated photon counting with the near-field optics. Figure 2.11 is the instrumental response function of the microscope using a fast avalanche photodiode diode detector which has high quantum efficiency and extremely low dark noise. The FWHM is 120 ps, shorter than previously reported using similar detectors.

We are currently conducting time-resolved fluorescence measurements on a single-molecule basis in order to investigate chemical reactions at interfaces (for example, electron transfer reactions) with much greater detail.

\section{References:}

1. E. Betzig and J. K. Troutman, Science 257, 189 (1992). 
2. X. S. Xie, E. V. Allen, G. R. Holtom, R. C. Dunn, and L. Mets, Time-Resolved Laser Spectroscopy in Biochemistry, Proc. SPIE, in press.

3. R. C. Dunn, E. V. Allen, S. A. Joyce, G. A. Anderson, and X.S. Xie, Ultramicroscopy, in press.

4. E. Betzig et al., Science 262, 1422 (1993).

5. W. P. Ambrose et al., Phys. Rev. Lett., submitted.

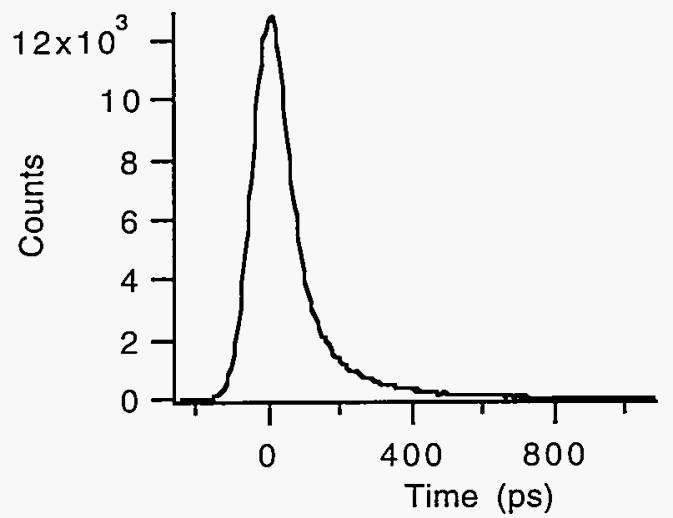

Figure 2.11. Instrumental response function of the near-field fluorescence microscope, which has a FWHM of 120 ps.

\section{Electronic Structure and Dynamics of Silicon Oxide Clusters L. S. Wang, S. D. Colson, J. Fan,* and J. B. Nicholas ${ }^{\dagger}$ \\ Supported by Office of Basic Energy Sciences. \\ * Postdoctoral Research Associate. \\ $\uparrow$ Theory, Modeling, and Simulation.}

Silicon oxide is an important material in many technological and scientific areas. Its unique properties provide the key for the manufacture of silicon-based devices in the electronics industry, and it forms the base for glass and zeolite materials. As importantly, its surface chemistry plays a major role in the underground transport of waste materials. We have initiated a project to study small silicon oxide clusters and to use these model systems to better understand the structure and dynamics of silicon oxide surfaces and defects. The small, controlled sizes of these cluster species provide an excellent testing ground for theoretical models which are intended for large and "real world" systems.

We have obtained both positive and negative cluster mass spectra of small silicon oxide clusters, $\mathrm{Si}_{\mathrm{x}} \mathrm{O}_{\mathrm{y}}{ }^{ \pm}$, which were produced through laser vaporization of a silicon target with a $5 \% \mathrm{O}_{2}$ seeded He carrier gas. Figure 2.12 shows the nega-

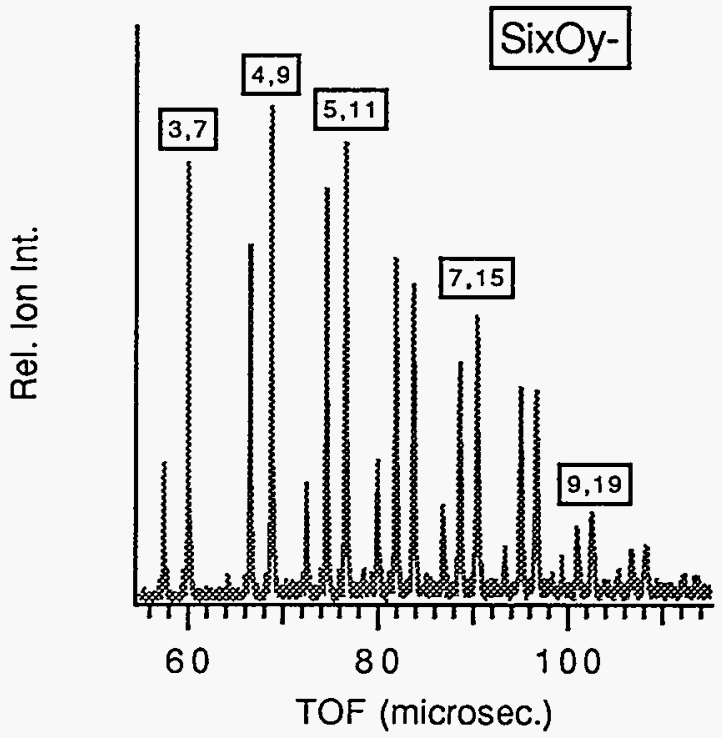

Figure 2.12. Time-of-flight mass spectrum of negative silicon oxide clusters.

tive cluster distributions. Three species were observed for each $x$ with $y=2 x$ and $2 x \pm 1, y=2 x$ +1 being the most abundant. Figure 2.13 displays the positive clusters. Five species were observed for each $x$ with $y=2 x, 2 x \pm 1,2 x-2,2 x-3, y=2 x-$ 1 being the most abundant.

The cluster distributions reflect the stability of the various cluster sizes. It is interesting to note that the most abundant clusters occur near the bulk stoichiometry for both the negative and the positive ions. In bulk $\mathrm{SiO}_{2}$, different-sized ring struc-

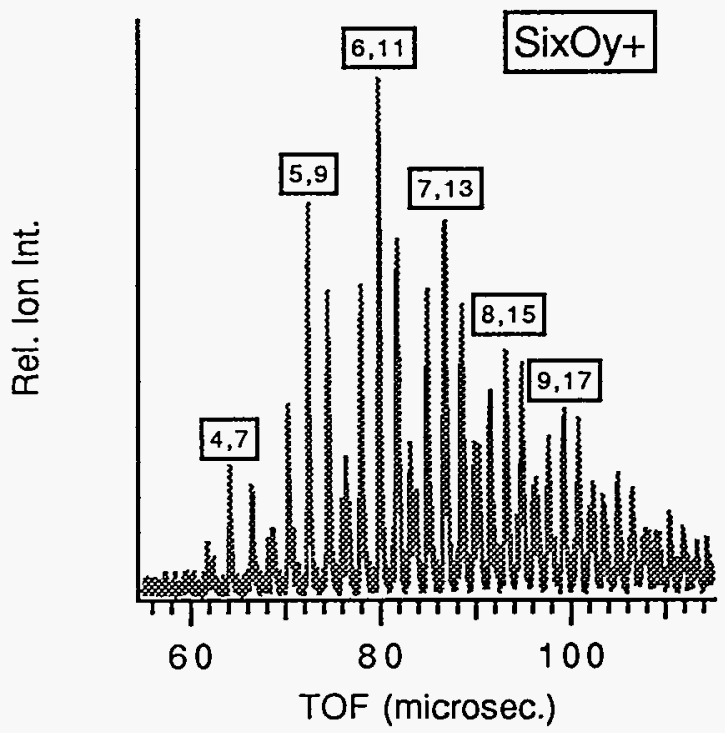

Figure 2.13. Time-of-flight mass spectrum of positive silicon oxide clusters. 
tures with alternating $\mathrm{Si}$ and $\mathrm{O}$ atoms are found as defect sites. The smaller clusters produced in our cluster source may also assume similar ring-type structures. However, preliminary theoretical calculations indicate that for $\mathrm{Si}_{3} \mathrm{O}_{6}$ a linear structure with two bridging $\mathrm{O}$ atoms (Fig. 2.14) is about 23 $\mathrm{kcal} / \mathrm{mol}$ lower in energy than a ring structure (Fig. 2.15).

Electronic structures of size-selected $\mathrm{Si}_{\mathrm{x}} \mathrm{O}_{\mathrm{y}}{ }^{-}$clusters will be studied by photoelectron spectroscopy, in which the spectral transitions take place from the ground state of $\mathrm{Si}_{\mathrm{x}} \mathrm{O}_{\mathrm{y}}{ }^{-}$to the ground state and various low-lying excited states of $\mathrm{Si}_{x} \mathrm{O}_{y}$ neutral clusters. The electronic structure information thus obtained should provide insights about their reactivities and other chemical and physical properties. By comparing this experimental electronic structure information with theoretical calculations, it should be possible to obtain their geometric structures as well. In favorable cases, if vibrational structure can be resolved in the photoelectron spectra, more direct structural information will be obtained.

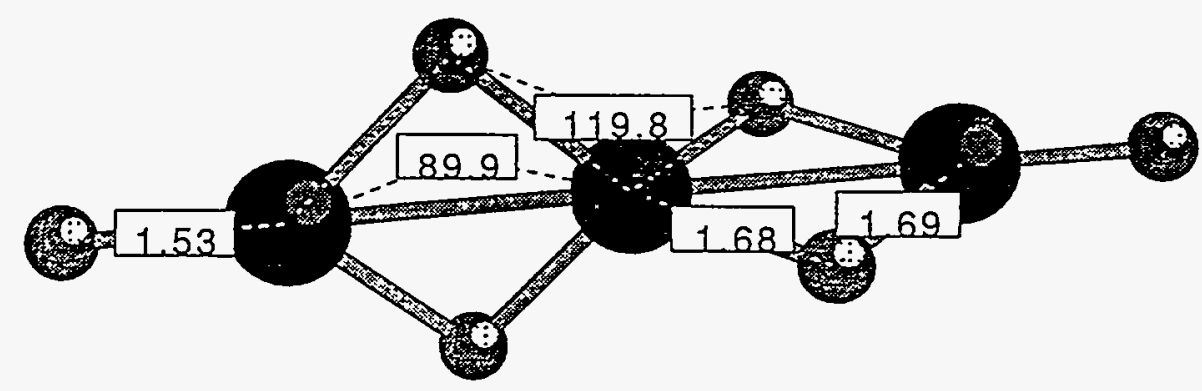

Figure 2.14. A linear bridging oxygen structure for $\mathrm{Si}_{3} \mathrm{O}_{6}$, calculated with $\mathrm{MP2} / 6-316$. The larger spheres are $\mathrm{Si}$, the smaller $\mathrm{O}$.

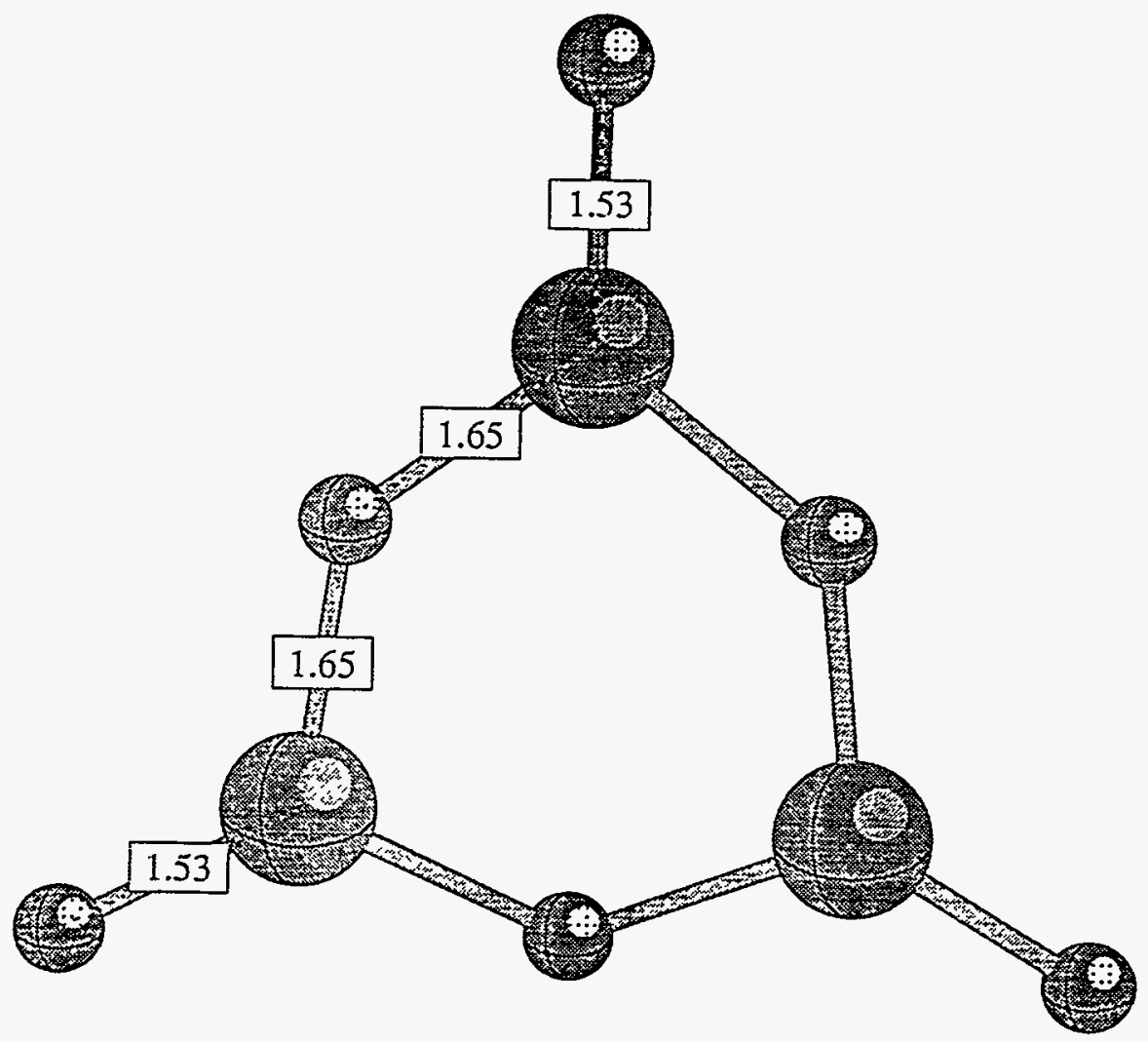

Figure 2.15. A ring structure for $\mathrm{Si}_{3} \mathrm{O}_{6}$, calculated with $\mathrm{MP2} / 6-316$. The larger spheres are $\mathrm{Si}$, the smaller O. 
Photoelectron Spectroscopy and

Electronic Structure of Metal Clusters and Chemisorbed Metal Cluster Complexes

\section{S. Wang and J. Fan*}

Supported by Office of Basic Energy Sciences.

* Postdoctoral Research Associate.

Clusters containing two to several hundred atoms are considered to be ideal models for studying chemisorption on surfaces due to their finite sizes, which enable more rigorous theoretical calculations. Cluster chemical reactivities have been studied extensively in the past few years and have been found to be a strong function of cluster size, and can vary by orders of magnitude simply by adding or subtracting one atom. Yet it is not understood why some clusters are more reactive than others. We are interested in investigating the cluster-molecule interactions through ultraviolet photoelectron spectroscopy (PES) of size-selected negative cluster ions by probing the change of the electronic structure of a cluster upon chemisorption. This knowledge obtained from comparing PES spectra of the bare clusters with that of the cluster-adsorbate complexes should lead to detailed insight about how a molecule interacts with the cluster.

We have completed the construction of a state-ofthe-art PES instrument, as shown schematically in Fig. 2.16. This apparatus consists of a laser vaporization cluster source, an improved time-of-flight mass spectrometer for cluster size selection, and a magnetic-bottle type of time-of-flight photoelectron analyzer. The latter, due to its near unit col-

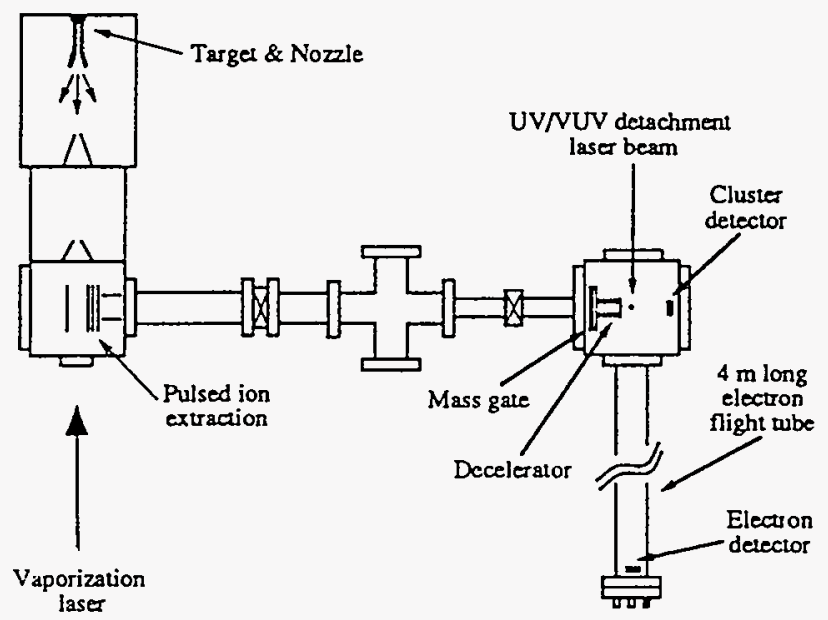

Figure 2.16. Schematic of the cluster photoelectron spectrometer. lection efficiency, is of paramount importance for the study of clusters, because the negative-cluster PES cannot afford the luxury of high target densities. A simple modification of the conventional TOF mass spectrometer enables us to achieve high mass resolution ( $M / \Delta M=\sim 300-500)$, which is important for studying cluster-adsorbate species and other complicated heteronuclear clusters.

We have developed an impulse deceleration technique to slow down cluster ions for the minimization of Doppler-broadening in PES spectra. Figure 2.17 displays a sequence of our cluster size
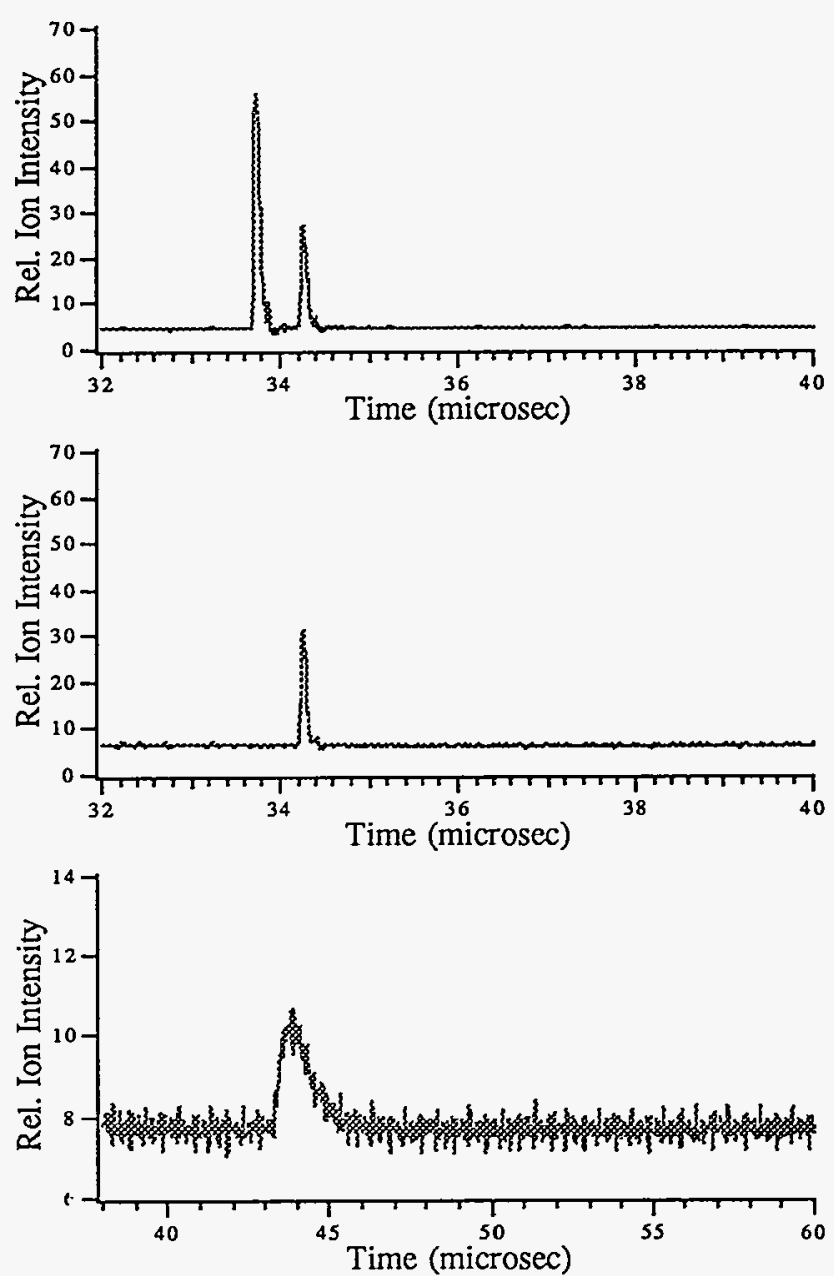

Figure 2.17. A sequence of ion size selection and deceleration. Top: Mass spectrum of $\mathrm{Cu}^{+}$showing the two well-resolved isotopes of $\mathrm{Cu}\left({ }^{63} \mathrm{Cu}\right.$ and ${ }^{65} \mathrm{Cu}$ ). The mass resolution here is $\mathrm{M} / \Delta \mathrm{M}=340$. Middle: Mass-selected ${ }^{65} \mathrm{Cu}^{+}$isotope peak. Bottom: Decelerated ${ }^{65} \mathrm{Cu}^{+}$isotope peak with a square high voltage pulse ( $2 \mathrm{kV}$ pulse amplitude, $500 \mathrm{~ns}$ pulse width). 
selection and deceleration. The top panel shows a mass spectrum of a $\mathrm{Cu}^{+}$ion with its two natural isotopes $\left({ }^{63} \mathrm{Cu}, 69 \%\right.$ and $\left.{ }^{65} \mathrm{Cu}, 31 \%\right)$. The middle panel shows the mass selection of the ${ }^{65} \mathrm{Cu}^{+}$ion. The bottom panel shows the decelerated signal of the mass-selected ${ }^{65} \mathrm{Cu}^{+}$ion with a square highvoltage pulse having a pulse amplitude of $2 \mathrm{kV}$ and a pulse width of $500 \mathrm{~ns}$. With this impulse deceleration, the mean ion energy is reduced from the original $950 \mathrm{eV}$ to about $20 \mathrm{eV}$. This technique allows us to achieve high electron-energy resolution by reducing the Doppler-broadening.

Figure 2.18 demonstrates the effect of the deceleration on the PES resolution. It shows the photoelectron spectra of $\mathrm{Cu}^{-}$negative ion with a photon energy of $3.49 \mathrm{eV}$ at three different decelerations. The top panel shows a spectrum at a deceleration with a pulse of $2 \mathrm{kV}$ amplitude and $200 \mathrm{~ns}$ pulse width. The peak at $2.2 \mathrm{eV}$ electron kinetic energy has a FWHM of $360 \mathrm{meV}$. The middle panel shows a deceleration of $2 \mathrm{kV} \times 400 \mathrm{~ns}$ and the $2.2 \mathrm{eV}$ peak is reduced to $109 \mathrm{meV}$ FWHM. Finally at a deceleration of $2 \mathrm{kV} \times 550 \mathrm{~ns}$, the same peak is reduced to $52 \mathrm{meV}$ FWHM, while the $0.9-\mathrm{eV}$ peak is reduced to a FWHM of $25 \mathrm{meV}$. The lowest-energy peak has an even more impressive width of $12 \mathrm{meV}$, but the counting statistics is rather low here to allow a meaningful measure of the peak width. This resolution is to be compared with more than $100 \mathrm{meV}$ resolution achieved previously with similar apparatus. At the present high resolution, PES will not only yield quantitative electronic structure information of clusters, but also vibrational information in favorable cases.

We have begun the study of small iron clusters and oxygen-iron cluster adsorbate species. Figure 2.19 shows the photoelectron spectra of $\mathrm{Fe}_{\mathrm{n}}{ }^{-}, \mathrm{n}=$ $3-7$, at a photon energy of $3.49 \mathrm{eV}$. We have obtained photoelectron spectra of $\mathrm{Fe}_{n}{ }^{-}$with $\mathrm{n}$ up to 25. Transition metal clusters are very complicated electronic systems because of their open dshell and the expected high density of electronic states. The photoelectron spectra reveal the complicated nature of their electronic structure and will provide insight to their chemical reactivity.

Figure 2.20 displays the photoelectron spectra of oxygen-iron cluster adsorbate species. We have obtained photoelectron spectra of these $\mathrm{O} / \mathrm{Fe}_{\mathrm{n}}{ }^{-}$ species with $n$ up to 16 . The oxygen-adsorbed clusters show considerably different spectra from the bare clusters. These spectra should reveal details about the O-cluster interactions.
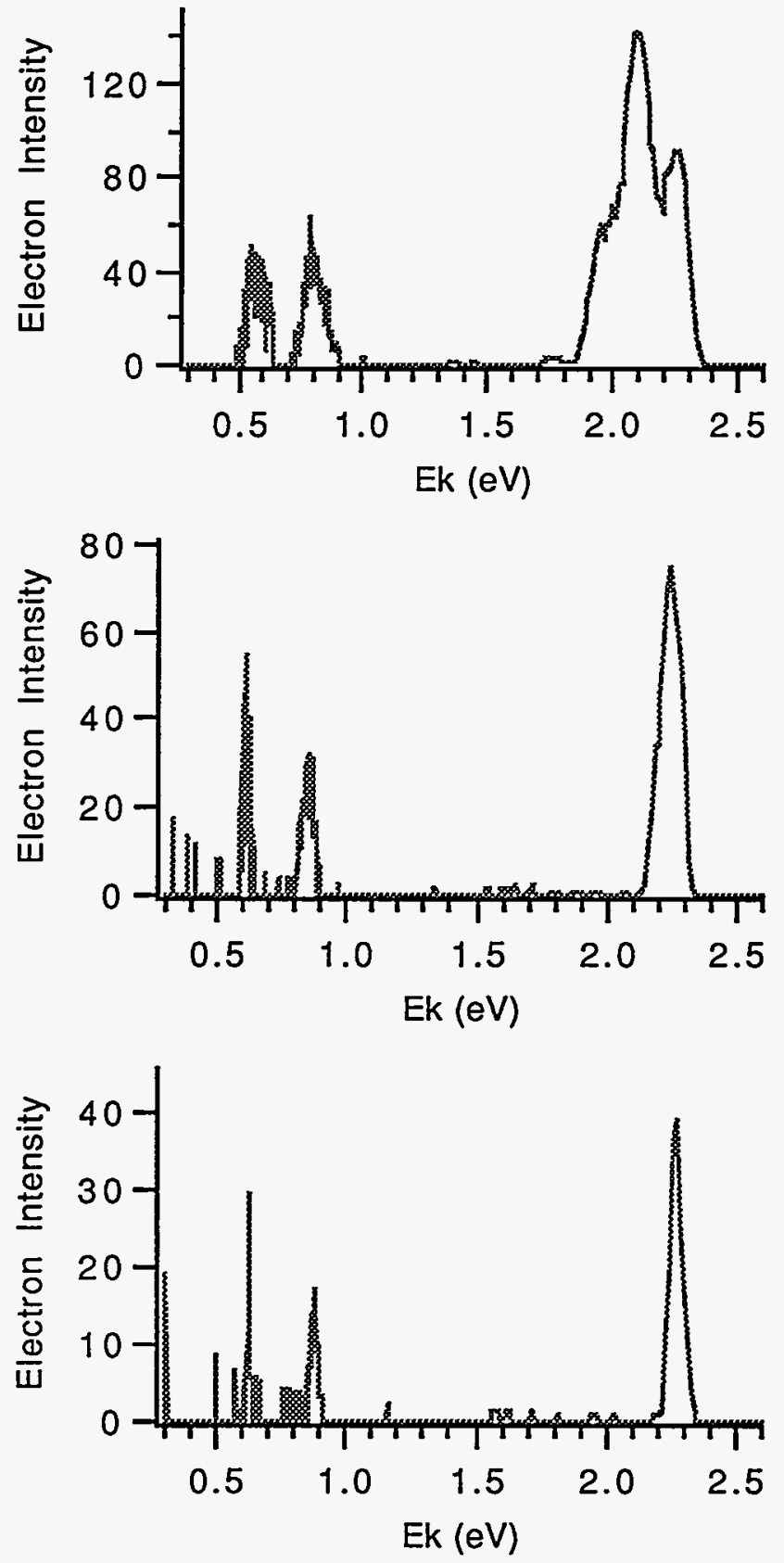

Figure 2.18. Photoelectron spectra of $\mathrm{Cu}^{-}$at 3.49 $\mathrm{eV}$ photon energy, showing the effect of ion deceleration on the photoelectron spectral resolution. Top: $2 \mathrm{kV} \times 200 \mathrm{~ns}$ high-voltage pulse. Middle: 2 $\mathrm{kV} \times 400 \mathrm{~ns}$ high-voltage pulse. Bottom: $2 \mathrm{kV} \times 550$ ns high-voltage pulse.

Extensive theoretical efforts are required to quantitatively understand these results. Preliminary local spin density calculations on $\mathrm{O} / \mathrm{Fe}_{4}$ by $\mathrm{L}$. Lu of Rice University indicate that the $\mathrm{Fe}_{4}$ has a tetrahedral structure with the oxygen atom bound to one edge of the tetrahedron. 

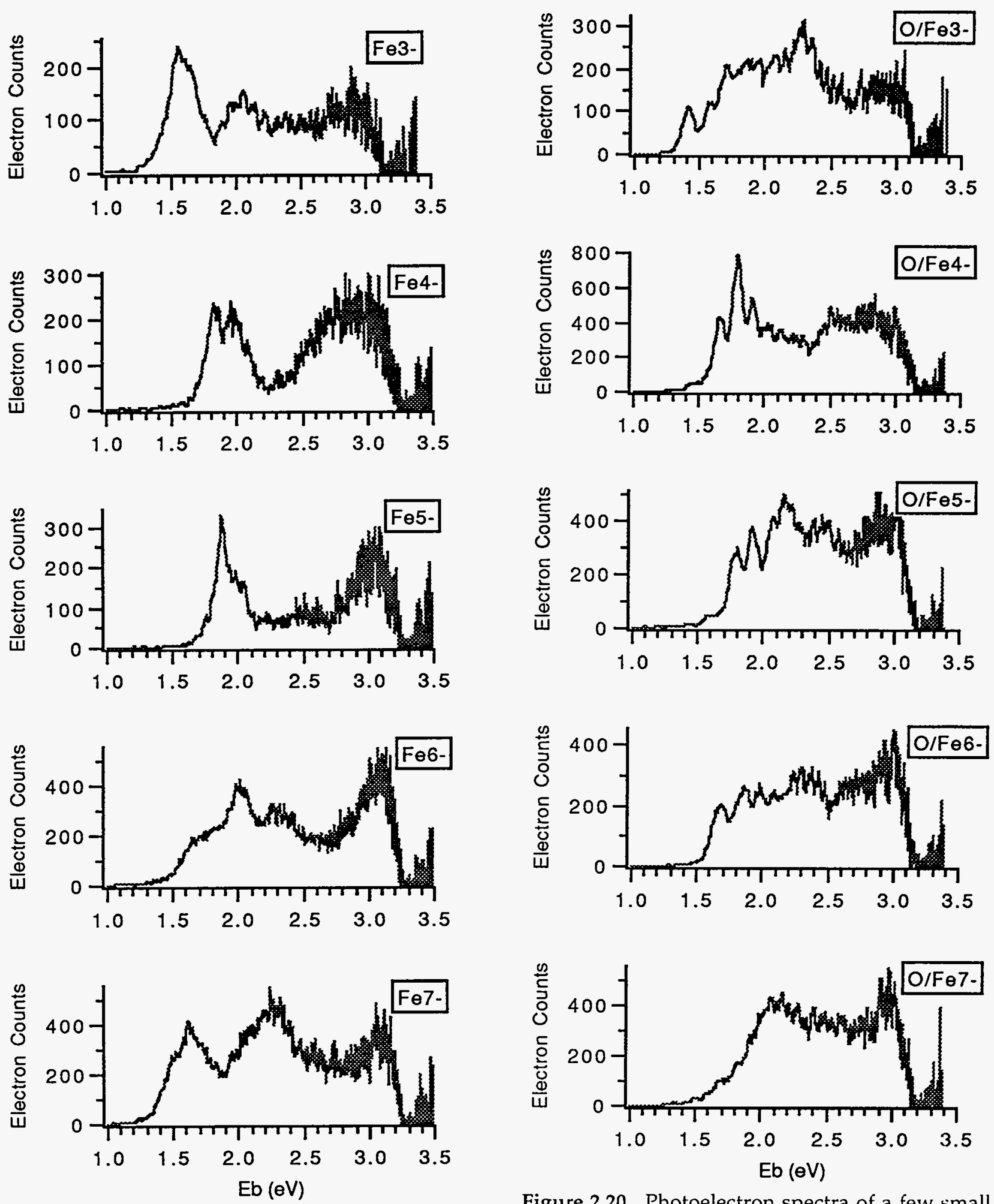

Figure 2.19. Photoelectron spectra of a few small iron clusters at $3.49 \mathrm{eV}$ photon energy.

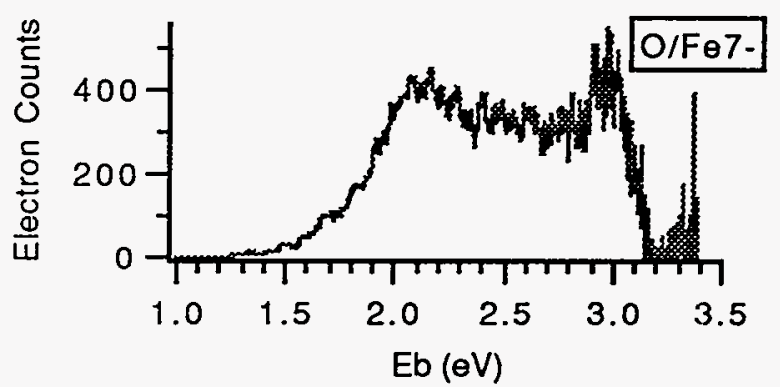

Figure 2.20. Photoelectron spectra of a few small oxygen-iron cluster adsorbate species at $3.49 \mathrm{eV}$ photon energy. 


\section{Solutions and Solution Interfaces}

Solutions: No solvent is more important than water, and few have such a profoundly strong interaction with most dissolved molecules, the energetics of which often control aqueous reactions. The varieties of local structures for water is evident in the breadth of the infrared absorption band of the $\mathrm{OH}$ stretching region. Infrared "holeburning" experiments can select one type of water geometry out of this spectral width. However, the water structure is dynamic: hydrogen bonds dissociate and reassociate on picosecond time scales. To gather useful kinetic data, it is crucial to use femtosecond infrared pulses to burn these holes and follow the femto- to picosecond dynamics.

CS\&D is constructing an ultrafast laser system to provide high-energy, high-repetition-rate, stable, femtosecond IR pulses. It uses the latest solidstate technologies, such as self-modelocking, Ti: sapphire regenerative amplification, and optical parametric oscillators. Tunable especially near 3 $\mu \mathrm{m}$ (the OH-stretching region), the laser will be ideal for studying aqueous solvation. Photon echo, hole burning, and other methods will be used to study the vibrational relaxation and dephasing time, outer-sphere/inner-sphere transitions, and other aspects of molecule-solvent systems.

To study charge transfer and solvation in bulk liquids, much use has recently been made of intramolecular charge transfer (ICT) processes, as charge transfer distances can be controlled easily, and provide good tests of theories of charge transfer. Compounds demonstrating ICT include parasubstituted aromatics. Most previous studies of ICT have followed the broad photon emission from excited electronic states, which are very difficult to interpret unambiguously in terms of molecular motion and electron hopping dynamics. CS\&D is using more detailed, active probes, such as UV resonance Raman spectroscopy and the picosecond pump-probe methods of transient absorption and time-resolved Raman scattering.

The acid-base properties of water and of dissolved molecules are important in many ground, tank, and remediation reactions. To study how an $\mathrm{H}^{+}$ transfers from one molecule to another, CS\&D is using frequency-domain analysis of resonance Raman scattering to resolve questions about the early time behavior of the $\mathrm{H}^{+}$motion, and how the donor and acceptor molecules begin to reshape to accommodate the $\mathrm{H}^{+}$transfer. Proton-transfer reactions are also being studied in water clusters and ultrafine aerosols.

Solution Interfaces: Optical methods are ideal for probing the solid-liquid interface, as they can penetrate the media. The small number of molecules adsorbed on the typical surface $\left(10^{12}\right.$ to $10^{15}$ per $\mathrm{cm}^{2}$, compared to solution concentrations of perhaps $10^{16}$ to $10^{20}$ per $\mathrm{cm}^{3}$ of solvent) does not prevent their study. High-surface-area powders can be studied by direct transmission, and many optical techniques rely on the optical discontinuity at the interface to create surface sensitivity. These include non-linear optics (second-harmonic and sum-frequency generation), evanescent waves from total internal reflection, and Fourier transform reflectance IR through thin film solutions. The solid NMR spectrometers of the Macromolecular Structure and Dynamics group also provide an important solution interface probe.

The first such experiments are (1) looking at rareearth metal ion complexes (such as Eu(III)-EDTA) to explore inner-sphere vs. outer-sphere redox mechanisms at aquatic mineral surfaces; and (2) FTIR vibrational spectroscopic studies testing current hypotheses regarding the binding of $\mathrm{Co}(\mathrm{III})$ EDTA to metal oxide surfaces. These studies will further use high-pressure techniques to perturb the solution density and observe its effects on solvation. Future experiments will use $\mathrm{ps} / \mathrm{fs}$ nonlinear laser methods to directly follow solvation and to determine charge transfer rates.

Small clusters of water surrounding a molecule or ion are also being studied by CS\&D. The properties of these clusters are determined by the same physics that determine solvation effects in real solutions. Experimental studies of these model systems, in conjunction with detailed calculations, provide important input to theoretical models of simple solutions. Thus the cluster studies are essential to the development and verification of theoretical models for eventual application to complex solutions and solution interfaces. Studies of solvent molecules around small ions (e.g., Cs ${ }^{+}$, $\mathrm{Cl}^{-}$, and $\mathrm{NH}_{4}{ }^{+}$) and aromatic compounds (e.g., flavones, chromones, pyrones, aromatic bases like acridine and the quinolines, and aromatic acids such as naphthol and phenol) are being pursued. 
Intramolecular Charge Transfer (ICT) in Cyanoaniline Compounds

D. M. Friedrich, A. G. Joly, H. B. Lueck, *

M. A. Thompson, $\dagger$ J. P. LaFemina, $\S$

and A. R. HebeckerII

Supported by Office of Basic Energy Sciences.

* Postdoctoral Research Associate.

$\uparrow$ Theory, Modeling, and Simulation.

$\S$ Materials and Interfaces.

II Visiting Graduate Student from Max-Planck

Institut für Biophysikalische Chemie, Göttingen.

Para-substitution on benzene of an electron-donor group and an electron-acceptor group (D-Ar-A) results in an intense optical transition to a polar excited state. In the ground-state equilibrium geometry of cyanoaniline derivatives $\left(D=R_{2} N\right.$; $A$ $=\mathrm{CN})$, this polar electronic state $\left({ }^{1} \mathrm{~L}_{\mathrm{a}}\right)$ lies above the lowest excited singlet state $\left({ }^{1} \mathrm{~L}_{\mathrm{b}}\right)$, which has "locally excited" (LE*) character (D-Ar-A)*, smaller oscillator strength, a lower dipole moment, and is the origin of the prompt near-UV fluorescence. In some para-substituted aniline derivatives in polar solvents, dielectric polarization of the solvent further drives charge separation by stabilizing a higher-energy, more polar chargetransfer $\left(\mathrm{CT}^{*}\right)$ state $\left(\mathrm{D}^{+}-\mathrm{Ar}-\mathrm{A}^{-}\right)^{*}$. When the stabilization is large, the $\mathrm{CT}^{*}$ state can lie below the ${ }^{1} \mathrm{~L}_{\mathrm{b}} \mathrm{LE}^{*}$ state, resulting in a second, Stokes-shifted, and delayed fluorescence band in the visible. Indirect evidence accumulating in the literature for many years suggests that solvent-relaxation and increased charge separation is accompanied by large-amplitude motions of the amine group, especially twisting about the ring-amine bond, leading to a twisted intramolecular charge transfer (TICT) electronic excited state. Recently, this model has been disputed for some cyanoanilines, and there is some speculation that vibration of the amine pyramidal angle may assist in forming the $\mathrm{CT}^{*}$ state.

Some structural information about the $\mathrm{CT}^{*}$ state has been inferred from the effects of chemical substitution and solvent polarity on the dynamics of the structureless $\mathrm{LE}^{*}$ and $\mathrm{CT}^{*}$ emission bands. There is little detailed knowledge about the structure and formation of the $\mathrm{CT}^{*}$ state. UV resonance Raman scattering and time-resolved transient absorption spectra from these excited states can provide more structural detail, especially when informed by bonding changes predicted by electronic structure calculations.

Transient absorption spectra for $p$-DMABN in methanol are shown in Fig. 3.1. Mataga had earlier assigned a rising absorption edge in the blue $(\lambda \leq 400 \mathrm{~nm})$ seen at long time delay (>100 ps) to the $\mathrm{CT}^{*}$ state, since the spectrum is similar to that of the benzonitrile radical anion. At shorter times, our results show that the temporal changes in the transient absorption spectrum are more complicated. Our spectra show an initial transient band $(580 \mathrm{~nm})$ suggestive of the radical cation of an aromatic amine. Future measurements will test this hypothesis by extending the wavelength and time ranges in polar and nonpolar solvents.

Static UV resonance Raman scattering intensities from cyanoanilines reveal the electronic excited-
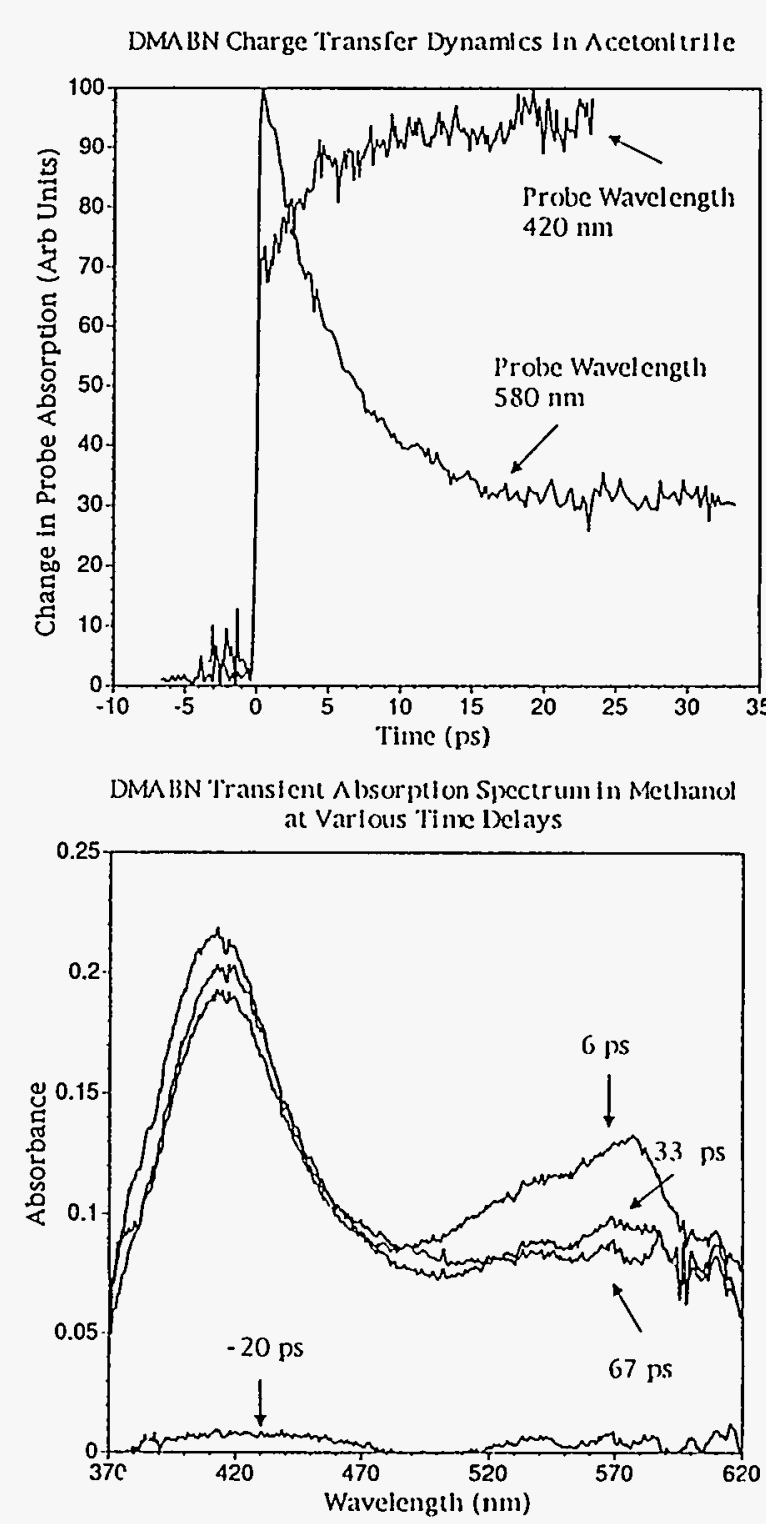

Figure 3.1. Transient absorption spectra of $p$ $D M A B N$ in methanol. 
state structural changes in the Franck-Condon region. For example, enhancement of scattering by the ring-breathing, deformation and elongation, and $\mathrm{CH}$-rocking modes indicate overall expansion and increased bond-alternation of the benzene ring in the ${ }^{1} \mathrm{~L}_{\mathrm{a}}$ state, consistent with changes in the occupied molecular orbitals for this transition. Enhancement of scattering by the nitrile stretch in the para-substituted compounds is predicted by the increased antibonding charge density on the nitrile in the excited state, providing support for the traditional interpretation that the ${ }^{1} \mathrm{~L}_{\mathrm{a}}$ state carries significant charge-transfer character.

Large-amplitude intramolecular motion leading to charge-transfer in $p$-DMABN and related compounds must affect the bond between the benzene ring and the amine nitrogen atom on the excitedstate surface. At one extreme, in a planar (quinoidal) structure conjugation of the nitrogen lone-pair orbital with the $\pi$ orbital of the ring leads to stiffening of the ring-to-amine bond (Ar-N). At another extreme, twisting of the amine with respect to the benzene plane should lead to a weaker bond (TICT structure). The Raman intensity of the Ar-N stretching mode is sensitive to twisting. On resonance $\left({ }^{1} \mathrm{~L}_{\mathrm{a}}\right)$, the intensity of this mode is vanishing in $p$-DMABN. Ortho-dimethyl substitution (MMD) results in a severe twist of the amine group $60-70^{\circ}$ out of plane. In MMD the Ar$\mathrm{N}$ stretching mode appears with good Raman intensity. The $\mathrm{Ar}-\mathrm{N}$ mode also appears at somewhat lower frequency $\left(\sim 1300 \mathrm{~cm}^{-1}\right)$ than in typical unstrained aromatic amines $\left(1330-1380 \mathrm{~cm}^{-1}\right)$, but well within the range of all tertiary anilines (1265$1380 \mathrm{~cm}^{-1}$ ). The vanishing resonance Raman intensity for this mode in $p$-DMABN can be understood by the failure of the excitation to change the $\mathrm{Ar}-\mathrm{N}$ bond order (CNDO/S3 calculations). This can be seen clearly in the molecular orbital patterns for the ${ }^{1} \mathrm{~L}_{\mathrm{a}}$ transition, which is dominated $(>80 \%)$ by the HOMO $\rightarrow$ LUMO configuration. Such changes of the $\mathrm{Ar}-\mathrm{N}$ bond are important for any discussion of large-amplitude motion involv-
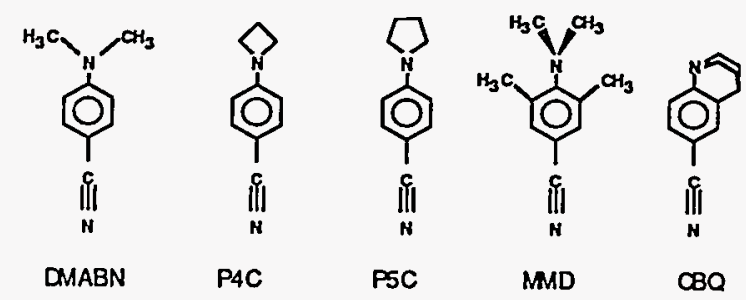

ing the amine group during charge transfer.

To understand the role of solvent dynamics on the mechanism of ICT, it is essential to know the energies and order of the lower two locally excited $\pi \pi^{*}$ states $\left({ }^{1} \mathrm{~L}_{a},{ }^{1} \mathrm{~L}_{b}\right)$. In MMD these have been controversial because they are merged under a single broad absorption band. The literature has not been clear on whether both states contribute to the observed UV band. Our recent measurements of the wavelength dispersion of Raman depolarization ratios demonstrate in MMD that the broad near-UV absorption is composed of two $\pi \pi^{*}$ electronic states. Unlike $p$-DMABN and other cyanoanilines, the state ordering in MMD is reversed, making ${ }^{1} \mathrm{~L}_{\mathbf{a}}$ the lowest excited singlet state.

The cage compound $\mathrm{CBQ}$ is especially interesting. The amine nitrogen lone-pair electrons are forced to lie in the plane of the benzene ring and therefore are nonbonding, decoupled from the $\pi$-electron system. Excitation of a nonbonding electron is via the $n \pi^{*}$ transition, which is blue-shifted by $\mathrm{H}$-bonding in protic solvents. Thus, in nonpolar solvents the lowest $\mathrm{LE}^{*}$ state is $n \pi^{*}$, while in protic solvents the lowest $\mathrm{LE}^{*}$ state is $\pi \pi^{*}$. These two precursors to ICT have very different dynamics and photophysical properties, which have yet to be explored with respect to ICT processes. Because it is already pre-twisted to the $90^{\circ}$ conformation, this molecule also allows theoretical study of the interacting effects of amine pyramidalization (hybridization) and solvent-dielectric relaxation on the dynamic energy lowering of the $\mathrm{CT}^{*}$ state. Calculations in progress by using the INDO/S together with a dielectric relaxation show that a high-energy $\mathrm{CT}^{*}$ state in $\mathrm{CBQ}$ is stabilized by a small decrease of the pyramidal angle of the amine group (toward planarity). Additional stabilization by solvent dielectric relaxation is calculated to bring this $\mathrm{CT}^{*}$ state below the energy of the two locally excited $\pi \pi^{*}$ states $\left({ }^{1} \mathrm{~L}_{\mathrm{a}}\right.$ and $\left.{ }^{1} \mathrm{~L}_{\mathrm{b}}\right)$, in agreement with the observed $\mathrm{CT}^{*}$ emission from $\mathrm{CBQ}$.

This is the beginning of a more detailed understanding of the $\mathrm{CT}^{*}$ state and of the effect of solvent relaxation on the electronic couplings between the electron donor and acceptor groups in these different compounds. 


\author{
Dynamics of Large Water Clusters \\ Probed by Excited-State Proton Transfer \\ R. D. Knochenmuss, ${ }^{*}$ D. E. Smith, $\dagger$ \\ G. R. Holtom, and D. Ray \\ Supported by Office of Basic Energy Sciences. \\ * Senior Research Fellow. \\ $\dagger$ Postdoctoral Research Associate, \\ Theory, Modeling, and Simulation.
}

The intermolecular excited-state proton transfer (ESPT) reactions of aromatic alcohols such as 1naphthol have long been known to depend strongly on solvent properties. ${ }^{1}$ The hydroxyl proton of these species becomes moderately acidic in the first excited singlet state, but reaction of $\mathrm{ROH}$ to form $\mathrm{RO}^{-}$and $\mathrm{H}^{+}$will occur only if the solvent is a good proton acceptor, and if the product ions become well solvated within the excitedstate lifetime. In other words, the solvent is a reactant and its properties are as important as those of the alcohol in determining the extent of reaction. Occurrence of the reaction is readily detected: the $\mathrm{RO}^{-}$conjugate base fluorescence appears at substantially lower energy than that of the neutral $\mathrm{ROH}$. Thus, these molecules are attractive probes of both static and dynamic properties of the solvent.

ESPT of 1-naphthol in bulk water occurs at a rate of $35 \mathrm{psec}^{-1}$, regardless of temperature, indicative of a non-activated process. ${ }^{2}$ This rate is near the Debye relaxation rate for water $\left(10 \mathrm{psec}^{-1}\right)$, suggesting that large-amplitude solvent reorganization is rate-limiting. This hypothesis is strengthened by the fact that ESPT occurs in supercooled water but does not occur upon freezing. In this work, we have measured the rates of ESPT in 1naphthol-water clusters as a function of cluster size and internal energy, by time-resolving the product fluorescence. These rate measurements, in conjunction with molecular dynamics simulations, provide a detailed, direct picture of the dynamical processes constituting solvation in water.

The clusters were synthesized in a conventional molecular beam apparatus. Photoexcitation was accomplished with the frequency-doubled output of a synchronously-pumped, cavity-dumped dye laser; pulse widths were approximately $10 \mathrm{psec}$ FWHM. Fluorescence was imaged onto a cooled microchannelplate photomultiplier, and measured with a conventional time-correlated photon counting apparatus. The instrument response, derived from the UV scatter from the molecular beam, was approximately 60 psec FWHM. After passing though a skimmer, the clusters were resonantly 2photon ionized with a second laser (at the same wavelength used for fluorescence excitation), and mass analyzed in a reflectron time-of-flight mass spectrometer. A typical mass spectrum is shown in Fig. 3.2.

Figure 3.3 shows time-resolved naphtholate proton-transfer product fluorescence from cluster distributions of differing size ranges. A trend from faster to slower reaction is evident as the average cluster size increases. Approximate rate trends vs. size were inferred from fits of the data to one rising and one falling exponential (convoluted with the instrument function). In addition to the exponential rising component, there is a significant fast component appearing within the excitation pulse. This component decreases in relative magnitude as larger cluster sizes are sampled.

The slower, dominant, part of the apparent ESPT rates varies from 0.5 to $1.5 \mathrm{nsec}$, which is much slower than in liquid water. This difference, along with the clear size dependence shown in Fig. 3.3, strongly supports the idea that this reaction is

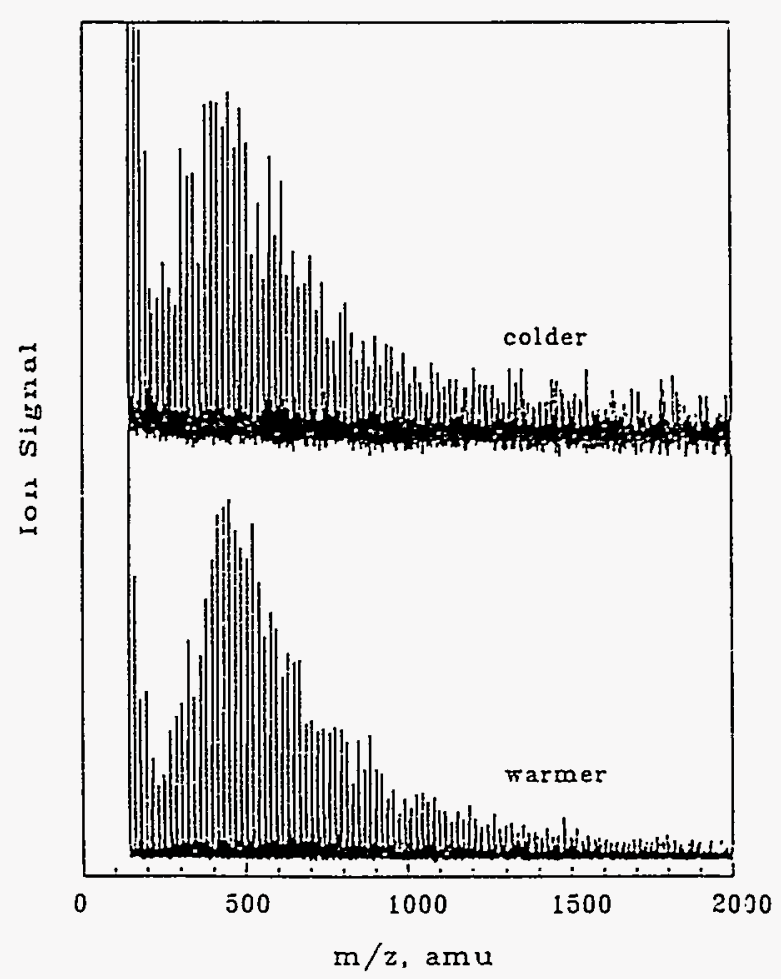

Figure 3.2. Resonant one-color two-photon ionization mass spectrum of 1-naphthol-water clusters at $312.5 \mathrm{~nm}$. 
kinetically controlled by the solvent, or cluster, environment. In other words, the nascent ion pair must be solvated via large rotational and/or translational motions in order for the reaction to proceed. The low values and significant variation in the rates indicates that 1-naphthol ESPT does not proceed via tunneling in water clusters, in contrast to intramolecular ESPT. The decrease in relaxation rate with increasing cluster size may be related to the size dependence of the solid-liquid phase transition. 3,4 As cluster size decreases, the melting point decreases. If effective cluster temperatures change slowly with size compared to the rapidly varying melting range, then small clusters are likely to be more fluxional (have a lower viscosity) than large clusters, resulting in faster ESPT rates for smaller clusters, as is observed. The fluorescence spectra also shift to the red on a longer (10 nsec) time scale when warmer cluster distributions are probed (see Fig. 3.4), suggestive of activated solvation of the $\mathrm{RO}^{-} \mathrm{H}^{+}$nascent ion pair following ESPT.

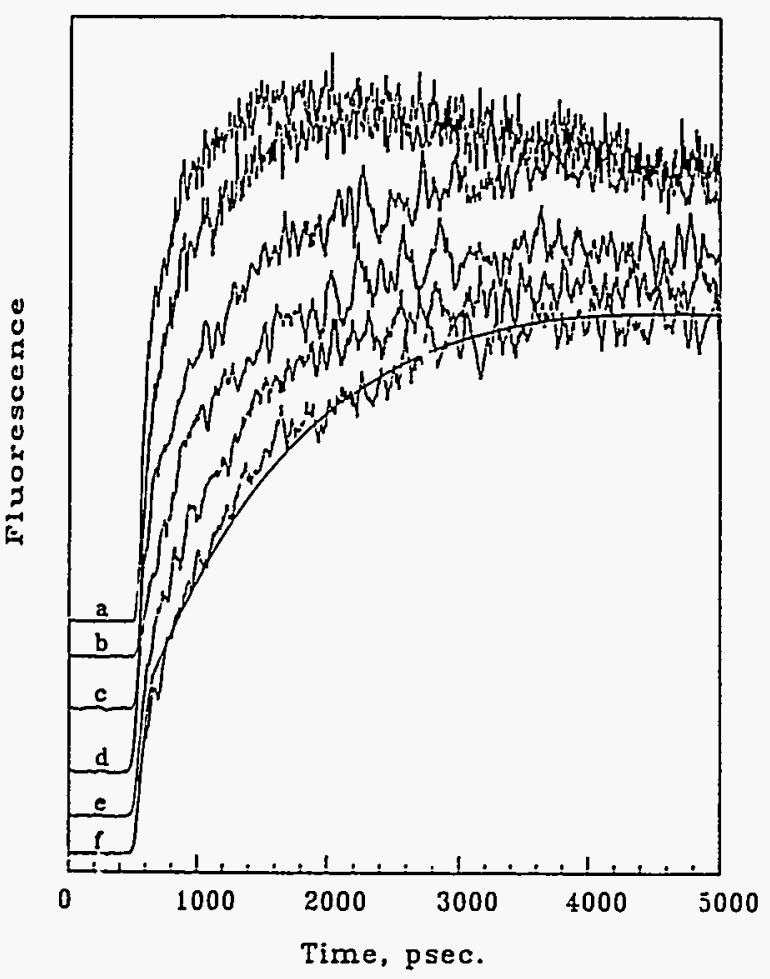

Figure 3.3. Time-resolved fluorescence curves from 1-naphthol-water clusters. The different curves result from excitation of different cluster size ranges: (a) 20-100, (b) 30-100, (c) 40-300, (d) 40-400, (e) 40-600, and (f) 40-800. The data have been offset for clarity. Also shown is a curve calculated from the fit parameters for curve (f).
Molecular dynamics simulations on neat water clusters were performed to elucidate the dynamics responsible for the observed kinetics. The simulations were performed using the polarizable interaction model of Dang. 5 Rotational and translational motions were characterized as a function of cluster energy for kinetic temperatures ranging between 150 and $220 \mathrm{~K}$. Averages were performed for $1.5 \mathrm{nsec}$ at each temperature. Typical results of the simulations are shown in Fig. 3.5. The simulations evidence both a temperature dependence and a size dependence, in qualitative agreement with the time-resolved fluorescence data. This agreement lends support to the arguments presented above that ESPT in 1-naphthol-water clusters is reflective of the solvent dynamics. even though the time scales are up to three orders of magnitude slower than in liquid water.

References:

1. T. Förster, Z. Elektrochem. Angew. Phys. Chem., 54,42 (1950).

2. G. W. Robinson, P. J. Thistlewaite, and J. Lee, J.

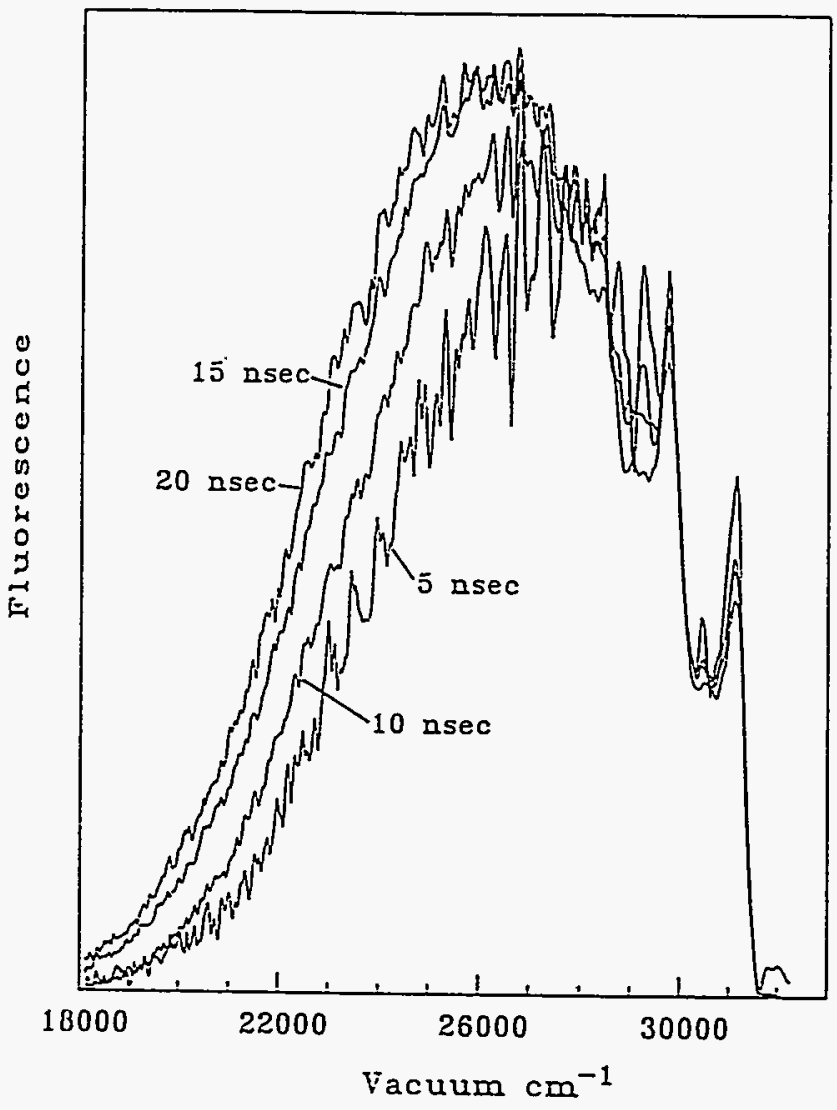

Figure 3.4. Time-resolved fluorescence spectra of a 1-naphthol-water clusters following photoexcitation at $312.5 \mathrm{~nm}$. 


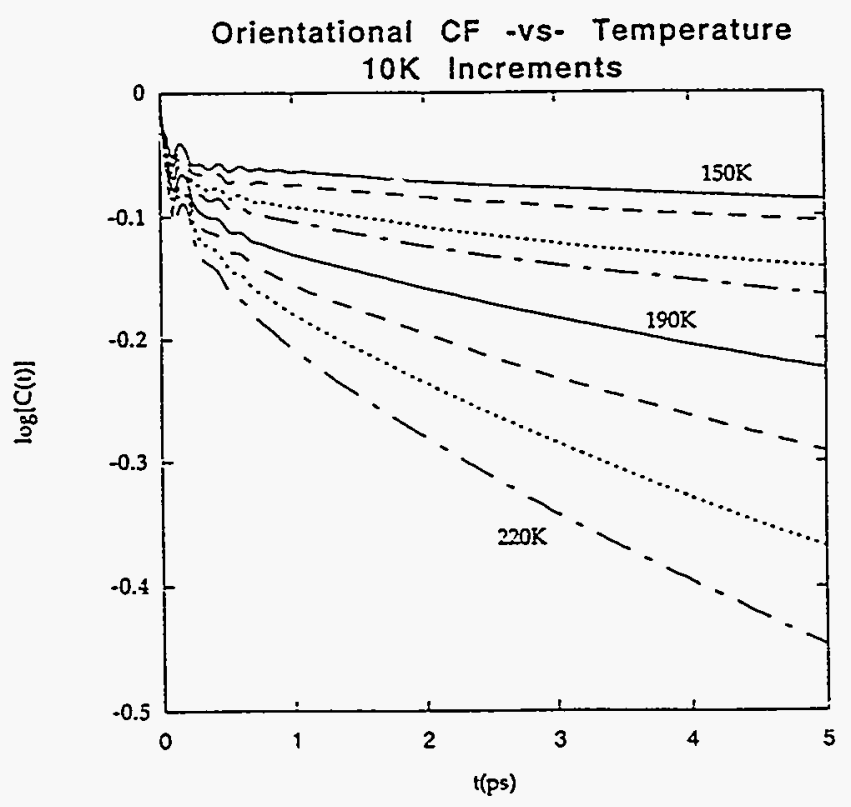

Figure 3.5. Results of molecular dynamics simulations of the dipole correlation function vs. time, for $\left(\mathrm{H}_{2} \mathrm{O}\right)_{20}$ clusters at various temperatures.

Phys. Chem. 90, 4224 (1986); S. P. Webb, L. A. Philips, S. W. Yeh, L. M. Tolbert and J. H. Clark, J. Phys. Chem. 90, 5154 (1986).

3. P. Pawlow, Z. Physik. Chem. 65, 545 (1909).

4. R. S. Berry, T. L. Beck, and L. H. Davis, Adv. Chem. Phys. 90, 75 (1988); H. Reiss, P. Mirabel, and R. L. Whetten, J. Phys. Chem. 92, 7241 (1988).

5. L. X. Dang, J. Chem. Phys. 97, 2659 (1992).

\section{High-Resolution Spectroscopy of Molecular Species and Clusters}

\section{S. W. Sharpe}

Supported by Office of Basic Energy Sciences.

Weakly-bonded clusters of small molecules are promising systems for the study of chemical reactions on a microscopic level. They provide an opportunity to study energy transfer and vibrational relaxation processes in the regime between isolated molecules and the condensed state. Infrared spectroscopy is one of several powerful techniques which the physical chemist can call upon for studying the behavior of such systems. Both structural and dynamical (e.g., vibrational shifts, predissociation rates, changes in transition moments, etc.) properties of clusters and selected monomers will be determined. These investigations are motivated by the need for a molecularlevel understanding of clusters and their unique properties. They serve as a benchmark for evaluation of fundamental theories, and provide a new basis for the study of chemical reactions and dynamics.

Tunable infrared diode lasers posses a number of unique properties which make them ideal devices for high-resolution spectroscopy. Currently, leadsalt diodes are available for contiguous coverage of 3,000 to $300 \mathrm{~cm}^{-1}$. These devices can be frequency-tuned at extremely high rates, allowing a 3-wavenumber region to be covered in less than $1 / 1000$ of a second. In addition, diode lasers have extremely low noise associated with their operation. The high tuning rate, low noise, and intense spectral brightness allow the researcher to approach and in some cases reach the shot limit, which is the theoretical limit for laser absorption detection schemes.

High-resolution gas-phase infrared spectroscopic techniques have traditionally been plagued by a number of problems, including spectral congestion, Doppler broadening, and pressure broadening. Spectral congestion is related to the number of quantum states populated at a given temperature and is dictated by Maxwell-Boltzmann statistics. Doppler broadening is related to temperature through the kinetic energy relationship, but also involves the random 3-dimensional motion of the gas molecules. Pressure broadening is related to temperature through the collisional frequency of the molecules, which in turn depends on the density and velocity of the sample. By cooling and reducing the pressure of a gas sample, these three effects can be minimized, but at the expense of drastically reduced signals.

A relatively new technique that takes advantage of the properties of rapidly expanding a gaseous sample into a moderate vacuum has been used in our laboratory for the last year. A gas is expanded through a slit orifice that measures 5 inches in length by $1 / 6000$ of an inch wide. The ensuing ribbon of gas expands at supersonic velocities and in the process molecules entrained in this ribbon are cooled to a few degrees above absolute zero. In addition, the random 3-dimensional motion of the gas molecules are changed to a 2-dimensional flow having little velocity component in the plane of expansion but perpendicular to the mass flow. If infrared laser light is used to interrogate the gas molecules through the plane of expansion, spectral congestion, Doppler broadening, and pressure broadening are all reduced significantly.

We have recently obtained high-resolution infra- 
red absorption spectra of a number of weaklybonded dimer systems including SCO-HF, SCO$\mathrm{HCl}$ and $\mathrm{SCO}-\mathrm{H}(\mathrm{D}) \mathrm{Br}$. The infrared spectra of these weakly-bonded dimers are indicative of linear rotors with well-developed P- and R-branch features. From spectra such as that of Fig. 3.6, it is possible to determine structural and dynamical properties for these dimers. Our results support a few previous microwave studies indicating a linear hydrogen-bonded arrangement. The experimentally-derived information can then be used to verify $a b$ initio calculations that will ultimately allow a better understanding of the transformation between gas/liquid/solid states.

Small hydrogen-bonded species such as $\mathrm{HCl}-\mathrm{H}_{2} \mathrm{O}$ will be investigated by $I R$ interrogation of both the $\mathrm{HCl}$ and $\mathrm{H}_{2} \mathrm{O}$ moieties. This work is being done in close collaboration with the Theory and Modeling Group (S. X. Xantheas and D. E. Woon). $A b$ initio calculations on clusters of $\mathrm{HCl}-\left(\mathrm{H}_{2} \mathrm{O}\right)_{n}$ have already been used to predict the relevant spectral regions. High-level calculations incorporating extensive basis sets are used to calculate normal-mode motions and corresponding vibrational frequencies.

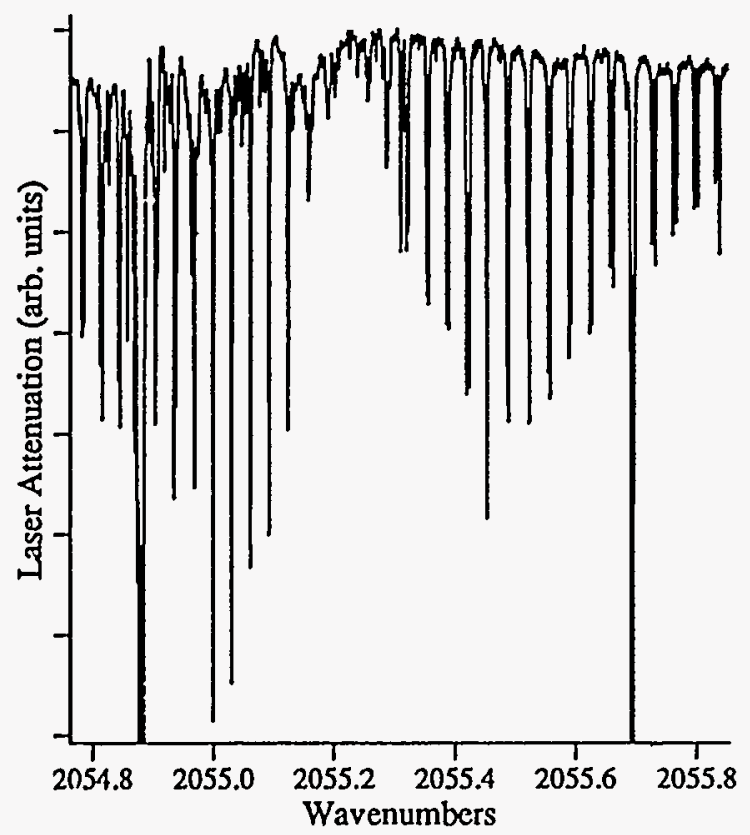

Figure 3.6. Spectrum of the weakly-bonded SCO$\mathrm{DBr}$ dimer produced by supersonic expansion of $\mathrm{SCO} / \mathrm{DBr}$ in neon. Note the splitting of the higher-J rotational lines for the two isotopes of ${ }^{79} \mathrm{Br}$ and ${ }^{81} \mathrm{Br}$.
Structure and Dynamics of Liquid Water Molecules by Femtosecond Infrared Spectroscopy

G. R. Holtom, R. C. Crowell, * and X. S. Xie

Supported by Office of Basic Energy Sciences.

* Postdoctoral Research Associate.

The importance of water as a universal and unique solvent for chemical and biological reactions has continued to stimulate theoretical, computational, and experimental efforts on understanding the structure and dynamics of liquid water. Liquid water has a broad absorption band in the $3-\mu \mathrm{m}$ region due to its fundamental stretching vibrations, which are particularly sensitive to its hydrogen-bonding structure. Graener et al. ${ }^{1}$ have originated picosecond hole-burning experiments on liquid water in this spectral region, and revealed the inhomogeneous nature of the hydrogen bonding structures. Femtosecond coherent experiments would be particularly informative about the vibrational dephasing and other dynamical properties of the system. A 50 -fs pulse at $3 \mu \mathrm{m}$ is needed in order to coherently excite the entire inhomogeneously-broadened band. However, this has been experimentally difficult due to the lack of femtosecond sources in this spectral region.

We have recently demonstrated a stable femtosecond infrared source at $3 \mu \mathrm{m}$ using a synchronously-pumped optical parametric oscillator, ${ }^{2}$ which is suitable for performing femtosecond coherent spectroscopy in the $\mathrm{OH}$ stretching region. The OPO, synchronously pumped by a modelocked Ti:Sapphire, is operated at a center frequency of $3660 \mathrm{~cm}^{-1}$, providing nearly transformlimited 120 -fs pulses with 0.2 -nanojoule pulse energy at a repetition rate of $76 \mathrm{MHz}$.

Using this new laser source, we have made the direct observation of infrared optical free induction decay (FID) of water molecules dissolved in deuterated methylene chloride. This experiment is the initial step toward our goal of understanding liquid water.

The solid line in Fig. 3.7 shows the FTIR absorption spectrum of $\mathrm{H}_{2} \mathrm{O}$ dissolved in $\mathrm{CD}_{2} \mathrm{Cl}_{2}$. The 3600 $\mathrm{cm}^{-1}$ peak is assigned to the symmetric stretching and the $3684-\mathrm{cm}^{-1}$ peak the asymmetric stretching of the water molecules. The IR spectrum indicates no water cluster formation at this concentration. The dashed line in Fig. 3.7 shows the spectrum of the excitation pulses from the OPO, which clearly has enough bandwidth to coherently excite the 


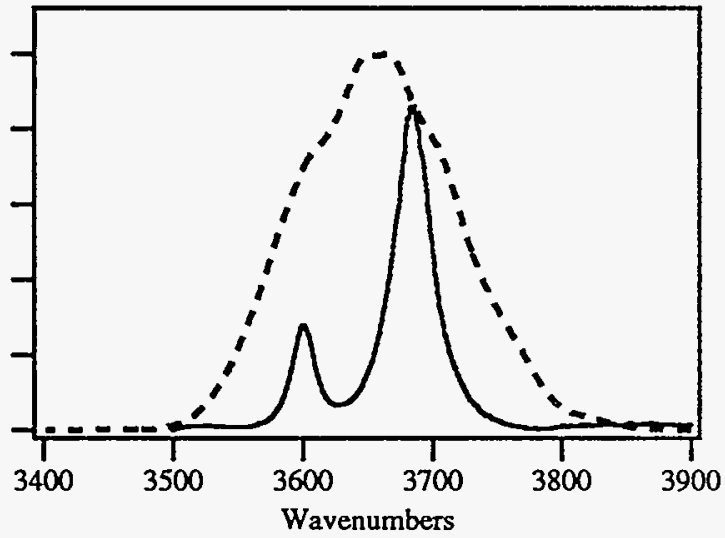

Figure 3.7. The infrared absorption spectrum of water dissolved in deuterated methylene chloride (solid line) and the infrared spectrum of the pulses from the femtosecond OPO (dashed line).

two vibrational modes of the solute water molecules.

Figure 3.8a shows the up-converted infrared FID (solid line) and the instrumental response function (cross correlation of IR and 816-nm beam, dashed line). The later has a FWHM of $180 \mathrm{fs}$. The FID first follows the instrumental function and has the distinct first recurrence at $365 \mathrm{fs}$. The $365-\mathrm{fs}$ time delay corresponds to the $84-\mathrm{cm}^{-1}$ splitting in the IR spectrum in Fig. 3.7. Figure $3.8 \mathrm{~b}$ shows a logarithmic plot of the same data, which shows the subsequent beats. Such a FID is the result of the two interacting vibrational modes of the water molecule radiating in a coherent manner. We have directly measured the ground state vibrational quantum beats of water molecules at room temperature.

We are working on even shorter IR pulses as well as amplification of the IR source for nonlinear experiments. This initial experiment shows promise for using multiple infrared pulse sequences to conduct femtosecond nonlinear vibrational spectroscopy in order to unscramble the complex molecular interactions and dynamics in molecular liquids.
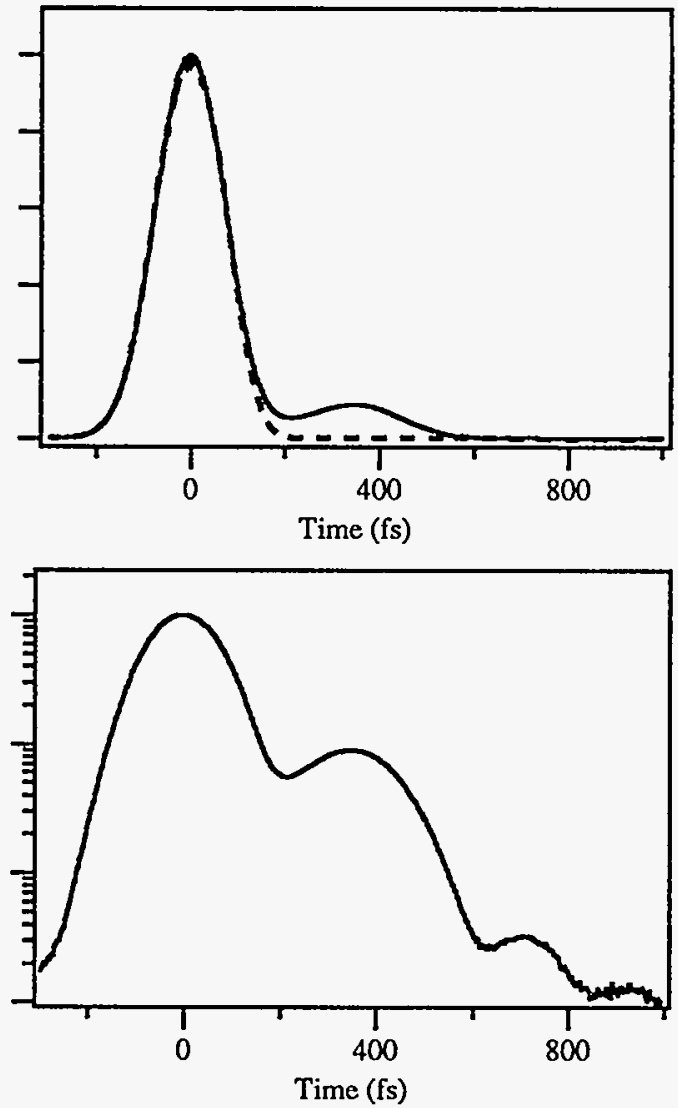

Figure 3.8. (a) Upper panel: The up-converted infrared FID of water dissolved in $\mathrm{CD}_{2} \mathrm{Cl}_{2}$ (solid line) and the instrumental response (dashed line). (b) Lower panel: The same data on a logarithmic scale.

\section{References:}

1. H. Graener, G. Seifert, and A. Laubereau, Phys. Rev. Lett. 66, 2092 (1991).

2. G. R. Holtom, R. A. Crowell, and X. S. Xie, to appear in Ultrafast Phenomena IX, 1994. 


\section{Structure and Dynamics of Biological Systems}

Dynamics of Protein Motion: The "rational" enzyme redesign effort in Biomolecular Modeling \& Simulation of the TM\&S program is aimed at understanding enzyme reactivity and exploring potentials for destruction of organic contaminants. This effort is built upon molecular dynamics simulations that reveal the interaction between enzymes and target substrates. When fully developed, the CS\&D program in time-resolved laser spectroscopy will allow direct measurements of protein motions for evaluation and subsequent improvements in the predictability of these calculations. In particular, time-resolved fluorescence depolarization and time-resolved infrared spectroscopic measurements can be carried out to study protein conformational motion. The experimental results can be directly compared with trajectories of molecular dynamics simulations, testing the validity of the methodology and the potential energy surface used in the simulation. Such a coupling between experiment and theory can provide insights of enzymatic mechanisms and clues for engineering better enzymes for bioremediation.

Mapping the Structure of Macromolecules: Atomic force microscopy and scanning tunneling microscopy methods, offering atomic resolution, will be combined with a new near-field optical microscope that will have sufficient sensitivity to detect single protein molecules. These combined capabilities will allow the mapping of DNA and other macromolecules. In support of the study of the health effects of chemical and radiation damage to DNA at PNL's Life Science Center, a CS\&D atomic force microscope has been employed to image the structure of fully hydrated plasmid DNA on mica substrates. These studies are being extended to image the bonding of proteins to the DNA, and to modify the DNA during observation, to observe conformation and damage directly.

A near-field optical microscope is being developed at CS\&D to conduct molecular spectroscopy on a nanometer scale. This will make possible implementing the wealth of techniques of optical spectroscopy with an unprecedented spatial resolution, providing information about molecular species and their chemical reactions not accessible with SEM, STM and AFM. The time resolution afforded by optical measurements would allow observations in real time of fast molecular dynamics, such as electron-transfer reactions in specific local envi- ronments. Our instrumental development has achieved the sensitivity needed to conduct spectroscopy on a single protein or DNA molecule. From a chemical physics point of view, spectroscopy on a single molecule removes the effects of environmental inhomogeneity. From a biotechnology point of view, it becomes a powerful approach in mapping the structure of biological membranes and macromolecules, as well as understanding the structure-function relationship. The initial experiments are being carried out on well-characterized membrane proteins (photosynthetic) in order to evaluate the methodology. This technique can also be applied to investigate timedependent changes of DNA in support of studies of radiation and chemical damage to DNA and chromosomes.

\section{Scanning Probe Microscopy Users Facility M. J. Iedema \\ Supported by Laboratory Directed Research and Development (LDRD).}

Since its invention in 1981, scanning probe microscopy (SPM) has been finding new applications almost daily in such diverse fields as biochemistry and low-temperature physics. To exploit this capability, we have established in CS\&D a SPM Users Facility to make available the best commercial technology in scanning tunneling and atomic force microscopy, techniques that are suitable for the study of materials in air or in solution. To stimulate new research directions, and to foster bridges with other research centers at PNL, we have encouraged scientists in PNL to explore the capabilities of this facility.

Some studies (many of which are ongoing) have included:

- Growth and dissolution of the mineral calcite $\left(\mathrm{CaCO}_{3}\right)$ in aqueous environments.

- Morphology of ultra-pure optical thin films.

- Structure of magnesium oxide thin films grown on magnesium oxide single crystals and on metal (molybdenum) single crystals.

-Growth and dissolution of biologically important minerals (calcium oxylate, apatite) in aqueous environments.

-Structure of single-crystal materials (copper, molybdenum, titanium dioxide) surfaces.

-DNA morphology and chemistry in solution. 


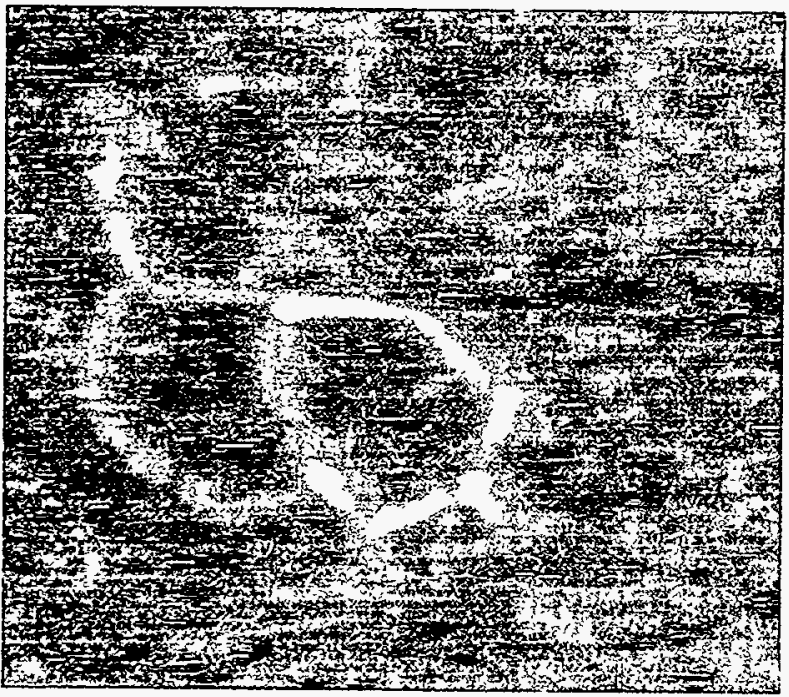

Figure 4.1. Image of plasmid DNA in an isopropanol solution. The image is approximately $350 \mathrm{~nm}$ across; the DNA molecule is about $3 \mathrm{~nm}$ high.

An example of some research recently begun is the study of plasmid DNA (Fig. 4.1), chemically tethered to mica. The structure of these molecules can be studied, as can the sites which are active for enzyme attachment and other chemical reactions.

\section{Biological Applications of Near-Field Fluorescence Spectroscopy X. S. Xie, R. C. Dunn, * G. R. Holtom, and E. V. Allen $\dagger$ \\ Supported by Office of Basic Energy Sciences and a Cooperative Research and Development Agree- ment (CRADA). \\ * Postdoctoral Research Associate. \\ $\dagger$ Applied Physics Center.}

The high spatial resolution, high time resolution, single molecule sensitivity, and noninvasive nature of our near-field microscope offers a powerful approach for studying biological systems with many new possibilities. In particular, the conformational change of proteins, the structure and dynamics of biological membranes, and optical imaging of DNA and chromosomes are our current interests.

Figure 4.2 shows the fluorescence image of single allophycocyanin (APC), ${ }^{1}$ a photosynthetic lightharvesting protein from red alga. Each protein contains only six chromophores. The bright fluorescence spots have diameters of $90 \mathrm{~nm}$, which are

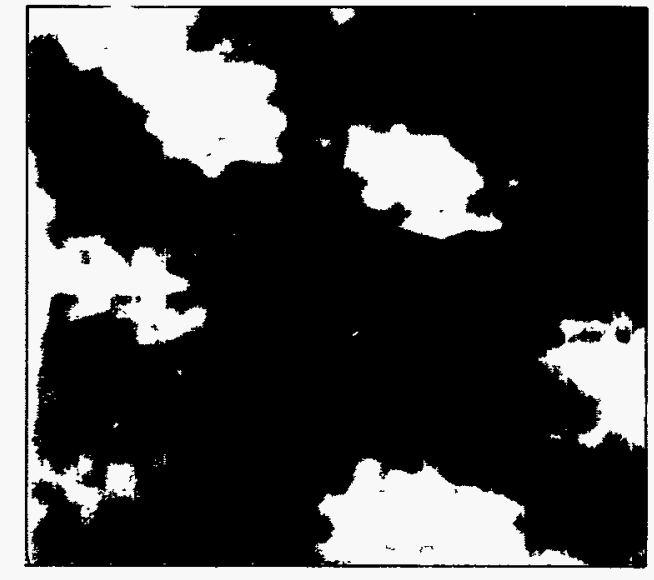

Figure 4.2. $633 \mathrm{~nm} \times 633 \mathrm{~nm}$ near-field fluorescence image of single APC dispersed on a glass cover slip, imaged with 633-nm excitation light. Each trimeric APC protein contains only six chromophores.

limited by the size of the tip and certainly better than the diffraction limit $(300 \mathrm{~nm})$. This demonstrates the feasibility of spectroscopic measurements on single proteins.

In collaboration with Professor Laurens Mets at the University of Chicago, we have began the spectroscopic mapping of the photosynthetic membrane, elucidating the relationship between its local structure and biological functionality. We have obtained simultaneous shear force images and near-field fluorescence images of photosynthetic membrane fragments, which allows us to correlate the topographic information with spectroscopic information at the nanometer scale.

We have also conducted a time-resolved fluorescence experiment on an intact photosynthetic membrane with the near-field microscope. Figure 4.3 shows the first fluorescence lifetime measurement done with nanometer resolution. ${ }^{2}$

\section{References:}

1. R. C. Dunn, E. V. Allen, S. A. Joyce, G. A. Anderson, and X.S. Xie, Ultramicroscopy, in press. 2. R. C. Dunn, G. R. Holtom, L. Mets, and X. S. Xie, J. Phys. Chem., in press. 

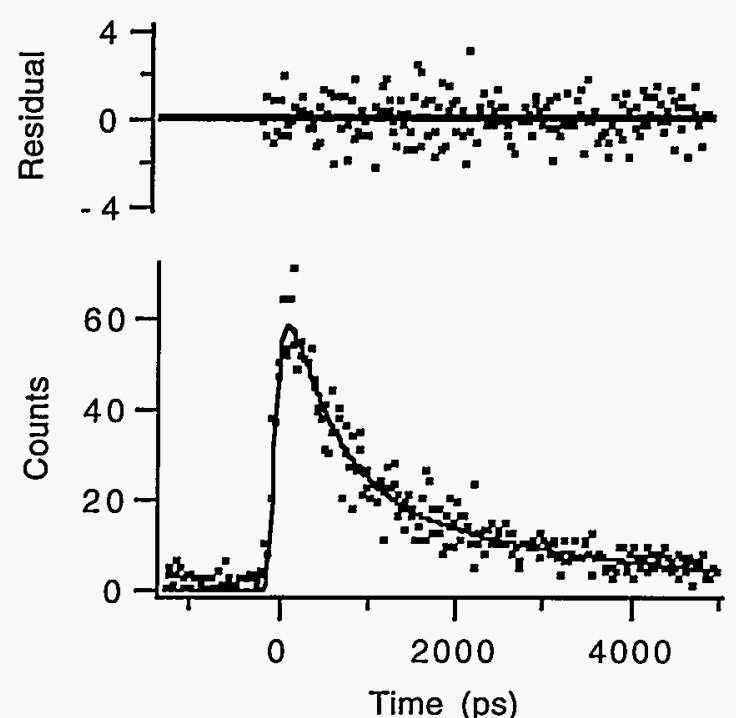

Figure 4.3. Fluorescence decay of LHC II proteins in an intact photosynthetic membrane taken with the near-field microscope. The decay is fit with a sum of exponentials with lifetimes of $450 \mathrm{ps}$ (65\%) and $2.7 \mathrm{~ns}(35 \%)$. The top trace shows the residuals. 


\section{Analytical Methods Development}

Characterization of contaminated soils and groundwater, decommissioned facilities, stored wastes, and waste process streams and waste forms is vital to the environmental restoration and waste management needs of the DOE. The need to evaluate complex, inhomogeneous materials containing both chemical and radioactive hazards is a particularly challenging setting for any analytical method. Central to the success of the CS\&D research programs is the development of frontier techniques: detecting single atoms/molecules; controlled vaporization of complex solids; highefficiency and specific laser-induced fluorescence, Raman scattering, and ionization methods; highsensitivity optical and mass spectroscopies; surface analysis probes; etc. It is significant that this work is being done at PNL, which is well suited for the development and deployment of these new capabilities to meet specific DOE needs.

PNL has significant efforts in both instrument development and analytical methods development and applications. The scope of work ranges from providing specialty analytical services to the development of instruments for remote field use. Thus, when a particularly difficult problem is identified, a team of scientists and engineers is available to approach the solution, each working at the forefront of their respective fields. As a result, CS\&D research staff are working on a number of challenging measurement science problems. New infrared techniques are being developed to detect trace levels of atmospheric species for a variety of needs including understanding global change, locating buried wastes, providing worker protection at waste sites, and supporting arms control efforts. Means for direct, remote analysis of solid wastes and of materials being evaluated for the long-term storage of wastes are being developed through the combination of laser ablation (vaporization) followed by either optical or mass spectral analysis. In support of these efforts, we are also studying the fundamental photophysical processes controlling laser ablation as well as laser ionization mass spectrometry. The optical methods under development, including Raman, laser-induced fluorescence, and multiphoton excitation, will be combined with sampling methods ranging from molecular-beam to high-pressure techniques. As a result, the measurement science efforts of the CS\&D program have a dual functionality. They enable new studies of fundamental science and they result in the development of unique analytical instruments and methods.

\section{Laser Ablation of Sodium Nitrate M. I. McCarthy, * R. A. Bradley, $\dagger$ and W. P. Hess}

CS\&D Support by Office of Basic Energy Sciences.

* Theory, Modeling, and Simulation.

$\dagger$ Postdoctoral Research Associate.

The remediation of Hanford-site defense waste and the long-term disposal of high-level mixed wastes requires chemical analysis of tank and crib waste and the waste streams. Analysis of mixed waste is needed to characterize the chemical classes and concentrations of a wide variety of waste materials. Waste sites contain broad distributions of organic compounds (aromatics, nitrates, chelating agents, halogenated hydrocarbons) and inorganic compounds (chromates, ferrocyanides, metals, and TRUs). The chemical speciation and concentration of these materials must be determined in order to design effective cleanup strategies. Additionally, the high concentrations of radioactive waste materials in tanks and cribs provide an energetic driving force that continuously transforms mixed waste in complex kinetic pathways. Hence, analyses need to be made in a timely fashion.

Laser-based analysis techniques are proposed to perform this analysis, primarily laser ablation mass spectroscopy (LAMS) and multiple photon ionization (MPI). Laser ablation can vaporize nearly any solid material in pulsed plumes of sufficient concentration for detailed analysis by mass spectrometry, laser-induced fluorescence, and other techniques. The LAMS approach couples laser vaporization with ultrasensitive mass spectrometry. The advantages of the LAMS approach include: small sample requirements, minimum sample preprocessing, minimum waste generation, and reliable technology. However, several uncertainties are introduced by the ablation process. For instance, it is not clear how well the composition of the ablated (gaseous) products reflects the sample composition: some sample components can be preferentially ablated. Changes in the chemical state (e.g., changes in the oxidation state of metals) in the solid and gas phase are also potential problems. In order to 
determine in more detail the mechanisms and consequences of laser ablation we have initiated experiments on the laser ablation of single crystal sodium nitrate.

Sodium nitrate laser ablation is being studied in order to determine in detail the mechanisms and consequences of laser ablation on relevant wideband-gap inorganic materials. Of particular importance are the effects of the absorption of intense UV light by the crystalline $\mathrm{NaNO}_{3}$ on the ablation process, the mechanism of particle emission, and particle interactions after emission but prior to the actual analysis. Developing quantitative analytical methods requires the study of both neutral and ionic species desorbed from the surface of $\mathrm{NaNO}_{3}$, their kinetic energies, and possible electronic excitations as a function of laser fluence and wavelength. Figure 5.1 displays the positive ion mass spectrum from the $355-\mathrm{nm}$ ablation of sodium nitrate. The mass spectrum is dominated by $\mathrm{Na}$ and $\mathrm{NaO}$ peaks at mass 23 and 39 . Figure 5.2 displays the velocity distribution of the neutral-fragment mass 30 channel. In this experiment, neutral molecules are ionized by a second laser pulse focused $5 \mathrm{~mm}$ from the surface of the sodium nitrate crystal. We plan to determine the velocity of the various NO product states using resonant MPI detection, and to determine how this distribution varies with ablation laser intensity and frequency. These studies are aimed at determining the details of the ablation mechanism.

A thorough knowledge of the crystalline and electronic structure of $\mathrm{NaNO}_{3}$ is required for a mechanistic determination of the laser ablation process, so ab-initio periodic HF calculations have been undertaken to examine the electronic structure of this material. At present, the laser ablation exper-

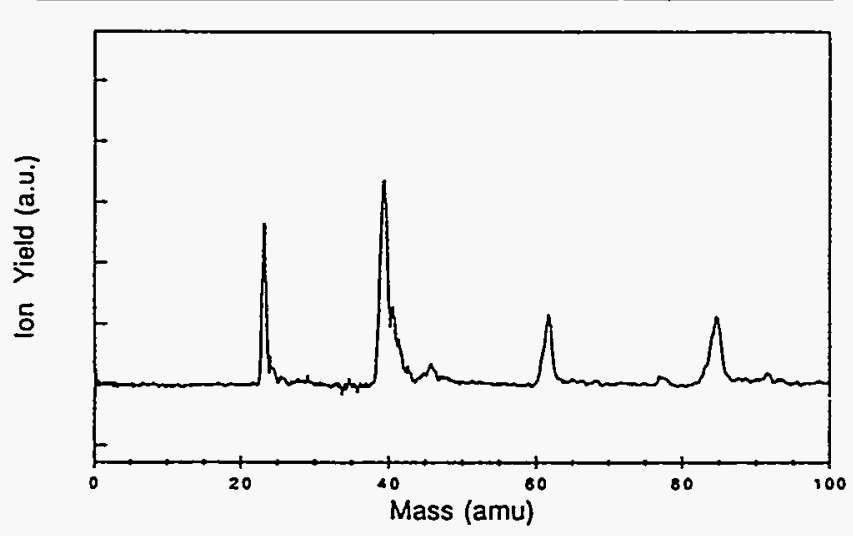

Figure 5.1. The positive ion mass spectrum from $355-\mathrm{nm}$ ablation of sodium nitrate.

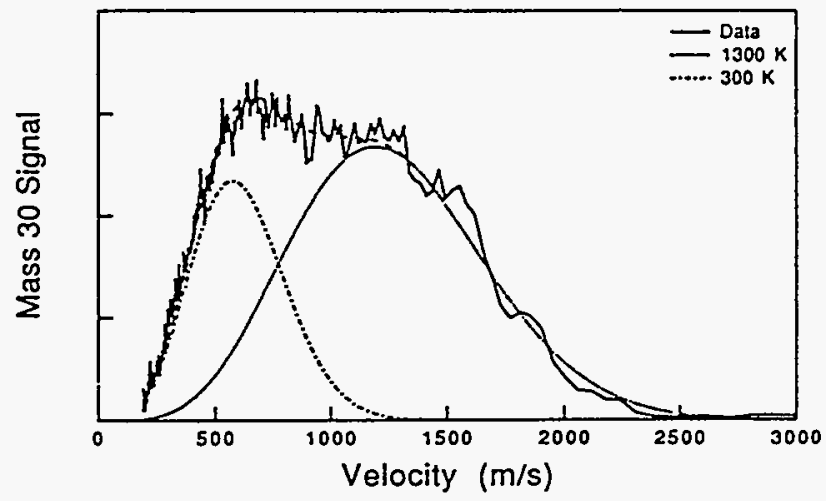

Figure 5.2. The velocity distribution of the neutral fragments of mass 30 (NO). In this experiment, neutral molecules are ionized by a second laser pulse focused $5 \mathrm{~mm}$ from the surface of the sodium nitrate crystal.

iment is designed to probe electronic transitions in the bulk material. The nature of these transitions can be understood by examining the character of the band structure. The valence bands are analyzed from the periodic HF wavefunction by projecting the density of states (DOS) onto site-specific atomic orbitals. Figure 5.3 shows a projection of the upper valence bands onto sodium, nitrogen and oxygen, with the dominant character of each band noted. It is apparent that the highest occupied crystalline orbital (HOCO), 0 to $-3 \mathrm{eV}$, is predominantly composed of $2 \mathrm{p}$ orbitals on the nitrate oxygen (non-bonded orbitals). The nitrogen states make a significant contribution to the band structure only in the states below $-10 \mathrm{eV}$ where the $\mathrm{N}$ $2 s$ and $2 p$ overlap with $2 s$ and $2 p$ orbitals on oxygen to form the intra-nitrate bonds. Contributions from the sodium cation are very small in the valence-band region. If a similar analysis were possible on the unoccupied conduction bands, one could deduce the energetics and selection rules dominating the laser-induced transitions. Methods are currently being developed that will provide a qualitative analysis of the conductionband character. With this information, the experiments may be able to correlate fragment type and yield with transition frequency and character. In 1994 this work will focus on understanding how the electronic structure of this material is effected by structural defects resulting from the ablation process.

\section{Reference:}

1. D. M. Strachan, et al. March 1991. A Survey of Available Information on Gas Generation in Tank 241101-SY,. PNL-7520, Pacific Northwest Laboratory, Richland, Washington. 


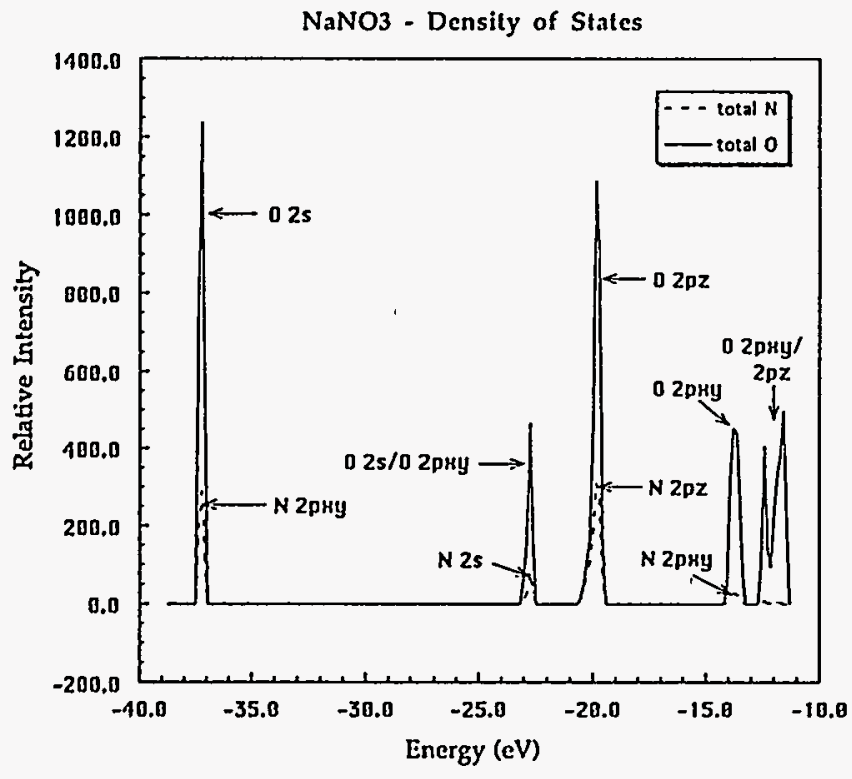

Figure 5.3. A projection of the upper valence bands onto sodium, nitrogen, and oxygen, with the dominant character of each band noted; energies are relative to the Fermi level.

\section{High-Resolution Infrared Analytical Methods}

S. W. Sharpe, J. F. Kelly, * and R. S. McDowell

Supported by Laboratory Directed Research and Development (LDRD) and Office of Arms Control.

* Materials and Chemical Sciences Center.

We are currently involved in a number of projects requiring rapid (under one second) trace detection of gases. Two techniques are currently being used to this end. The first involves locking the laser to a specific transition for a specific molecule. This is accomplished by frequency modulating the diode laser. An active feedback loop is constructed by detecting an absorption signal of a reference gas in first derivative. The first-derivative signal is fed back into the laser tuning circuit, forcing the laser to stay on resonance. Figure 5.4 illustrates the response of a derivative infrared diode laser spectrometer with a 1-meter sample at various concentrations of $\mathrm{CO}$ in 1 atmosphere of nitrogen.

The second technique takes advantage of the rapid tuning capabilities of diode lasers and involves scanning the laser over many absorption features. This allows us to measure the concentration of several molecules simultaneously. In addition, both speciation and detectivity are greatly enhanced by preparing low-pressure samples in

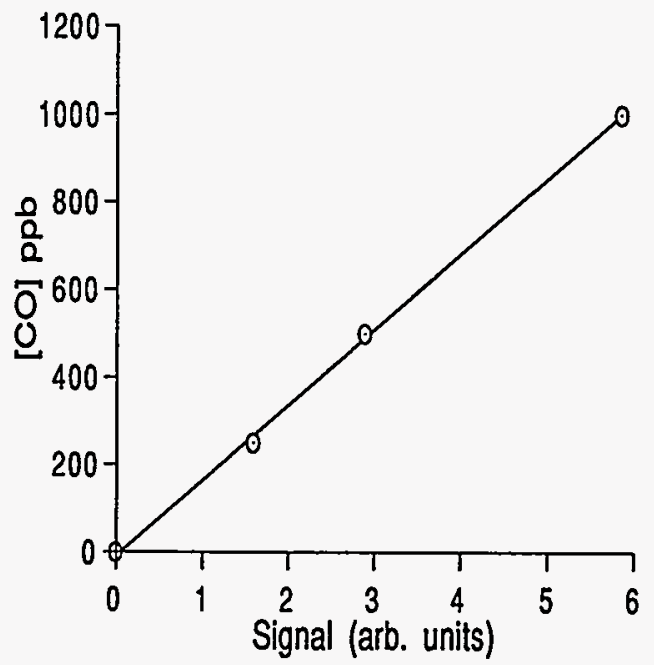

Figure 5.4. Calibration plot for infrared detection of $\mathrm{CO}$ utilizing derivative spectroscopy with active-feedback laser locking. Ultimate detectivity with the current (1-meter) apparatus is $5 \mathrm{ppb}$ in 5 seconds.

which the linewidths are Doppler-limited. Partsper-million detection of multicomponent systems can currently be obtained in less than 1 second, as illustrated in Fig. 5.5.

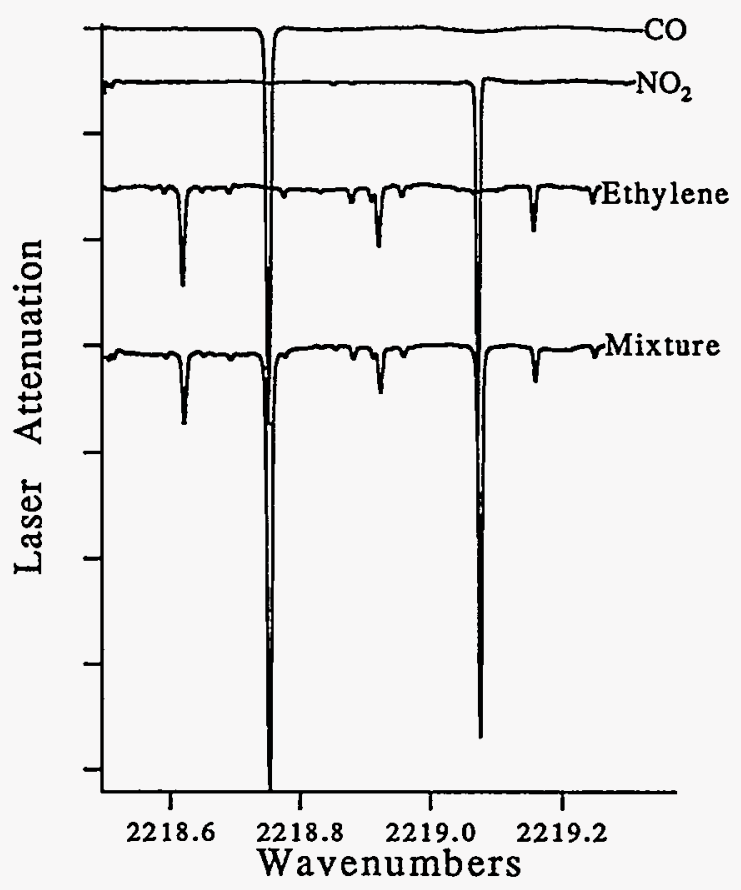

Figure 5.5. Simultaneous detection/quantification of a three-component system. Spectra taken in 200 milliseconds. 
Laser Ablation Mass Spectrometry Scanning of Waste Tank Core Samples S. E. Barlow, S. D. Colson, J. P. Cowin, M. E. Geusic, * and B. M. Wise $\dagger$

Supported by EM- 50 Characterization, Monitoring, and Sensor Technology Integrated Program.

* Materials and Chemical Sciences Center.

$\dagger$ Materials and Interfaces.

Laser Ablation/Mass Spectrometry (LA/MS) methods are being developed for analysis of waste tank core samples as part of a larger program to accelerate the characterization of the Hanford waste storage tanks. The LA/MS method (Fig. 5.6) relies upon three key steps: (1) the ablation of solid material to form small particles; (2) the entrainment of these particles in a carrier gas and their transport via a small tube to a low-radiation area; and (3) the chemical analysis of these particles by mass spectrometry. Our challenge is to optimize this method to analyze for the chemical species present in the waste material. Another component of the overall program to develop means for elemental analysis, is evaluating the impact of the second (transport) step on the overall process. Our findings, and those of other workers in the field, are that only aerosol particles in the micron to tenths-of-micron size are efficiently transported. Hence, one of our objectives is to develop methods for the production of aerosol particles of this size that quantitatively represent the chemical speciation distribution of the waste material. A second major component of our work focuses on the chemical analysis of the aerosol particles themselves. The third element of the program is data analysis (of both the elemental and chemical speciation data) via chemometric methods to enhance LA/MS as a screening tool, both alone and when used in conjunction with other methods such as Raman and infrared spectroscopies.

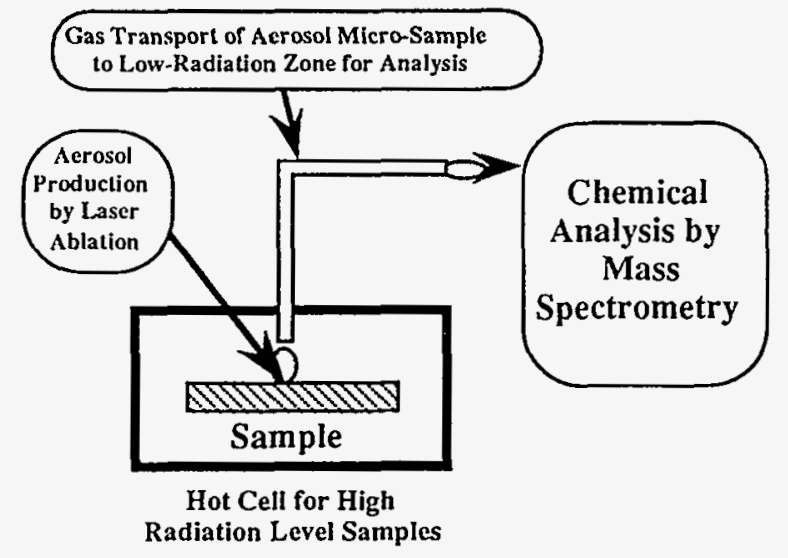

Figure 5.6. Laser Ablation Mass Spectrometry.
Current chemical analysis methods for Hanford waste tank core samples rely heavily on traditional wet-chemistry techniques. This frequently requires significant pretreatment of the samples to separate and concentrate the constituents of interest. These pretreatment processes generate additional unwanted mixed-waste materials. In addition, current techniques provide limited data on chemical constituents as a function of core depth in the tank, since much of the processing is done on core sample segments which are homogenized before the chemical analysis takes place. This prevents the tank safety program, the tank operations staff, and TWRS from obtaining detailed information on the depth distribution of chemical constituents within the tanks. In addition, the wet chemistry analysis techniques are very time consuming (up to six months to analyze and report) and expensive (often in excess of $\$ 500 \mathrm{~K}$ per core) to execute. Hot-cell chemical analysis process throughput is currently a major time/cost factor in (1) meeting the schedule for analysis of Hanford tank core samples to support near term tank safety assessment needs, and (2) the longer-term waste processing needs.

The minimum criteria for success of the overall program will be the reliable detection of a sufficient range of elements and compounds to guide the more detailed analysis of specific segments of core samples, dramatically increasing the throughput and reducing the costs. The optimal criteria will be finding that traditional analyses for certain species can be eliminated by this direct analysis technique, perhaps in combination with simultaneous application of other methods such Raman, infrared, or laser-induced emission scanning. An existing LA/MS instrument at PNL has been modified for use in selecting the best parameters for the production of aerosol particles. Of particular interest are (1) the effects of cover gases on the ablation process, and (2) the most appropriate wavelengths and laser powers for use with the type of waste materials at the Hanford site.

A meeting of a working group on aerosol analysis methods was held at PNL on December 3-4, 1993. The off-site team members were: Jim Davis, University of Washington; Bob Fletcher, NIST/Maryland; Murray Johnston, University of Delaware; and David Thomson, NOAA/Colorado. The general findings and recommendations of the working group were:

(1) Chemical speciation analysis of aerosol particles is a very challenging task with high potential 
benefits going well beyond the scope of the Hanford waste tank characterization program;

(2) Numerous potential methods of analysis should be evaluated in parallel through experiments at PNL and by having simulants analyzed at industrial and other laboratories; and

(3) Both on-line, direct aerosol analysis and offline, captured aerosol analysis methods should be considered.

Several simulant samples have been sent to industrial and other laboratories for comparative analyses using SIMS and other methods. These results will be compared to laser ablation and ion bombardment measurements being conducted in our laboratories to select the best technique for chemical speciation analysis of aerosol particles produced from Hanford waste tank simulants.

\section{Flowing-Afterglow Mass Spectrometry of High-Energy Coronas}

T. M. Orlando, R. Tonkyn, and S. E. Barlow

Supported by Laboratory Directed Research and Development (LDRD).

Researchers in the Waste Technology Center of PNL have been developing high-energy corona reactors for the destruction of hydrocarbon contaminants. These reactors, which generate lowtemperature plasmas and operate at atmospheric pressure, are potentially useful in large-scale remediation efforts. However, the details of the physical and chemical parameters that govern the destruction efficiency are, at present, poorly understood. We have developed a differentiallypumped mass spectrometer system that can be used to sample virtually any plasma source. We have equipped this system with a FlowingAfterglow and Chemical Ionization Source that allows us to sample selectively the neutrals present in the discharge region. This capability, when coupled with quadrupole mass spectrometry, allows us to sample the cation, anion, neutral, and electron number densities and hence "pick apart" the plasma for detailed studies. A particular emphasis is on understanding the role of fundamental processes such as dissociative electron attachment in the destruction of halogenated hydrocarbons such as carbon tetrachloride.

The Flowing-Afterglow Mass Spectrometer is currently being used to probe the plasma parameters and plasma chemistry occurring in point-to-plane discharges, as well as in packed-bed coronas.
Work is also in progress to address the specific role of the packing material (such as glass beads and other wide-bandgap materials) in enhancing the destruction efficiencies. We are concerned with understanding the surface-interface interactions and possible catalytic effects. Therefore, several catalytically "active" materials will be tested in an effort to minimize power consumption and hence reduce remediation costs. 


\section{Atmospheric Chemistry}

Chemical Structure and Dynamics possesses capabilities that can address critical areas of atmospheric chemistry, such as chemistry in aqueous media, the chemistry of aerosols, and heterogeneous chemistry. Current activities focus on the kinetics and thermodynamics of adsorption, desorption, and absorption of gas-phase species on water surfaces, and on spectroscopic probes of small cluster molecules and ultrafine aerosols. Recent experiments have measured the sticking probability of water on ice at low temperatures in ultrahigh vacuum. Experiments studying the photochemistry and stimulated desorption of adsorbates from ice surfaces are in progress.

In ultrahigh vacuum, at temperatures below $170 \mathrm{~K}$, multilayer ices are being grown to simulate the aqueous or acid aerosols found in our atmosphere. These can be doped with molecules and ions with great precision. One apparatus has the vacuum system interfaced to an ultrafast laser system. This will allow us to compare directly the results of time-resolved nonlinear optical measurements (such as second-harmonic generation and sumfrequency generation) with the structural results of traditional surface techniques such as Auger, LEED, EELS, and reflection-absorption FTIR. An ongoing study will determine the effect of surfaces of water ice and nitric-acid ice on the relative yields of the two known photodissociation pathways for the higher-energy isomer of chlorine dioxide:

$$
\begin{aligned}
& \mathrm{OClO}+\mathrm{hv} \rightarrow \mathrm{ClO}+\mathrm{O} \\
& \mathrm{OClO}+\mathrm{hv} \rightarrow \mathrm{Cl}+\mathrm{O}_{2} .
\end{aligned}
$$

The branching ratio is known for the gas phase and in bulk liquid water. However, the recentlydiscovered important role of ice aerosols in stratospheric chemistry mechanisms has raised the question of the role of such particles in determining the actual yields of $\mathrm{ClO}$ and $\mathrm{Cl}$ coming from the surface of water, and from mixed water-acid films.

Experimental studies of the structure of anionwater clusters are being used to refine computational methods for cluster and aerosol structures. Time-resolved spectroscopy of water clusters and ultrafine water aerosols is being used to probe the phase diagrams of these small particles. Future activities could include reactivity and uptake measurements on ultrafine aerosols using high-resolution mass spectrometric methods and measure- ments of the photophysics of molecules adsorbed on clusters and ultrafine aerosols by photofragment imaging and resonance ionization mass spectrometry.

CS\&D also has a small effort in the area of homogeneous air chemistry. The primary photochemistry of $\mathrm{OClO}, \mathrm{Cl}_{2}$, and other important chlorocompounds is being studied. In addition, measurements of electron affinities (e. g., $\mathrm{SO}_{3}, \mathrm{HSO}_{4}$ ) via negative-ion photoelectron spectroscopy and bond strengths $\left(e .8 ., \mathrm{O}_{3}\right)$ via anion photodissociation are under way. The capabilities of CS\&D in infrared spectroscopy are a valuable resource in the study of atmospherically-important species (including $\mathrm{H}_{2} \mathrm{O}, \mathrm{CO}_{2}, \mathrm{~N}_{2} \mathrm{O}, \mathrm{CH}_{4}$ and $\mathrm{ClNO}_{3}$ ), and can also play a significant role in the development of advanced measurement techniques. Infrared absorption measurements played a key role in the recent development of a 2-photon (IR + UV) laserinduced fluorescence technique for the determination of $\mathrm{OH}$ concentrations in both the troposphere and the stratosphere.

\section{Photodissociation of the Ozonide Ion in the Gas Phase: Implications for Ozone Thermochemistry K. W. Brown* and D. Ray \\ Supported by Office of Basic Energy Sciences. \\ * Postdoctoral Research Associate.}

The properties of the ozonide ion, $\mathrm{O}_{3}{ }^{-}$, in the gas phase are of interest both because it plays a role in the chemistry of the upper atmosphere and because it serves as a means to indirectly probe the thermodynamics of a very important molecule, ozone. In this work we measure the photodissociation threshold of ozonide into superoxide $\left(\mathrm{O}_{2}^{-}\right)$ and oxygen $(\mathrm{O})$. The measured value of the threshold for the production of $\mathrm{O}_{2}-$ from $\mathrm{O}_{3}{ }^{-}$, in combination with accurate values for the electron affinities $^{1,2}$ of $\mathrm{O}_{2}$ and $\mathrm{O}_{3}$, yields a rigorous upper bound to the dissociation energy of $\mathrm{O}_{3}$ to $\mathrm{O}_{2}+\mathrm{O}$. The ozone dissociation energy calculated from the only previous threshold measurement ${ }^{3}$ is $<0.77$ $\mathrm{eV}$. This value is in serious disagreement with the widely-accepted calorimetrically determined value of 1.05 (2) $\mathrm{eV}$ for the dissociation energy of ozone to dioxygen and oxygen. 4

A significant difficulty in determining a photodis- 
sociation threshold lies in verifying that all of the molecules are in their lowest energy state prior to photodissociation. With the newly-constructed ion beam apparatus in our laboratory, we are able to measure the internal energy distribution in molecular anions by negative-ion photoelectron spectroscopy, and to perform photodissociation measurements by mass analysis of the charged photofragments.

In this work, we form $\mathrm{O}_{3}{ }^{-}$and isolate it in the first stage of a tandem time-of-flight (TOF) mass spectrometer. Following this initial mass selection, the photoelectron spectrum of the anion is obtained. A typical photoelectron spectrum of $\mathrm{O}_{3}{ }^{-}$is shown in Fig. 6.1. Photoelectron spectra are measured by crossing the output of a fixed-frequency pulsed ultraviolet laser with the ozonide ion beam at the spatial focus of the first TOFMS. The kinetic energy of the photodetached electrons is measured by a time-of-flight photoelectron energy analyzer. The kinetic energy resolution $(10 \mathrm{meV}$ at $1.0 \mathrm{eV}$ ) of the spectrometer is sufficient to resolve vibrational structure in $\mathrm{O}_{3}$ and $\mathrm{O}_{3}{ }^{-}$. The ultraviolet photoelectron spectrum of $\mathrm{O}_{3}^{-}$has recently been measured at this resolution by Neumark and coworkers. Our measured photoelectron spectra indicate no significant population in vibrationally excited states of $\mathrm{O}_{3}{ }^{-}$. Thus, the threshold energy we report for the production of $\mathrm{O}_{2}{ }^{-}$from $\mathrm{O}_{3}-$ allows the precise

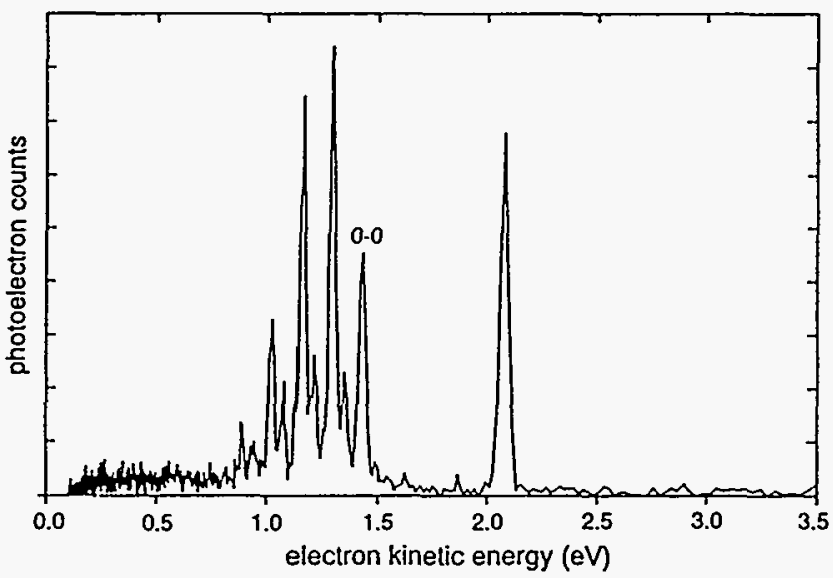

Figure 6.1. Photoelectron spectrum of $\mathrm{O}_{3}^{-}$taken with $3.5-\mathrm{eV}$ photons. The origin transition is denoted 0-0. Features at lower electron kinetic energy $(\mathrm{eKE})$ than the origin correspond to excitation of vibrational states in the neutral. The isolated feature at higher eKE corresponds to photodetachment of $\mathrm{O}^{-}$, subsequent to photodissociation of $\mathrm{O}_{3}^{-}$into $\mathrm{O}_{2}$ and $\mathrm{O}^{-}$. determination of an upper bound to the dissociation energy of $\mathrm{O}_{3}$ to $\mathrm{O}_{2}+\mathrm{O}$.

Determination of the photodissociation threshold is accomplished by photofragmentation spectroscopy. In these measurements, again following initial mass selection, the ionic photofragments from $\mathrm{O}_{3}-$ are mass-analyzed in the second stage of the tandem TOF mass spectrometer. The cross section for the production of $\mathrm{O}_{2}-$ from $\mathrm{O}_{3}{ }^{-}$as a function of photon energy is shown in Fig. 6.2. We determine a photodissociation threshold of 2.68(2) $\mathrm{eV}$ for the photodissociation of $\mathrm{O}_{3}{ }^{-}$into $\mathrm{O}_{2}{ }^{-}$and $\mathrm{O}$ from these data, which represents an upper bound for $\mathrm{D}_{0}\left(\mathrm{O}_{2}^{-}-\mathrm{O}\right)$, the dissociation energy of $\mathrm{O}_{3}{ }^{-}$. Combining this value with the electron affinities of ozone ${ }^{2}$ and dioxygen ${ }^{1}$ yields an upper bound of $1.03(3) \mathrm{eV}$ for $\mathrm{D}_{0}\left(\mathrm{O}_{2}-\mathrm{O}\right)$, the dissociation energy of ozone, in excellent agreement with the value derived calorimetrically, $1.05(2) \mathrm{eV}{ }^{4}$

\section{References:}

1. M. Travers, D. Cowles, and G. B. Ellison, Chem.

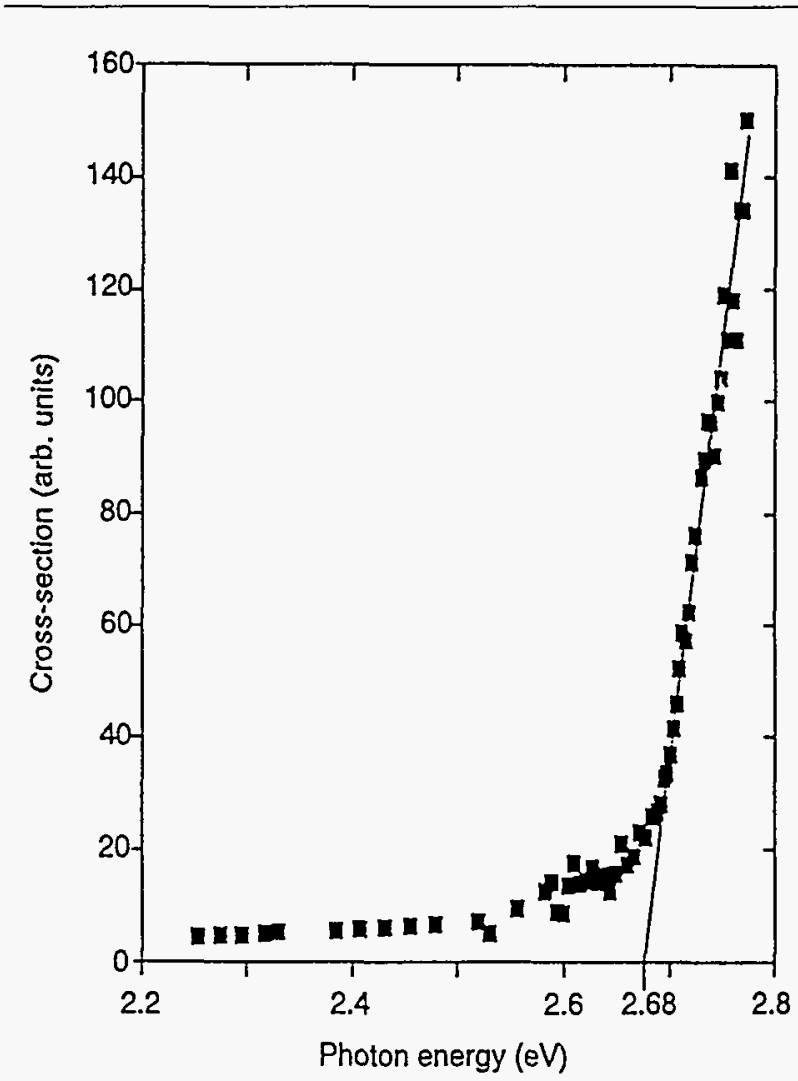

Figure 6.2. Cross-section for the production of $\mathrm{O}_{2}{ }^{-}$ from $\mathrm{O}_{3}{ }^{-}$as a function of photon energy. The straight line is fit to the steeply rising portion of the curve; the intercept is assigned to the photodissociation threshold. 
Phys. Lett. 164, 449 (1989).

2. S. E. Novick, P. C. Engelking, P. L. Jones, J. H. Futrell, and W. C. Lineberger, J. Chem. Phys. 70, 2652 (1979).

3. J. F. Hiller and M. L. Vestal, J. Chem. Phys. 74, 6096 (1981).

4. J. L. Gole and R. N. Zare, J. Chem. Phys. 57, 5331 (1972).

\section{Cl $\left({ }^{2} P_{j}\right)$ Fine Structure Quantum Yields from UV Dissociation of $\mathrm{PCl}_{3}, \mathrm{CCl}_{4}, \mathrm{CHCl}_{3}$, and $\mathrm{Cl}_{2}$ \\ S. M. Deshmukh* and W. P. Hess}

Supported by Office of Basic Energy Sciences.

* Postdoctoral Research Associate.

Chlorine-containing compounds and chlorine atom reactions play important roles in atmospheric chemistry, electronic materials deposition, and in various industrial processes. The largescale use of chlorocompounds and their subsequent discharge to the environment is a potential threat to stratospheric ozone, terrestrial ecosystems, and groundwater supplies. The sensitive detection of atomic chlorine and various chlorocompounds is necessary to model damage to terrestrial ecosystems and the effectiveness of remediation efforts on polluted soil and groundwater sites. A thorough understanding of chlorocompound photochemistry and detection techniques is key to monitoring waste remediation efforts.

Traditionally, one-photon absorption and resonance fluorescence of VUV light produced with atomic resonance lamps has been used to monitor the concentration of chlorine atoms in many processes. Much greater sensitivity in $\mathrm{Cl}$ atom detection has been achieved by Gordon and co-workers $^{1}$ using two-photon resonant, three-photon ionization of chlorine atoms in the $230-245 \mathrm{~nm}$ region. Recently, several groups have used this $\mathrm{Cl}$ atom detection scheme to study the photodissociation dynamics of simple CI-containing molecules such as $\mathrm{HCl}_{1}{ }^{2} \mathrm{CCl}_{4},{ }^{3} \mathrm{OClO}, 4$ and $\mathrm{Cl}_{2} .5$

The ground $\left({ }^{2} \mathrm{P}_{3 / 2}\right)$ and spin-orbit excited $\left({ }^{2} \mathrm{P}_{1 / 2}\right)$ states of atomic chlorine are separated by $\sim 882$ $\mathrm{cm}^{-1}$ and are designated $\mathrm{Cl}$ and $\mathrm{Cl}^{*}$, respectively. We obtain $\mathrm{Cl}^{*}$ yields for both ${ }^{35} \mathrm{Cl}$ and ${ }^{37} \mathrm{Cl}$ isotopes to investigate any possible effect of mass on the dissociation dynamics. Additionally, we obtain the ratio of oscillator strengths for the $\mathrm{Cl}$ transition ${ }^{4} \mathrm{D}_{5 / 2} \leftarrow{ }^{2} \mathrm{P}_{3 / 2}$ at $237.73 \mathrm{~nm}$ and the $\mathrm{Cl}^{*}$ transition ${ }^{2} \mathrm{D}_{3 / 2} \leftarrow{ }^{2} \mathrm{P}_{1 / 2}$ at $237.80 \mathrm{~nm}$. These two transitions are separated in their single-photon energies by only $12.38 \mathrm{~cm}^{-1}$ and, hence, are more convenient for quantum yield measurements.

The experimental apparatus consists of a pulsed molecular beam that is passed through a repeller plate toward the center of a position-sensitive ion detector. The skimmed molecular beam is crossed with the photolysis/ionization laser in the extraction region of the linear time-of-flight mass spectrometer. A $1 \%$ chlorine precursor $\left(\mathrm{Cl}_{2}, \mathrm{PCl}_{3}\right.$, $\mathrm{CCl}_{4}$, or $\mathrm{CHCl}_{3}$ )/ He mixture, at a total pressure of 1000 Torr, is passed through a solenoid-pulsed valve (500 ms open duration) equipped with a $0.5-$ mm orifice.

Laser light pulses of 5-ns duration in the 232-238 $\mathrm{nm}$ region are generated by frequency-doubling the output of a Coumarin 480 dye laser pumped by the third harmonic output of an injectionseeded Nd:YAG laser. The laser beam, which is used for both photolysis of $\mathrm{Cl}$ precursors and detection of atomic $\mathrm{Cl}$ photofragments, is focused into the photolysis/ionization region with a $15-\mathrm{cm}$ focal length lens. Following ionization, $\mathrm{Cl}^{+}$ions are extracted and accelerated along the molecular beam axis into a time-of-flight mass spectrometer, and impinge upon a dual-chevron microchannel plate detector.

Relative $\mathrm{Cl}^{*}$ quantum yields are obtained from the integrated line strengths of laser scans over the ${ }^{2} \mathrm{D}_{3 / 2} \leftarrow{ }^{2} \mathrm{P}_{3 / 2}$ and ${ }^{4} \mathrm{D}_{5 / 2} \leftarrow{ }^{2} \mathrm{P}_{3 / 2}$ transitions for ground-state $\mathrm{Cl}$ atoms and over the ${ }^{2} \mathrm{D}_{3 / 2} \leftarrow$ ${ }^{2} \mathrm{P}_{1 / 2}$ transition for the excited state $\mathrm{Cl}^{*}$ atoms. Laser pulse energies are held constant at $400 \mu \mathrm{J}$ during acquisition of the line profiles. Line profiles were also acquired at several different laser powers between 300 and $500 \mu \mathrm{J}$, and we observed no variation in quantum yields with respect to the laser powers in this range.

Figure 6.3 shows a $2+1$ REMPI spectrum of chlorine atoms generated from $\mathrm{Cl}_{2}$ photodissociation. We observe nine two-photon chlorine atom transitions between 232 and $235.5 \mathrm{~nm}$ and three transitions between 236.5 and $238 \mathrm{~nm}$. Figure 6.4 displays the REMPI line profiles of $\mathrm{Cl}\left({ }^{2} \mathrm{D}_{3 / 2} \leftarrow{ }^{2} \mathrm{P}_{3 / 2}\right)$ and $\mathrm{Cl}^{*}$ $\left({ }^{2} \mathrm{D}_{3 / 2} \leftarrow{ }^{2} \mathrm{P}_{1 / 2}\right)$ transitions following the photodissociation of $\mathrm{Cl}_{2}$. The experimental points are fitted to Lorentzian functions to obtain the integrated areas under the profiles. The ratio of these areas, corrected for the relative two-photon oscillator strengths of the two transitions, yields the relative concentrations of $\mathrm{Cl}$ and $\mathrm{Cl}^{*}$. The ratio for the 


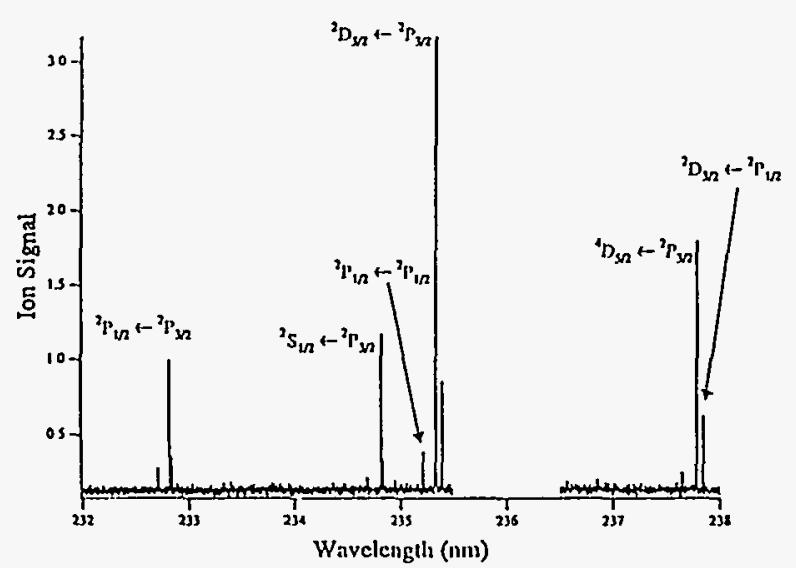

Figure 6.3. REMPI $(2+1)$ spectrum of $\mathrm{Cl}$ atoms generated from $\mathrm{Cl}_{2}$ photodissociation. The peak assignments are from Ref. 1 . The abscissa displays single-photon wavelengths. The laser pulse energy varied between $300-400 \mu \mathrm{J}$ over the scan range and this spectrum is not corrected for pulse energy variation. There were no strong peaks in the region between 235.5 and $236.5 \mathrm{~nm}$, so this region was not scanned.

two-photon transition strengths for $\mathrm{Cl}$ and $\mathrm{Cl}^{*}$ has been determined to be ${ }^{5}$

$$
\mathrm{f}\left({ }^{2} \mathrm{D}_{3 / 2} \leftarrow{ }^{2} \mathrm{P}_{3 / 2}\right) / f\left({ }^{2} \mathrm{D}_{3 / 2} \leftarrow{ }^{2} \mathrm{P}_{1 / 2}\right)=2.5,
$$

and we adopt this value here.

The relative $\mathrm{Cl}^{*}$ yields are calculated using the equation

$$
\varphi^{*}=\left[\mathrm{Cl}^{*}\right] /\left([\mathrm{Cl}]+\left[\mathrm{Cl}^{*}\right]\right)=\mathrm{S}_{\mathrm{Cl}^{*}} /\left(\mathrm{S}_{\mathrm{Cl}^{*}}+2.5 \mathrm{~S}_{\mathrm{Cl}}\right) \text {, }
$$

where $\mathrm{SCl}^{*}$ and $\mathrm{S}_{\mathrm{Cl}}$ denote the integrated line strengths for the $\mathrm{Cl}^{*}\left({ }^{2} \mathrm{D}_{3 / 2} \leftarrow{ }^{2} \mathrm{P}_{3 / 2}\right)$ and $\mathrm{Cl}$ $\left({ }^{2} \mathrm{D}_{3 / 2} \leftarrow{ }^{2} \mathrm{P}_{1 / 2}\right)$ transitions.

The absorption spectrum of $\mathrm{PCl}_{3}$ peaks at $216 \mathrm{~nm}$ with an absorption cross-section of $1.1 \times 10^{-18}$ $\mathrm{cm}^{2}$, which drops to $3.2 \times 10^{-19} \mathrm{~cm}^{2}$ at $235 \mathrm{~nm}$ and $1.4 \times 10^{-20} \mathrm{~cm}^{2}$ at $248 \mathrm{~nm}$. We have measured a $\varphi^{*}$ of 0.33 for $\mathrm{PCl}_{3}$, near $235 \mathrm{~nm}$. We have obtained a $\varphi^{*}$ of 0.43 in the $235-\mathrm{nm}$ photodissociation of $\mathrm{CHCl}_{3}$, where the absorption coefficient is very low. The most striking result is the difference for $\mathrm{Cl}^{*}$ for the ${ }^{35} \mathrm{Cl}$ and ${ }^{37} \mathrm{Cl}$ isotopes in the dissociation of $\mathrm{CCl}_{4}$. We have measured $\varphi^{*}$ of 0.2 for ${ }^{35} \mathrm{Cl}$ and $\varphi^{*}$ of 0.44 for ${ }^{37} \mathrm{Cl}$, and clearly, the $\varphi^{*}$ values for the two isotopes are appreciably different. It is known that one of the dissociation pathways in $\mathrm{CCl}_{4}$ in this wavelength range leads to the formation of two $\mathrm{Cl}$ atoms, and perhaps it is possible that we are generating two $\mathrm{Cl}$ atoms from one $\mathrm{CCl}_{4}$ molecule. This effect could explain the difference in $\mathrm{Cl}^{*}$ quantum yields of the two isotopes,
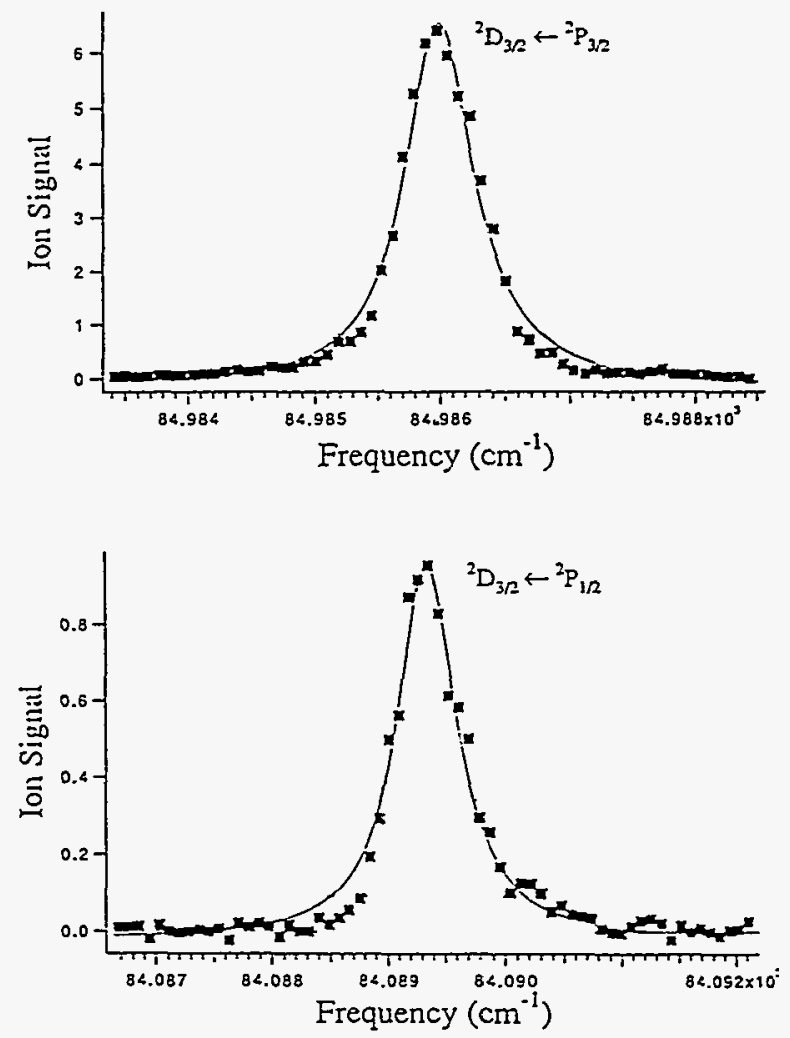

Figure 6.4. REMPI $(2+1)$ line profiles of $\mathrm{Cl}\left({ }^{2} \mathrm{D}_{3} / 2\right.$ $\left.\leftarrow{ }^{2} \mathrm{P}_{3 / 2}\right)$ and $\mathrm{Cl}^{*}\left({ }^{2} \mathrm{D}_{3 / 2} \leftarrow{ }^{2} \mathrm{P}_{1 / 2}\right)$. The abscissas display resonance two-photon frequencies. The experimental points (solid squares) are fitted to Lorentzian functions (curve fitting shown by solid lines) to obtain integrated areas under the profiles.

but at the present time we have no definitive explanation for the difference in the isotopic $\mathrm{Cl}^{*}$ yields. We have obtained a $\varphi^{*}$ of 0.43 in the 235$\mathrm{nm}$ photodissociation of $\mathrm{CHCl}_{3}$, where the absorption coefficient is very low. Matsumi et al. 5 have measured $\varphi^{*}=0.38$ at $157 \mathrm{~nm}$, and $\varphi^{*}=0.20$ at $193 \mathrm{~nm}$ for this compound.

In the 235-238 nm photodissociation of $\mathrm{Cl}_{2}$, we have obtained $\varphi^{*}=0.23$. However, we must include a significant caveat to these results. In the $235-238 \mathrm{~nm}$ range, $\mathrm{Cl}_{2}$ absorbs only very weakly, and we can not rule out the possibility of multiple photon absorption by $\mathrm{Cl}_{2}$. In addition, under the experimental conditions described in this work, we have observed evidence for the formation of dimers and clusters; therefore, we can not rule out the possibility of single- or multiple-photon absorption by molecular chlorine clusters.

Typically, $\mathrm{Cl}^{*}$ quantum yields have been obtained using the $\mathrm{Cl}\left({ }^{2} \mathrm{D}_{3 / 2} \leftarrow{ }^{2} \mathrm{P}_{3 / 2}\right)$ and $\mathrm{Cl}^{*}\left({ }^{2} \mathrm{D}_{3 / 2} \leftarrow\right.$ ${ }^{2} \mathrm{P}_{1 / 2}$ ) transitions that are separated by $441 \mathrm{~cm}^{-1}$ 
in their single-photon energies. In order to obtain reliable yield measurements, ion signals need to be normalized for the dye laser intensity, which can vary considerably over the broad region between these two transitions. Normalizing the $\mathrm{Cl}$ signal can be difficult, particularly when the power dependence of the ion signal is unknown. In our experiments, we avoid this problem by maintaining laser energy at $400 \mu \mathrm{J}$-for the scans over both atomic chlorine transitions. Alternatively, we can use $\mathrm{Cl}$ and $\mathrm{Cl}^{*}$ transitions that are close to each other in frequency, such that the laser does not need to be scanned over broad wavelength regions; hence, laser power is more easily maintained at a constant level. Figure 6.5 displays a short scan used to acquire line profiles of $\mathrm{Cl}$ $\left({ }^{4} \mathrm{D}_{5 / 2} \leftarrow{ }^{2} \mathrm{P}_{3 / 2}\right)$ and $\mathrm{Cl}^{*}\left({ }^{2} \mathrm{D}_{3 / 2} \leftarrow{ }^{2} \mathrm{P}_{1 / 2}\right)$ transitions. These two transitions are separated by only $12.38 \mathrm{~cm}^{-1}$ in one-photon energies and the laser intensity is easily maintained at $300 \mu \mathrm{J}$. In order to use these transitions for yield measurements, we have calculated the ratio of their oscillator strengths,

$$
f\left({ }^{4} D_{5 / 2} \leftarrow{ }^{2} \mathrm{P}_{3 / 2}\right) / f\left({ }^{2} \mathrm{D}_{3 / 2} \leftarrow{ }^{2} \mathrm{P}_{1 / 2}\right)=1.5 \text {. }
$$

These two transitions will likely prove more convenient for quantum yield measurements.

\section{References:}

1. S. Arepalli, N. Presser, D. Robie, and R. J. Gordon, Chem. Phys. Lett. 118, 88 (1985).

2. M. H. Alexander, B. Pouilly, and T. Duhoo, J. Chem. Phys. 99, 1752 (1993).

3. J. Park, Y. Lee, and G. W. Flynn, Chem. Phys. Lett. 186, 441 (1991).

4. E. Bishenden, J. Haddock, and D. J. Donaldson,

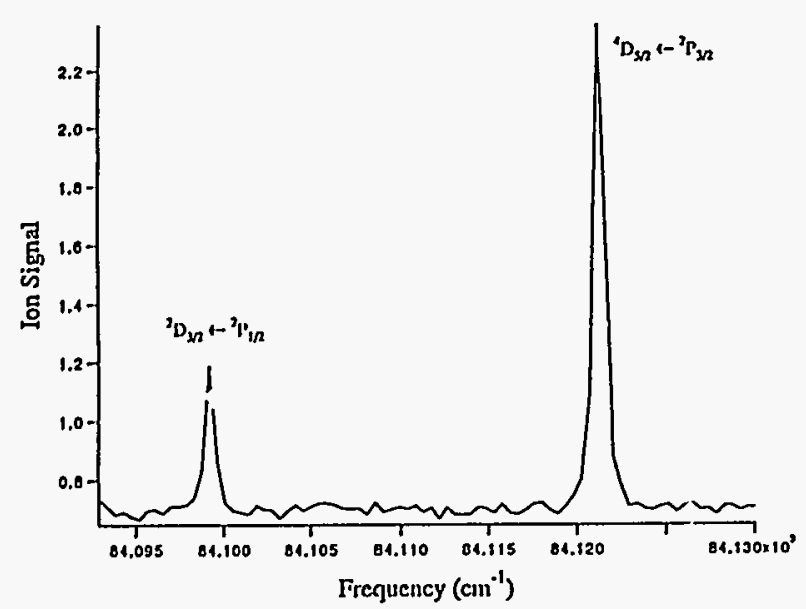

Figure 6.5. REMPI line profiles of $\mathrm{Cl}\left({ }^{4} \mathrm{D}_{5} / 2 \leftarrow\right.$ $\left.{ }^{2} \mathrm{P}_{3 / 2}\right)$ and $\mathrm{Cl}^{*}\left({ }^{2} \mathrm{D}_{3 / 2} \leftarrow{ }^{2} \mathrm{P}_{1 / 2}\right)$ acquired in a single scan. The abscissa displays resonance twophoton frequencies.
J. Phys. Chem. 95, 2113 (1991)

5. Y. Matsumi, K. Tonokura, and M. Kawasaki, J. Chem. Phys. 97, 1065 (1992); Y. Matsumi, K. Tonokura, M. Kawasaki, G. Inoue, S. Satyapal, and R. Bersohn, J. Chem. Phys. 97, 5261 (1992). 


\section{Publications and Presentations 1992-1993}

\section{Publications}

A. R. Burns, E. B. Stechel, D. R. Jennison, and T. M. Orlando, "Effects of Coadsorbed Atomic Oxygen on the Electron-Stimulated Desorption of NO from Pt(111)," Phys. Rev. B 45, 1373 (1992).

W. P. Hess, D. W. Chandler, and J. W. Thoman, Jr., "Photofragment Imaging: The 205-nm Photodissociation of $\mathrm{CH}_{3} \mathrm{Br}$ and $\mathrm{CD}_{3} \mathrm{Br}$," Chem. Phys. 163, 277 (1992).

T. A. Hu, E. L. Chappell, and S. W. Sharpe, "Infrared Diode Laser Spectroscopy of the Ar$\mathrm{N}_{2} \mathrm{O}$ Complex: Observation of the Intermolecular Bending Mode in Combination with the HighestFrequency Intramolecular Stretching Mode," $J$. Chem. Phys. 98, 6162 (1993).

T. A. Hu, E. L. Chappell, J. T. Munley, and S. W. Sharpe, "Improved Multipass Optics for Diode Laser Spectroscopy," Rev. Sci. Instrum. 64, 1 (1993).

S. A. Joyce, J. E. Houston, and T. A. Michalske, "Differentiation of Chemical and Topographical Features Using the Interfacial Force Microscope," Appl. Phys. Lett. 60, 1175 (1992).

S. A. Joyce, J. E. Houston, T. A. Michalske, R. C. Thomas, and R. M. Crooks, "Mechanical Relaxations of an Organic Monolayer Film by Force Microscopy," Phys. Rev. Lett. 68, 2790 (1992).

S. A. Joyce, J. A. Yarmoff, T. E. Madey, and P. Nordlander, "The Influence of Coadsorbed Potassium on the Electron Stimulated Desorption of Fluorine from $\mathrm{PF}_{3}$ on $\mathrm{Ru}(0001)$," Phys. Rev. B 45, 14624 (1992).

S. A. Joyce, J. A. Yarmoff, and T. E. Madey, "Radiation Damage in an Adsorbed Monolayer: $\mathrm{PF}_{3}$ on $\mathrm{Ru}(0001)$," Surf. Sci. 254, 144 (1992).

R. Knochenmuss, G. R. Holtom, and D. Ray, "Proton Transfer Reaction Rates as a Probe of Size-Dependent Properties of Large Water Clusters," Chem. Phys. Lett. 215, 188-192 (1993).

R. Knochenmuss, D. Ray, and W. P. Hess, "Electronic Absorption Spectra of Large Benzene. $\mathrm{Ar}_{\mathrm{n}}$ Clusters," J. Chem. Phys. 100, 44-51 (1994).

M. Kwini, M. J. Iedema, J. P. Cowin, and T. L. Gilton, "Probing Femtosecond Dynamics at the
Condensed Phase-Vacuum Interface," J. Phys. Chem. 96, 2795-2800 (1992).

R. S. McDowell, "Infrared Spectroscopy" and (in part) "Molecular Structure and Spectra," McGraw-Hill Encyclopedia of Science \& Technology, 7th ed. (McGraw Hill Book Co., 1992), 9, 171-177; 11, 365-366.

T. M. Orlando, A. R. Burns, D. R. Jennison, and E. B. Stechel, "Electronically-Stimulated Adsorbate Dissociation in the Presence of an Electronegative Coadsorbate: $\left(\mathrm{NO}_{2}+\mathrm{O}\right)$ on $\mathrm{Pt}(111), "$ Phys. Rev. B 45, 8679 (1992).

T. M. Orlando, J. P. Cowin, G. R. Teeter, and S. E. Barlow, "Dynamical Acceleration Effects in Laser-Induced Particle Emission From Surfaces," AIP Conference Proceedings 288, Laser Ablation: Mechanisms and Applications-II, ed. by J. C. Miller and R. Haglund Jr. (Springer-Verlag, New York, 1993), pp. 341-346.

T. M. Orlando, A. R. Burns, E. B. Stechel, and D. R. Jennison, "Quantum Resolved Stimulated Surface Reactions," in Desorption Induced by Electronic Transitions, DIET V, edited by A. R. Burns, E. B. Stechel, and D. R. Jennison (Springer-Verlag, New York, 1993), pp. 194-197.

S. P. Sapers and W. P. Hess, "Photodissociation of $\mathrm{BrCH}_{2} \mathrm{CH}_{2} \mathrm{OH}$ and $\mathrm{ICH}_{2} \mathrm{CH}_{2} \mathrm{OH}$ : Formation and Characterization of $\mathrm{OH}\left(\mathrm{X}^{2} \mathrm{P}\right), " \mathrm{~J}$. Chem. Phys. 97, 3126 (1992).

S. X. Xie, M. Du, L. Mets, and G. R. Fleming, "Femtosecond Fluorescence Depolarization Study of Photosynthetic Antenna Proteins: Observation of Ultrafast Energy Transfer in Trimeric C-phycocyanin and Allophycocyanin," Proc. Internat. Soc. Opt. Eng. (SPIE) 1640, 690 (1992).

\section{In Press and Submissions}

S. M. Deshmukh and W. P. Hess, " $\mathrm{Cl}\left({ }^{2} \mathrm{P}_{j}\right)$ Fine Structure Quantum Yields from UV Dissociation of $\mathrm{PCl}_{3}, \mathrm{CCl}_{4}, \mathrm{CHCl}_{3}$, and $\mathrm{Cl}_{2}$ in a Supersonic Jet," submitted to J. Photochem. and Photobiol. Section A. Chemistry.

S. M. Deshmukh and W. P. Hess, "Photodissociation of Acetyl Chloride: $\mathrm{Cl}$ and $\mathrm{CH}_{3}$ Quantum 
Yields and Energy Distributions," submitted to J. Chem. Phys.

O. Dopfer, G. Reiser, K. Muller-Dethlefs, E. W. Schlag and S. D. Colson, "Zero-Kinetic-Energy Photoelectron Spectroscopy of the HydrogenBonded Phenol-Water Complex," submitted to $J$. Chem. Phys.

M. Du, S. X. Xie, Y. Jia, L. Mets, and G. R. Fleming, "Direct Observation of the Initial Energy Transfer Step in PSI Core Antenna," Chem. Phys. Lett., in press.

R. C. Dunn and X. S. Xie, "Characterization of the Temporal Behavior of Ultrashort Pulses Emerging from a Near-Field Probe," J. Ultramicroscopy, in press.

R. C. Dunn, E. V. Allen, S. A. Joyce, G. A. Anderson, and X. S. Xie, "Near-Field Fluorescent Imaging of Single Proteins," J. Ultramicroscopy, in press.

R. C. Dunn, G. R. Holtom, L. Mets, and X. S. Xie, "Near-field Fluorescence Imaging and Fluorescence Lifetime Measurement of Light Harvesting Complexes in Intact Photosynthetic Membranes," J. Phys. Chem., in press.

A. J. Howard, T. R. Guilinger, M. J. Kelly, J. O. Stevenson, S. A. Joyce, J. E. Houston, and T. A. Michalske, "Electrochemical Microfabrication Utilizing Porous Silicon," Proc. AIChE, in press.

J. F. Kelly and R. S. McDowell, "Optical Spectroscopy in Environmental Analysis," Encyclopedia of Energy Technology and the Environment (John Wiley and Sons, New York, 1994), in press.

G. A. Kimmel, T. M. Orlando, C. Vézina, and L. Sanche, "Low-Energy, Electron-Stimulated Production of Molecular Hydrogen from Amorphous Water Ice," submitted to J. Chem. Phys.

G. A. Kimmel, T. M. Orlando, C. Vézina, and L. Sanche, "Low-Energy (5-50 eV) Electron-Stimulated Production of Molecular Hydrogen from Amorphous Ice Layers," submitted to J. Chem. Phys.

R. Knochenmuss and D. E. Smith, "Time and Energy Dependent Fluorescence Spectra of Napthol-Water Clusters," in preparation.

J. E. Murphy, J. F. Kelly, T. M. Orlando, B. Bushaw, and R. J. Miller, "Multistate Perturbations Between Rydberg and Valence States in NO," submitted to J. Chem. Phys.
A. Peurrung, T. M. Orlando, S. E. Barlow, G. R. Teeter, and J. P. Cowin, "Dynamical Plasma Acceleration Effects in Laser-Surface Interactions," submitted to J. Appl. Phys.

D. Ray and K. D. Brown, "Photodissociation of the Ozonide Ion in the Gas Phase: Implications for Ozone Thermochemistry," in preparation.

M. R. Schneider, C. P. Dehnbostel, T. L. Gilton, M. Kwini, and J. P. Cowin, "Photoelectron Induced Surface Chemistry: Methyl Chloride on GaAs(100)," submitted to J. Appl. Phys.

M. O. Trulson, H. B. Lueck and D. M. Friedrich, "Performance of a Spatial Filter Equipped Single Monochromator for Raman Spectroscopy," submitted to Appl. Spectrosc.

X. S. Xie, R. C. Dunn, G. R. Holtom, and L. Mets, "Near-Field Time Resolved Fluorescence Spectroscopy on Single Proteins: Application to Photosynthetic Membranes," Ultrafast Phenomena IX, in press.

X. S. Xie, R. C. Dunn, E. V. Allen, and G. R. Holtom, "Near-Field Fluorescence Spectroscopy on Single Chromophores, Single Proteins, and Biological Membranes," SPIE Proc., TimeResolved Fluorescence 1994, in press.

Y. P. Zeng, S. W. Sharpe, S. K. Shin, C. Wittig, and R. A. Beaudet, "Infrared Spectroscopy of $\mathrm{CO}_{2}-\mathrm{D}(\mathrm{H}) \mathrm{Br}$ : Molecular Structure and its Reliability," J. Chem. Phys., in press.

\section{Presentations}

K. W. Brown and D. Ray, "Photodissociation of the Ozonide Ion in the Gas Phase," presented at International Conference on Photochemistry, Vancouver, B.C., Aug. 1-6, 1993.

K. W. Brown and D. Ray, "Photodissociation of the Ozonide Ion in the Gas Phase: Implications for Ozone Thermochemistry," presented at American Chemical Society Fall 1993 Meeting, Aug. 23-27, 1993.

J. P. Cowin, "Photoelectron Induced Etching at the GaAs(100) Surface via $\mathrm{CH}_{3} \mathrm{Cl}$," presented at Interuniversity Semiconductor Research Center, Seoul National University, Korea, Jan. 23, 1992.

J. P. Cowin, "Femtosecond Solvation Dynamics of Anions at UHV Multilayer Surfaces," presented at Chemical Technology Group, Seoul National University, Korea, Jan. 23, 1992. 
J. P. Cowin, "Femtosecond Solvation Dynamics of Anions at UHV Multilayer Surfaces," presented at Korean Institute of Science and Technology, Korea, Jan. 24, 1992.

J. P. Cowin, "Photodissociation Probes of Femtosecond Solvation Dynamics," presented at University of Oregon, Eugene, Ore., March 4, 1992.

J. P. Cowin, "Photodissociation Probes of Femtosecond Solvation Dynamics," presented at Oregon State University, Corvallis, Ore., March 5, 1992.

J. P. Cowin, "Photodissociation Probes of Femtosecond Solvation Dynamics," presented at Oregon Graduate Institute, March 6, 1992.

J. P. Cowin, "Photochemical Surface Reactions and The Environment," presented at American Physical Society, New York, N.Y., March 1992.

J. P. Cowin, "Laser-Induced Photochemistry at Surfaces," presented at DIET V (Desorption Induced by Electronic Transitions Workshop V), Taos, N.M., April 1-4, 1992.

J. P. Cowin, "Photochemical Surface Reactions and the Environment," presented at American Chemical Society Symposium on Surface Photochemistry, San Francisco, Cal., April 5-10, 1992.

J. P. Cowin, "Chemistry at the Water-Solid Interface: Options for Study," presented at Northwest Regional American Chemical Society Meeting, University of Montana, Missoula, Mont., June 17-19, 1992.

S. M. Deshmukh and W. P. Hess, " $\mathrm{Cl}\left({ }^{2} \mathrm{P}_{\mathrm{j}}\right)$ Fine Structure Quantum Yields from UV Photodissociation of $\mathrm{Cl}_{2}$ and $\mathrm{PCl}_{3}$ in a Supersonic Jet," presented at International Conference on Photochemistry, Vancouver, B.C., Aug. 1-6, 1993.

S. M. Deshmukh and W. P. Hess, "Photodissociation of Acetyl Chloride in a Supersonic Jet: $\mathrm{CH}_{3}$ Photofragment Ion Imaging," presented at Interdisciplinary Laser Science Conference, Optical Society of America, Toronto, Ont., Oct. 3-8, 1993.

R. C. Dunn, G. R. Holtom, and X. Xie, "Progress Towards Time Resolved Spectroscopy with NearField Optics," presented at 2nd International Conference on Near-Field Microscopy, Raleigh, N.C., Oct. 20-23, 1993.

R. C. Dunn, E. V. Allen, S. A. Joyce, and X. S. Xie, "Near-Field Optical Microscope for Fluorescence Spectroscopy," presented at XVI International Conference on Photochemistry, Vancouver, B.C., Aug. 1-6, 1993.
R. C. Dunn, E. V. Allen, S. A. Joyce, and S. X. Xie, “Near-Field Optical Microscopy for Fluorescence Spectroscopy," presented at 206th National ACS Meeting, Chicago, Ill., Aug. 22-27, 1993.

R. C. Dunn, E. V. Allen, S. R. Joyce, and X. S. Xie, "Towards the Ultimate Sensitivity of NearField Fluorescence Detection," presented at Second International Conference on Near-Field Optics, Raleigh, N.C., Oct. 20-22, 1993.

R. C. Durn and X. S. Xie, "Progress Towards TimeResolved Spectroscopy with Near-Field Optics," presented at Second International Conference on Near-Field Optics, Raleigh, N.C., Oct. 20-22, 1993.

D. M. Friedrich, "Characterization of Photoinduced Charge Transfer Dynamics by Resonance Raman Spectroscopy," presented at Gordon Research Conference on Vibrational Spectroscopy, Wolfeboro, N.H., Aug. 3, 1992.

D. M. Friedrich, M. O. Trulson, and J. P. LaFemina, "Intramolecular Charge Transfer Dynamics in Cyanoanilines," presented at Western Spectroscopy Association Conference, Jan. 28, 1993.

M. C. Gallagher, "Epitaxially Grown GaAs Surfaces Studied by Scanning Tunneling Microscopy," presented at Department of Physics Seminar, University of Alberta, Edmonton, Alta., Oct. 7, 1993.

W. P. Hess, "Photodissociation Study of $\mathrm{BrCH}_{2} \mathrm{CH}_{2} \mathrm{OH}$ and $\mathrm{ICH}_{2} \mathrm{CH}_{2} \mathrm{OH}$ : Formation and Characterization of $\mathrm{OH}\left(\mathrm{X}^{2} \mathrm{P}\right)$," presented at American Chemical Society National Meeting, San Francisco, Cal., April 1992.

W. P. Hess, "Programs at the Molecular Science Research Center and Environmental Restoration at the Hanford Site," presented at Sandia National Laboratory Symposium, Albuquerque, N.M., June 1992.

W. P. Hess, "Two-Step Photodissociation of Bromoethanol by Photofragment Imaging and Laser-Induced Fluorescence," presented at Washington State University Physics Colloquium, Pullman, Wash., Sept. 1992.

T. A. Hu, E. L. Chappell, and S. W. Sharpe, "Observation of the Weakly Bonded $\mathrm{Ar}-\mathrm{N}_{2} \mathrm{O}$ Complex in the $2256 \mathrm{~cm}^{-1}$ Combination Region: The Intermolecular Bend or Stretch?" presented at Ohio State University International Symposium on Molecular Spectroscopy, Columbus, Ohio, June 15-19, 1992. 
T. A. Hu and S. W. Sharpe, "Observation and Analysis of the Rovibrational Spectra of OCS.. $\mathrm{HX}(\mathrm{HX}=\mathrm{HF}, \mathrm{HCl}, \mathrm{HBr}$ ) Dimers," presented at Ohio State University International Symposium on Molecular Spectroscopy, Columbus, Ohio, June 14-18, 1993.

B. Jackson, M. Persson and B. D. Kay, "A Quantum Mechanical Study of the Reaction of Gas-Phase $\mathrm{H}$ with $\mathrm{Cl}$ Adsorbed on $\mathrm{Au}(111)$ : Eley-Rideal Mechanism," presented at Gordon Conference on the Dynamics of Gas-Surface Interactions, Andover, N.H., Aug. 1-6, 1993.

S. A. Joyce, "Force Microscopy Studies of Interfacial Phenomena," presented at Washington State University Physics Colloquium, Pullman, Wash., March 12, 1992.

S. A. Joyce, "Force Microscopy Studies of Interfacial Phenomena," presented at Lawrence Berkeley Laboratory, Berkeley, Cal., Feb. 1993.

B. D. Kay, "Quantum-Resolved Inelastic and Reactive Gas-Surface Scattering," presented at Physical Chemistry Seminar, University of Washington, Seattle, Wash., May 28, 1992.

B. D. Kay, "Quantum-Resolved Inelastic and Reactive Gas-Surface Scattering," presented at Air Force Phillips Laboratory, Hanscomb Air Force Base, Mass., July 18, 1992.

B. D. Kay, "State-to-State Dynamics of Inelastic $\mathrm{N}_{2}$ Molecular Beam Scattering From $\mathrm{Au}(111)$, $\operatorname{Pd}(111)$, and $\operatorname{Pd}(111): \mathrm{H}$," presented at Gordon Conference on Atomic and Molecular Interactions, New London, N.H., July 20-24, 1992.

B. D. Kay, "Surface Kinetics of H/D Exchange on Pd(111): A Steady-State Molecular Beam Study," presented at Gordon Conference on Atomic and Molecular Interactions, New London, N.H., July 20-24, 1992.

B. D. Kay, "Quantum-Resolved Inelastic and Reactive Molecular Beam Scattering From Surfaces," presented at Physical Chemistry Seminar, Oklahoma State University, Stillwater, Okl., July 27, 1992.

B. D. Kay, "Quantum-Resolved Inelastic and Reactive Gas-Surface Scattering," presented at Surface Science Seminar, Naval Research Laboratory, Washington, D.C., Aug. 31, 1992.

B. D. Kay, "Surface Kinetics of H/D Exchange on Pd(111): A Steady-State Molecular Beam Study," presented at Chemistry Seminar, Argonne National Laboratory, Argonne, Ill., Nov. 6, 1992.
B. D. Kay and V. A. Shamamian, "Dynamics of Surface-to-Bulk Hydrogen Migration on Pd(111) Induced by the Chemisorption of $\mathrm{CO}$," presented at 39th American Vacuum Society Symposium, Chicago, Ill., Nov. 9-13, 1992.

B. D. Kay, "Quantum-Resolved Inelastic and Reactive Gas-Surface Scattering," presented at Physical Chemistry Seminar, University of Massachusetts, Amherst, Mass., Jan. 25, 1993.

B. D. Kay, "Quantum-Resolved Inelastic and Reactive Gas-Surface Scattering," presented at Chemical Physics Seminar, University of Oregon, Eugene, Ore., April 26, 1993.

B. D. Kay and K. R. Lykke, "State-to-State Reactive Gas-Surface Scattering: $\mathrm{H}+\mathrm{Au}(111): \mathrm{Cl}$ $\rightarrow \mathrm{HCl}(\mathrm{v} . \mathrm{J})$," presented at Gordon Conference on Molecular Energy Transfer, New Hampton, N.H., June 20-25, 1993.

B. D. Kay and K. R. Lykke, "Quantum Resolved Reactive Gas-Surface Scattering: $\mathrm{H}+\mathrm{Au}(111): \mathrm{Cl}$ $\rightarrow \mathrm{HCl}(\mathrm{v} . \mathrm{J})$," presented at Gordon Conference on the Dynamics of Gas-Surface Interactions, Andover, N.H., Aug.1-6, 1993.

B. D. Kay and K. R. Lykke, "State-to-State Reactive Gas-Surface Scattering: $\mathrm{H}+\mathrm{Au}(111): \mathrm{Cl} \rightarrow$ $\mathrm{HCl}(\mathrm{v} . \mathrm{J})$," presented at 40th National American Vacuum Society Meeting, Orlando, Fla., Nov. 1319, 1993.

G. Kimmel, T. M. Orlando, C. Venzia, and L. Sanche, "Electron-Stimulated Reactive Scattering in Water Ice: Molecular Hydrogen Production," presented at Gordon Conference on Dynamics of Gas-Surface Interactions, Andover, N.H., Aug. 2-6, 1993.

G. Kimmel, T. M. Orlando, C. Venzia, and L. Sanche, "Electron-Stimulated Reactive Scattering in Water Ice: Molecular Hydrogen Production," presented at American Vacuum Society Meeting, Seattle, Wash., Sept. 16-17, 1993.

R. D. Knochenmuss, D. Ray, and W. P. Hess, "Electronic Absorption Spectra vs. Internal Energy of Large Benzene.ArN Clusters," presented at International Conference on Photochemistry, Vancouver, B.C., Aug. 1-6, 1993.

R. D. Knochenmuss, D. Ray, and G. R. Holtom, "Excited-State Proton Transfer Reaction Rates in Very Large 1-Naphthol $\left(\mathrm{H}_{2} \mathrm{O}\right)_{\mathrm{N}}$ Clusters," presented at International Conference on Photochemistry, Vancouver, B.C., Aug. 1-6, 1993. 
R. S. McDowell, "Basic Research in Molecular Sciences to Meet Environmental Needs," presented at Portland State University Environmental Sciences and Resources Program, Portland, Ore., May 21, 1992.

J. E. Murphy, J. F. Kelley, T. M. Orlando, B. Bushaw, and R. J. Miller, "Multistate Pertubations Between Rydberg and Valence States in NO," presented at 40th Annual Western Spectroscopy Association Conference, Asilomar, Cal., Jan. 27-29, 1993.

T. M. Orlando, A. R. Burns, E. B. Stechel, and D. R. Jennison, "Quantum Resolved Stimulated Surface Reactions," presented at International Workshop on Desorption Induced by Electronic Transitions, DIET V, Taos, N.M., April 1-4, 1992.

T. M. Orlando, "Quantum Resolved Studies of Stimulated Surface Reactions," presented at Physical Chemistry Seminar, Department of Chemistry, University of Washington, Seattle, Wash., April 29, 1992.

T. M. Orlando, "Electronically Stimulated Surface Reactions," presented at Condensed Matter Seminar, Exxon Research and Engineering Company, June 23, 1992.

T. M. Orlando, "Electronically Stimulated Surface Reactions," presented at Physical Chemistry Seminar, Departmentof Chemistry, SUNY at Stony Brook, N.Y., June 25, 1992.

T. M. Orlando, "Electronically Stimulated Surface Reactions," presented at GAANN Lecture, Department of Physics, Washington State University, Pullman, Wash., Oct. 13, 1992.

T. M. Orlando, "Quantum-Resolved ElectronStimulated Interface Reactions," presented at Dept. of Chemistry, Tulane University, New Orleans, La., April 26, 1993.

T. M. Orlando, A. R. Burns, E. B. Stechel, and D. R. Jennison, "Quantum Resolved Studies of Radiation-Induced Surface Reactions," presented at Gordon Conference on Radiation Chemistry, Salve Regina College, R.I., July 6-10, 1992.

T. M. Orlando, J. P. Cowin, G. R. Teeter, and S. E. Barlow, "Dynamical Acceleration Effects in Laser-Induced Particle Emission from Surfaces," presented at Second International Conference on Laser Ablation-COLA '93, Knoxville, Tenn., April 19-22, 1993.

T. M. Orlando, G. Kimmel, C. Venzia, and L. Sanche, "Low-Energy Electron-Stimulated Reac- tive Scattering in the Condensed Phase," presented at NATO Advanced Study Institute on Linking the Gaseous and Condensed Phases of Matter: The Behavior of Slow Electrons, Patras, Greece, Sept. 5-18, 1993.

D. Ray, "Time Resolved Dynamics in MassSelected Clusters," presented at SPIE OE/LASE, Los Angeles, Cal., Jan. 23-25, 1992.

D. Ray, "Reaction Dynamics in Size-Selected Molecular Clusters," presented at Symposium on Structure and Dynamics of Large Molecular Clusters, 204th American Chemical Society National Meeting, Washington, D.C., Aug. 23-28, 1992.

D. Ray and K. W. Brown, "Structural Probes of Size-Selected Cluster Ions," presented at 204th American Chemical Society National Meeting, Washington, D.C., Aug. 23-28, 1992.

D. Ray and R. D. Knochenmuss, "Vibrations and Dynamics of Hydrogen-Bonded Clusters," presented at 204th American Chemical Society National Meeting, Washington, D.C., Aug. 23-28, 1992.

D. Ray and K. D. Brown, "Photodissociation of the Ozonide Ion in the Gas Phase," presented at $X V I$ th International Conference on Photochemistry, Vancouver, B.C., Aug. 1-6, 1993.

D. Ray, R. Knochenmuss and G. R. Holtom, "Excited-State Proton Transfer Reaction Rates in Very Large 1-Napthol- $\left(\mathrm{H}_{2} \mathrm{O}\right)_{n}$ Clusters," presented at XVIth International Conference on Photochemistry, Vancouver, B.C., Aug. 1-6, 1993.

D. Ray, R. Knochenmuss, and W. P. Hess, "Electronic Absorption Spectra vs. Internal Energy of Large Benzene-Ar clusters," presented at XVIth International Conference on Photochemistry, Vancouver, B.C., Aug. 1-6, 1993.

D. Ray and K. D. Brown, "Photodissociation of the Ozonide Ion in the Gas Phase: Implications for Ozone Thermochemistry," presented at 206th American Chemical Society National Meeting, Chicago, Ill., Aug. 23-27, 1993.

D. Ray and R. Knochenmuss, "Time-Dependent Fluorescence Spectra vs. Internal Energy of Napthol-(water) $n$ Clusters," presented at 206th American Chemical Society National Meeting, Chicago, Ill., Aug. 23-27, 1993.

S. P. Sapers, "Photodissociation of $\mathrm{BrCH}_{2} \mathrm{CH}_{2}$ $\mathrm{OH}$ and $\mathrm{ICH}_{2} \mathrm{CH}_{2} \mathrm{OH}: \mathrm{OH}\left(X^{2} \mathrm{P}\right)$ Product State Distributions by Laser-Induced Fluorescence," presented at Western Spectroscopy Association, 
Asilomar Conference Center, Pacific Grove, Cal., Jan. 1992.

R. S. Smith, B. D. Kay, and S. D. Colson, "Methane Oxidative Coupling in a Rapidly Quenched Microreactor: Formation of Methyl Radicals," presented at 39th American Vacuum Society Symposium, Chicago, Ill., Nov. 9-13, 1992.

M. O. Trulson, D. M. Friedrich, and J. P. LaFemina, "Characterization of Photoinduced Charge Transfer Dynamics by Resonance Raman Spectroscopy," presented at American Chemical Society National Meeting, Aug. 24-28, 1992.

S. X. Xie, "Femtosecond Fluorescence Depolarization Study of Photosynthetic Antenna Proteins: Observation of Ultrafast Energy Transfer in Trimeric C-Phycocyanin and Allophycocyanin," presented at SPIE OE/LASE '92, Los Angeles, Cal., Jan. 1992.

S. X. Xie, "Electron Transfer and Energy Transfer in Photosynthetic Systems," invited seminar at University of California, Santa Cruz, Cal., Aug. 1992.

X. S. Xie and R. C. Dunn, "Application of NearField Optical Microscopy to Photosynthetic Studies," poster presentation at 1993 Gordon Research Conference on Photosynthesis: Biochemical Aspects, New Hampton, N.H., Aug. 16, 1993.

X. Xie, R. C. Dunn, E. V. Allen, S. A. Joyce, and G. R. Holtom, "Near-Field Optical Microscope for Fluorescence Spectroscopy," presented at ILS-IX (9th Interdisciplinary Laser Science) Conference, Toronto, Ont., Oct. 3-8, 1993.

X. Xie, R. C. Dunn, E. V. Allen, and S. A. Joyce, "Towards the Ultimate Sensitivity of Near-field Fluorescence Detection," presented at 2nd International Conference on Near-Field Microscopy, Raleigh, N.C., Oct. 20-23, 1993. 


\section{Collaborations}

\section{Outside Collaborations}

Hydrogen Bonding in Atmospheric Clusters

University of Washington (R. O. Watts)

MSRC Contacts: S. D. Colson and S. W. Sharpe

Electronic Spectroscopy of Benzene-Water Clusters Purdue University (T.S. Zwier)

MSRC Contact: W.P. Hess

Synthetic Radical Sites on Surfaces

University of Colorado (G. B. Ellison)

MSRC Contacts: J. P. Cowin, S. E. Barlow and T. M. Orlando

Measurement of SIFT Parameters

University of Colorado (C. H. Depuy)

MSRC Contact: S. E. Barlow

Reactions on High-Energy Surfaces: Destruction of Trichloroethylene

University of Pittsburgh (J. T. Yates and T. H. Ballinger)

MSRC Contact: S. D. Colson

Real-Time Surface Reaction Dynamics

University of California, San Diego (A. C. Kummel)

MSRC Contacts: D. M. Friedrich and J. P. Cowin

Thermal-Electron/Water Chemistry

University of Sherbrooke (L. Sanche)

MSRC Contact: T. M. Orlando

Photoelectron Spectroscopy of H-Bonded Clusters

University of Munich (E. W. Schlag)

MSRC Contact: S. D. Colson

Ion Traps in Environmental Monitoring

Colorado School of Mines (K. J. Voorhees)

MSRC Contact: S. E. Barlow

Fiber-Optic Laser Probes for Near-Field Optical Microscopy

Digital Instruments Inc.

MSRC Contact: X. Xie

UV Resonance Raman Scattering from Substituted Benzene Compounds

University of Oregon (B.S. Hudson)

MSRC Contact: D. M. Friedrich
Crown Ether-Cation Binding Energies

University of Utah (P. B. Armentrout)

MSRC Contact: D. Ray

Substituent Effects on Intramolecular Charge Transfer

Max-Planck Institute, Göttingen (K. A. Zachariasse)

MSRC Contact: D. M. Friedrich

Spectroscopy of Van der Waals Clusters

University of Washington (A. G. Maki)

MSRC Contact: S. W. Sharpe

Quantum Dynamics of Reactive Gas-Surface Scattering

University of Massachusetts (B. Jackson)

MSRC Contact: B. D. Kay

Infrared Spectroscopy of Clusters

University of UIm ( $\mathrm{H}$. Jones)

MSRC Contacts: D. Ray and S. D. Colson

\section{Collaborations within PNL}

Bonding and Structure of Organic Ligands at the Oxide/Water Interface

Earth and Environmental Sciences Center (C. C. Ainsworth and P. L. Gassman)

CS\&D Contact: D. M. Friedrich

Laser Fluorescence of Lanthanide Complexes and Adsorbates at Mineral Interfaces

Earth and Environmental Sciences Center (L. Rao and A. R. Felmy)

CS\&D Contact: D. M. Friedrich

Water Interactions with Oxide Surfaces

Materials and Chemical Sciences Center (B. C. Bunker)

CS\&D Contacts: B. D. Kay and J. P. Cowin

High-Energy Corona Reactors for Organic Destruction

Materials and Chemical Sciences Center (D. M. Camaioni) and Engineering Technology Center (T. M. Bergsman, W. O. Heath, and R. R. Shah)

CS\&D Contact: T. M. Orlando 
Radiation Damage Effects and Their Relation to Tank Waste Remediation Efforts

Materials and Chemical Sciences Center (R. K. Quinn and D. M. Camaioni)

CS\&D Contact: T. M. Orlando

Heterogeneous Atmospheric Chemistry

Earth and Environmental Sciences Center, Atmospheric Chemistry and Physics (R. D. Saylor)

CS\&D Contact: D. Ray

Waste Tank Speciation Methods (Mobile Analytical Reconnaissance System, MARS)

Applied Physics Center (J. S. Hartman) and Materials and Chemical Sciences Center (M. R. Smith and M. L. Alexander)

CS\&D Contacts: S. D. Colson, S. E. Barlow, J. P. Cowin, and R. S. McDowell

Spectroscopic Techniques for Atmospheric Monitoring

Materials and Chemical Sciences Center (J. F. Kelly)

CS\&D Contacts: S. W. Sharpe and R. S. McDowell 


\section{Distribution}

No. of

Copies

\section{OFFSITE}

12 DOE/Office of Scientific and Technical Information

Professor Peter B. Armentrout Department of Chemistry University of Utah 2020 Henry Eyring Bldg. Salt Lake City, Utah 84112

Professor Paul Barbara Department of Chemistry University of Minnesota 207 Pleasant Street SE Minneapolis, MN 55455

Richard Stephen Berry Department of Chemistry University of Chicago 5735 South Ellis Avenue Chicago, $\Pi 60637$

\section{S. Barnhart}

ER-14, G-338/GTN

U.S. Department of Energy 19901 Germantown Road

Germantown, MD 20874

Dr. N. F. Barr

Office of Health and Environmental Research Office of Energy Research U.S. Department of Energy Washington, D.C. 20545

Michelle Broido ER-72, G-155, GTN U.S. Department of Energy 19901 Germantown Road Germantown, MD 20874
No. of

Copies

Professor Sylvia T. Ceyer

Department of Chemistry

Massachusetts Institute of Technology

Cambridge, MA 02139

Dr. R. C. Dahlman

Office of Health and

Environmental Research

Office of Energy Research

U.S. Department of Energy

Washington, D.C. 20545

Professor J. G. Dash

Department of Physics, FM-15

University of Washington

Seattle, WA 98195

Dr. A. E. Depristo

Ames Laboratory

Iowa State University

Ames, IA 50011

Professor M. El-Sayed

Department of Chemistry and Biochemistry

University of California - Los Angeles

405 Hilgard Avenue

Los Angeles, CA 90024-1569

Professor Peter M. Felker

Department of Chemistry

405 Hilgard Avenue

University of California

Los Angeles, CA 90024-1569

Professor R. J. Fletterick

Biochemistry and Biophysics Department

University of California - San Francisco

San Francisco, CA 94143-0448 
No. of

Copies

C. W. Frank

EM-50, 5A-014/FORS

U.S. Department of Energy

1000 Independence Avenue, S.W.

Washington, D.C. 20585

Dr. M. E. Frazier

Office of Health and

Environmental Research

Office of Energy Research

U.S. Department of Energy

Washington, D.C. 20545

Professor T. F. George

Office of the Provost

Washington State University

Pullman, WA 99164-4660

Professor W. A. Goddard III

Division of Chemistry and

Chemical Engineering

California Institute of

Technology

Pasadena, CA 99125

Professor D. Wayne Goodman

Department of Chemistry

Texas A\&M University

College Station, TX 77843

Professor R. Griffin

Department of Chemistry

Massachusetts Institute of

Technology

Cambridge, MA 02139

Dr. J. Hay

T12, Mail Stop 0569

Los Alamos National Laboratory

Los Alamos, NM 87545

Professor Victor E. Henrich

Department of Applied Physics

Yale University

P.O. Box 2157

New Haven, CT 06520
No. of

Copies

Professor Bruce Hudson

Department of Chemistry

Chemical Physics Institute

Room 189 Science II

University of Oregon

Eugene, OR 97403-1253

Dr. C. D. Jorgensen

Office of Health and

Environmental Research

Office of Energy Research

U.S. Department of Energy

Washington, D.C. 20545

Professor S. D. Kevan

Department of Physics

University of Oregon

120 Willamette Hall

Eugene, OR 97403

Dr. W. H. Kirchhoff

Fundamental Interactions Branch

Division of Chemical Sciences

Office of Basic Energy Sciences

U.S. Department of Energy

Washington, D.C. 20545

Dr. T. A. Kitchens

Office of Scientific Computing

Office of Energy Research

U.S. Department of Energy

Washington, D.C. 20545

Professor David S. Kliger

Dean of Science

Department of Chemistry

University of California

Santa Cruz, CA 95064

Dr. M. Koch

Dow Chemical U.S.A.

Analytical Sciences Laboratory

1897 Building

Midland, MI 48667 
No. of Copies

Dr. A. H. Laufer

Fundamental Interactions Branch

Division of Chemical Sciences

Office of Basic Energy Sciences

U.S. Department of Energy

Washington, D.C. 20545

Professor Y. T. Lee

Department of Chemistry

University of California - Berkeley

Berkeley, CA 94720

Professor W. Carl Lineberger

Department of Chemistry and Joint

Institute for Laboratory Astrophysics

Campus Box 214

Boulder, CO 80309-0440

Dr. W. C. Luth

Engineering and Geosciences Division

Office of Basic Energy Sciences

Office of Energy Research

U.S. Department of Energy

Washington, D.C. 20545

R.S. Marianelli

ER-14, G-334/GTN

U.S. Department of Energy

19901 Germantown road

Germantown, MD 20874

Dr. W. S. Millman

Processes and Techniques Branch

Division of Chemical Sciences

Office of Basic Energy Sciences

U.S. Department of Energy

Washington, D.C. 20545

\section{A. A. Patrinos}

ER-74, E-156/GTN

U.S. Department of Energy

19901 Germantown Road

Germantown, MD 20874
No. of

Copies

Dr. M. Poutsma

Oak Ridge National Laboratory

MS-6182, Building 4500N

P.O. Box 2008

Oak Ridge, TN 37831-6182

M. R. Riches

ER-74, G-141/GTN

U.S. Department of Energy

19901 Germantown Road

Germantown, MD 20874

Professor Richard J. Saykall

Department of Chemistry

University of California - Berkeley

Berkeley, CA 94720

Professor Giacinto Scoles

Department of Chemistry

Princeton University

Princeton, NJ 08544

M. W. Shupe

EM-541, 464/TREV

U.S. Department of Energy

12800 Middlebrook Road

Germantown, MD 20874

Professor John D. Simon

Department of Chemistry, B-032

University of California - San Diego

La Jolla, CA 92093

Dr. D. A. Smith

Health Effects \& Life Sciences

Research Division

Office of Health and

Environmental Research

Office of Energy Research

U.S. Department of Energy

Washington, D.C. 20545 
No. of Copies

Dr. F. D. Stevenson

Processes and Techniques Branch

Division of Chemical Sciences

Office of Basic Energy Sciences

U.S. Department of Energy

Washington, D.C. 20545

Professor Richard M. Stratt

Department of Chemistry

Brown University

324 Brook Street, Box H

Providence, RI 02912

I. Thomas

ER-13, J-317/GTN

U.S. Department of Energy

19901 Germantown Road

Germantown, MD 20874

Dr. T. Torgersen

Engineering \& Geosciences Division

Office of Basic Energy Sciences

Office of Energy Research

U.S. Department of Energy

Washington, D.C. 20545

Professor R. O. Watts

Department of Chemistry

University of Washington

Seattle, WA 98195

Professor Robert L. Whetten

School of Chemistry and Biochemistry

Georgia Institute of Technology

Boggs Chemistry Building

Atlanta, GA 30332-0400

\section{S. M. Wolf}

EM-542, 413/TREV

U.S. Department of Energy

12800 Middlebrook Road

Germantown, MD 20874

Dr. J. C. Wooley

Office of Health and

Environmental Research

Office of Energy Research

U.S. Department of Energy

Washington, D.C. 20545
No. of

Copies

Professor John T. Yates

Director, Pittsburgh Surface

Science Center

Department of Chemistry

University of Pittsburgh

Pittsburgh, PA 15260

Professor Richard N. Zare

Department of Chemistry

Stanford University

Stanford, CA 94305-5080

\section{ONSITE}

5 DOE Richland Operations Office

H. E. Bell, A5-90

P. W. Kruger, K8-50

J. P. Neath, A5,90

J. J. Sutey, K8-50

D. E. Trader, K8-50

253 Pacific Northwest Laboratory

W. J. Apley, K1-73

J. F. Bagley, K1-64

R. A. Bair, K1-95

S. E. Barlow, K2-14

S. D. Colson, K2-14

C. A. Counts, K2-20

J. P. Cowin, K2-14

T. H. Dunning, Jr., K2-20

P. D. Ellis, P7-54

T. R. Fox, P7-35

D. M. Friedrich, K2-14

B. C. Garrett, K1-95

M. J. Graham, K6-78

J. S. Hartman, K5-25

A. C. Hess, K1-95

W. P. Hess, K2-14

G. R. Holtom, K2-14

P. M. Irving, K6-98

J. Janata, K2-12

A. G. Joly, K2-14

D. R. Jones, K1-87

S. A. Joyce, K2-14

B. D. Kay, K2-14

M. L. Knotek, K1-48

W. W. Laity, K2-50 
No. of

Copies

R. C. Liikala, K1-57

R. J. Mayer, K1-62

R. S. McDowell, K2-14 (100)

G. L. McVay, K2-50

R. L. Ornstein, K1-95

E. W. Pearson, K7-15

G. R. Peterson, K1-40

R. K. Quinn, K2-50

D. Ray, K2-14

G. A. Ritter, K2-14

J. A. Roberts, K1-73

S. W. Sharpe, K3-58

A. A. Shepherd, K1-55

B. D. Shipp, K8-28
No. of

Copies

R. L. Skaggs, K6-77

C. S. Sloane, K6-04

R. S. Smith, K2-14

J. D. Spencer, K1-40

G. M. Stokes, K1-74

B. R. Stults, K2-20

M. T. Thomas, K2-18

R. G. Tonkyn, K2-14

R. A. Walters, K1-50

W. R. Wiley, K1-46

G. L. Work, K7-02

Publishing Coordination

Technical Report Files (5) 